\title{
Local and Global Effects on Ozone from Titan Rocket Exhaust and Deorbiting Spacecraft Debris
}

by

Peter S. Connell

John J. Walton

Joyce E. Penner

Charles O'Connor

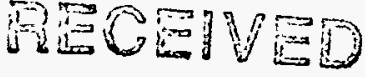

AU6 169935

\section{Lawrence Livermore National Laboratory}

Livermore, CA 94550

May 1996

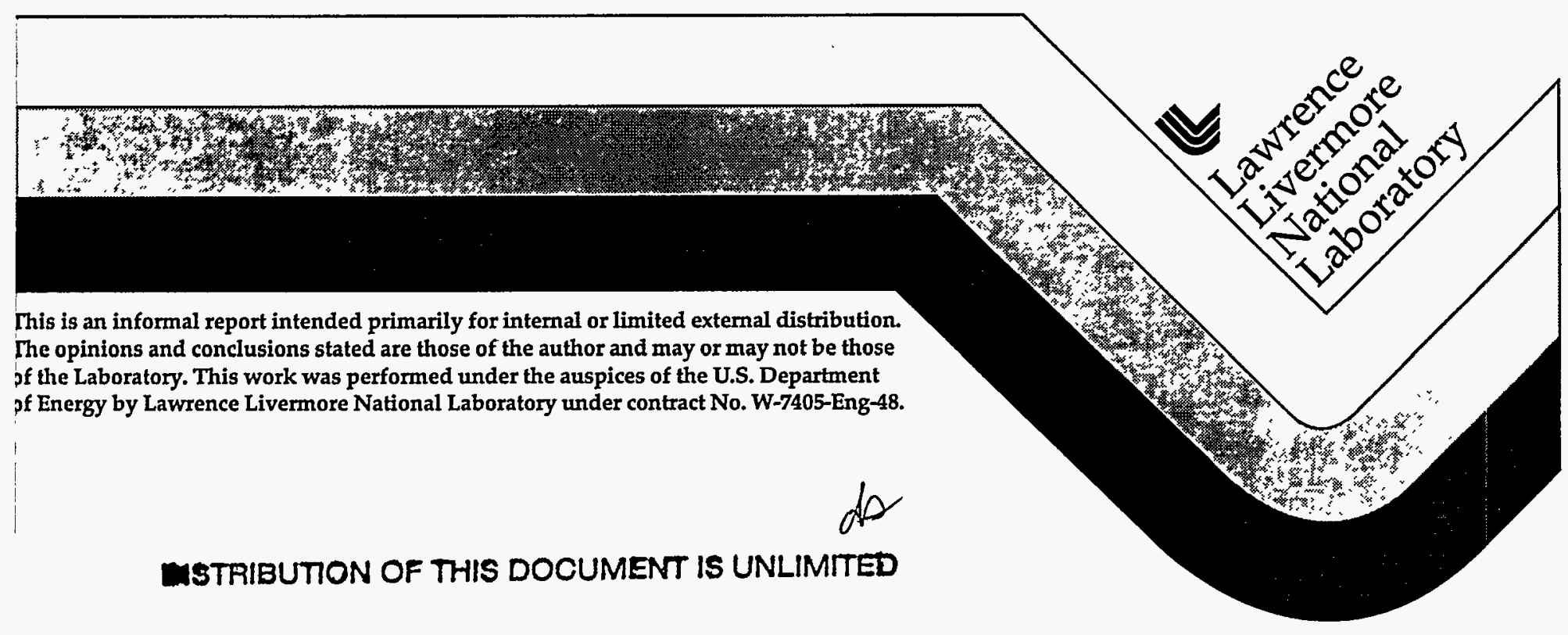

The opinions and conclusions stated are those of the author and may or may not be those

of the Laboratory. This work was performed under the auspices of the U.S. Department pf Energy by Lawrence Livermore National Laboratory under contract No. W-7405-Eng-48. 


\section{DISCLAIMER}

This document was prepared as an account of work sponsored by an agency of the United States Government. Neither the United States Government nor the University of California nor any of their employees, makes any warranty, express or implied, or assumes any legal liability or responsibility for the accuracy, completeness, or usefulness of any information, apparatus, product, or process disclosed, or represents that its use would not infringe privately owned rights. Reference herein to any specific commercial product, process, or service by trade name, trademark, manufacturer, or otherwise, does not necessarily constitute or imply its endorsement, recommendation, or favoring by the United States Government or the University of California. The views and opinions of authors expressed herein do not necessarily state or reflect those of the United States Government or the University of California, and shall not be used for advertising or product endorsement purposes.

This report has been reproduced directly from the best available copy.

Available to DOE and DOE contractors from the Office of Scientific and Technical Information P.O. Box 62, Oak Ridge, TN 37831

Prices available from (615) 576-8401, FTS 626-8401

Available to the public from the National Technical Information Service

U.S. Department of Commerce 5285 Port Royal Rd. Springfield, VA 22161 


\section{DISCLAIMER}

Portions of this document may be illegible in electronic image products. Images are produced from the best available original document.

- 


\title{
LOCAL AND GLOBAL EFFECTS ON OZONE FROM TITAN ROCKET EXHAUST AND DEORBITING SPACECRAFT DEBRIS
}

\author{
A Draft Report Prepared for TRW \\ Peter S. Connell, John J.Walton, Joyce E. Penner, and Charles O’Connor \\ Lawrence Livermore National Laboratory \\ Livermore, CA 94550
}

Both the launching and deorbiting of spacecraft introduce foreign material directly into the stratosphere, a region of the atmosphere extending from around 12 to $50 \mathrm{~km}$ above the earth's surface. Human activities in general have little direct contact with the stratosphere (some aircraft operate in the lower stratosphere); most anthropogenic pollution of the stratosphere occurs through upward transport of long-lived gases. The question of similarities and differences between these two paths of pollutant introduction to the stratosphere arises naturally, and a careful evaluation of environmental risks associated with rocket launches is, of course, prudent.

Solid rocket motor combustion produces gases and particles that are injected into the stratosphere during the few minutes that the rocket traverses the region. Potential effects of solid rocket motor exhaust have been assessed before, with chief concern focused on the emitted chlorine-containing gases (Jackman et al., 1996, Prather et al., 1990 and Denison et al., 1994 and references therein). These earlier studies have considered topics including the global and zonally averaged effects of accumulated chlorine ( $\mathrm{Cl})$ emissions from indefinitely continued launch operations, the transient response to a single launch plume dispersed over a $1000 \mathrm{~km}$ spatial scale in a three-dimensional global model, and the earlytime evolution of the plume composition in the seconds and minutes after exhaust. An important additional concern that we attempt to address in this report is the time period between establishment of the stabilized cold plume and its dispersal and the spatial range between the initial scale of hundreds of meters and the $1000 \mathrm{~km}$ scale of gridded global 3-D models. Can a vertically coherent region persist in which photochemical processes reduce ozone significantly?

The importance of chlorine in the stratosphere as a potentially efficient catalyzer of ozone destruction has been established over twenty years of research (WMO, 1995). The current level of abundance of inorganic chlorine-containing trace species, predominantly hydrochloric acid $(\mathrm{HCl})$, in the stratosphere is about 3500 parts per trillion by volume (ppt $\mathrm{v} / \mathrm{v})$. Recent observations of these species, hydrofluoric acid (HF), and chlorofluorocarbons (CFCs) show that the surface-emitted CFCs account for the observed excess of chlorine over the naturally occurring level of around $600 \mathrm{ppt}$.

Launching of Titan and similar solid rocket motors adds to the stratospheric inorganic chlorine burden through emissions of $\mathrm{HCl}$, atomic $(\mathrm{Cl})$ and molecular $\left(\mathrm{Cl}_{2}\right)$ directly into the stratosphere. Before the exhaust plume disperses, plume concentrations of 
these species are orders of magnitude above the background values (Denison et al, 1994). Dispersed through the stratosphere over the globe however, the additional $\mathrm{Cl}$ burden is small compared to the background for currently envisioned launch frequencies. Inorganic chlorine is cleared from the atmosphere by wet deposition of $\mathrm{HCl}$ in rain after transport processes return air from the stratosphere to the troposphere, with an overall lifetime of a few years. After several years, a continuing fixed injection rate will produce a chlorine enhancement that reaches a steady state, balanced with loss via rainout.

We report here on calculations in models in both two- and three-dimensions that address three questions in rocket/spacecraft/stratosphere interactions. We have attempted to represent the early evolution (1-50 hours) of a vertical plume in the stratosphere with a Lagrangian three-dimensional transport model driven by horizontal winds from a dataassimilating general circulation model. These horizontally sheared plume structures, illuminated by the sun, produce footprints on the surface. Depending on plume and solar orientation and plume dimensions, the possibility exists for ozone destruction in the path of the direct beam from the sun. We conducted simulations for launches in four different seasons (January, April, July, and October), surrounding a launch point (28 N, $280 \mathrm{E}$ ) representing Cape Canaveral.

We have also conducted global calculations of the potential steady state effects of $\mathrm{Cl}$ injection from a specified rate of continuous launches in a current two-dimensional model of the stratosphere including all known important ozone production and loss processes. In these calculations, we have used new estimates of the distribution of material injection as a function of altitude relevant to Titan and similar motors. The exhaust products are injected continuously and the integration is continued until the $\mathrm{Cl}$ enhancement levels to steady state. The distribution of the enhancement and the ozone response depend on season, latitude and launch latitude. The results support those obtained in earlier studies of Space Shuttle motor exhaust.

Finally, we have calculated the effect of increasing the steady state particulate surface area density in the stratosphere resulting from particle formation from satellite destruction on reentry. Recent stratospheric observations have demonstrated the importance of heterogeneous processes in affecting the trace constituent composition of the stratosphere and influencing the balance of ozone destroying processes. Of particular importance are processes that transform photochemically active nitrogen oxides into nitric acid, which is more stable, and processes that release active forms of chlorine from the relatively stable chlorine nitrate molecule. Laboratory studies indicate that chlorine nitrate decomposes by hydrolysis on alumina surfaces. This process, the collision of a gas phase chlorine nitrate molecule with an alumina particle, is included in the global two-dimensional model as a first order conversion of chlorine nitrate to hydrochlorous acid, $\mathrm{HOCl}$, at a rate consistent with the alumina surface area density calculated to result from the reentry of orbiting spacecraft. 


\section{Data and Methodologies}

\section{Cold Plume Advection Model}

The starting point for the exhaust plume advection calculations is the stabilized cold plume. The plume stabilizes when it reaches ambient temperature, after which its apparent radius is affected only by natural turbulent eddy diffusion. The plume is assumed to be axially symmetric, with the radius and exhaust composition provided by Wong and coworkers at TRW (Wong, TRW report, 1996; Denison et al, 1994) as functions of altitude in the stratosphere. While the TRW injection profile results from an analysis in which the vehicle flight profile pitches from the vertical while passing through the stratosphere, the assumption is made here that the plume is initially vertical. The profiles of radius and chlorine species concentrations are shown in Table 1.

Table 1. Cold Plume Parameter Profiles

\begin{tabular}{|c|c|c|c|c|}
\hline Altitude $(\mathrm{km})$ & Radius (m) & $\mathrm{Cl}$ & $\mathrm{Cl}_{2}$ & $\mathrm{HCl}$ \\
\hline \hline 7 & 118.8 & $1.22(10)^{+}$ & $8.60(13)$ & $1.09(15)$ \\
15 & 88.9 & $8.86(11)$ & $2.08(14)$ & $1.20(15)$ \\
20 & 111.7 & $1.75(12)$ & $1.73(14)$ & $4.65(14)$ \\
25 & 160.3 & $2.40(12)$ & $1.14(14)$ & $1.22(14)$ \\
30 & 214.5 & $3.60(12)$ & $6.29(13)$ & $3.34(13)$ \\
35 & 327.9 & $3.35(12)$ & $1.88(13)$ & $2.05(13)$ \\
40 & 398.6 & $7.39(12)$ & $2.23(12)$ & $2.71(13)$ \\
\hline
\end{tabular}

(E. Wong, TRW, private communication, 1996)

$+1.22(10)=1.22 \times 10^{10}$

The plume is represented in the advection model by a vertical stack of parcels which are advected horizontally (in longitude and latitude) by winds provided by the NASA Goddard Space Flight Center Data Assimilation Office (DAO). The DAO STRATAN simulation of 1992 was used (Schubert et al., 1995), which is based on NMC and other data, and has a resolution of $4^{\circ}$ in latitude by $5^{\circ}$ in longitude, 25 vertical layers of which 15 are in the stratosphere, and 6 hours in time. The global three-dimensional model used here is the advection component of the GRANTOUR chemical transport model (Atherton et al., 1995). GRANTOUR is a Lagrangian parcel model in which the gridded horizontal velocities are interpolated in three dimensions to the parcel locations at every time step. In this case, advection was carried out with a one hour timestep, with gridded velocities updated every six hours. Vertical velocities were set to zero in this study, to avoid any potential numerical problems in inferring the vertical velocity from the horizontal wind 
fields. Horizontal velocities are typically much faster than vertical velocities in the stratosphere.

Figures 1a-d and 2 a-d show three day average (solid lines) and instantaneous launch time (dashed line) vertical profiles of the horizontal wind components (meridional and zonal) for the four periods. Zonal winds are generally larger in magnitude than the meridional winds. At the launch latitude, the zonal wind direction is almost always from the west to the east (westerlies) except in summer when the direction reverses. Zonal wind velocities tend to increase with altitude in the winter and summer stratospheres. Meridional velocities at the launch latitude are southerlies (south to north or poleward) in the fall and winter and northerlies in the spring and summer and tend to be greater in the winter and spring. Given the horizontal resolution of the data assimilated wind products, the single profiles are similar to the time averages but can have variability with altitude similar to the average velocity magnitudes, for example the meridional velocities in April and October.

The advected parcels in GRANTOUR represent the centers of mass of the individual plume segments. As the simulation progresses, the 9 stratospheric plume parcels separate in horizontal location. Passage of the solar beam through the parcels projects their locations to the surface, according to parcel altitude and the declination and hour angle of the sun. The parcel locations are considered to be connected with 8 linear segments, representing the plume footprint at a particular time. The plume segments are assumed to maintain a circular horizontal section as they are sheared, so that a sheared plume segment can be visualized as a tilted stack of coins. Each segment represents a fraction of the total overhead column of ozone (shown in Figure 3), so that if the direct solar beam passes axially down the segment, that fraction of the total column can potentially be destroyed. If the solar beam intersects the plume segment at a sufficient angle, only a portion of that ozone column fraction would be affected by plume-related chemistry. From the hourly parcel locations, the sum of the segment footprints can be made in area and in fraction of the total ozone column that is affected by the plume.

\section{Global Photochemistry Transport Model}

In a global model, the dispersed chlorine contribution of a single launch and the transient response of ozone are quite small, and can be overwhelmed by drift in the integration of the background atmosphere and numerical significance. In this study we have considered a continuing series of launches, which produces a steady state enhancement of inorganic chlorine in the stratosphere and a steady state global ozone depletion. We used the LLNL two-dimensional model of photochemistry, dynamics, and radiation transport (Kinnison et al., 1994) to model this response for a launch frequency of 10 motors per year, continuing indefinitely. The model has a latitude resolution of $5^{\circ}$ extending from pole to pole, and a vertical resolution of approximately $1.5 \mathrm{~km}$, extending from the surface to 85 $\mathrm{km}$. The third spatial dimension, longitude or the zonal direction, is averaged over the globe. The model predicts ozone abundance as a function of altitude, latitude, and season

of the year, based on climatological temperature and self-consistently calculated fields of radiation and photochemical production and loss. Surface concentrations of trace gases 
including $\mathrm{N}_{2} \mathrm{O}, \mathrm{CFCs}$, and $\mathrm{CH}_{4}$ are prescribed as boundary conditions, giving rise to the radical family photochemistry in the troposphere and stratosphere. The chemical mechanism incorporates about 50 species and 150 reactions.

A steady state reference atmosphere was calculated in which the source gas surface concentrations were prescribed at their observed 1990 values, producing a stratospheric burden of inorganic chlorine of about 3,500 parts per trillion. The plume exhaust was input over the single latitude zone between 25 and $30 \mathrm{~N}$ and vertically distributed according to the profile in Table 2.

Table 2. $\mathrm{Cl}_{\mathrm{y}}$ Injection Profile in Two-Dimensional Global Model Between 20 and $30 \mathrm{~N}$ Latitude.

\begin{tabular}{|c|c|c|c|}
\hline Pressure (hPa) & $\begin{array}{l}\text { Approximate } \\
\text { Altitude }(\mathrm{km})\end{array}$ & $\begin{array}{l}\mathrm{Cl}_{\mathrm{y}} \text { Injection Rate } \\
\left.\text { (molecules } / \mathrm{cm}^{3} / \mathrm{S}\right)\end{array}$ & $\begin{array}{c}\text { Annual } \mathrm{Cl}_{\mathrm{y}} \\
\text { Injection } \\
\text { (kt as } \mathrm{Cl} \text { ) }\end{array}$ \\
\hline 114 & 15.75 & 0.6189 & 30.9 \\
\hline 92.3 & 17.25 & 0.5734 & 28.6 \\
\hline 74.9 & 18.75 & 0.5353 & 26.7 \\
\hline 60.9 & 20.25 & 0.5077 & 25.3 \\
\hline 49.4 & 21.75 & 0.4905 & 24.5 \\
\hline 40.1 & 23.25 & 0.4775 & 23.8 \\
\hline 32.6 & 24.75 & 0.4610 & 23.0 \\
\hline 26.4 & 26.25 & 0.4351 & 21.7 \\
\hline 21.5 & 27.75 & 0.4071 & 20.3 \\
\hline 17.4 & 29.25 & 0.3851 & 19.2 \\
\hline 14.2 & 30.75 & 0.3743 & 18.7 \\
\hline 11.5 & 32.25 & 0.3687 & 18.4 \\
\hline 9.33 & 33.75 & 0.3552 & 17.7 \\
\hline 7.58 & 35.25 . & 0.3274 & 16.3 \\
\hline 6.15 & 36.75 & 0.2950 & 14.7 \\
\hline 4.99 & 38.25 & 0.2818 & 14.1 \\
\hline 4.06 & 39.75 & 0.3040 & 15.2 \\
\hline 3.29 & 41.25 & 0.3748 & 18.7 \\
\hline
\end{tabular}

+10 motors/year 
Because the input material must be dispersed meridionally over $500 \mathrm{~km}$ and zonally averaged around the globe, this calculation represents the response smoothed over several weeks. In this case, the input can be considered to exist entirely in the form of $\mathrm{HCl}$, which is formed rapidly from $\mathrm{Cl}$ (and $\mathrm{Cl}_{2}$ ) by reaction with the large background abundance of methane. For this run, the $\mathrm{HCl}$ injection was performed continuously through the integration, at a flux that summed over the year to 10 Titan motor launches, or $378,000 \mathrm{~kg}$ of $\mathrm{Cl}$ deposited into the stratosphere each year. To provide the most accurate comparison, the self-consistently derived atmospheric circulation form the reference atmosphere was prescribed for the launch-perturbed model run. The perturbations to $\mathrm{Cl}_{\mathrm{y}}$ and ozone were calculated by difference in the fifth year of runs with and without the additional $\mathrm{HCl}$ input.

The LLNL two-dimensional model was also used to investigate the potential effects of $\mathrm{ClONO}_{2}$ activation on aluminum oxide particles formed from disintegrated reentrant satellites. The reference atmosphere described above was again used. In this study the perturbation took the form of an additional term in the calculated rate constant for the reaction

$\mathrm{ClONO}_{2}+$ particle $=\mathrm{HOCl}+\mathrm{HNO}_{3}$.

The background rate constant depends on sulfuric acid aerosol surface area density and local temperature. Two values for the perturbation term were used, 5.0E-9 and 5.0E-8 seconds $s^{-1}$. These terms were applied throughout the stratosphere and produce an augmented rate of $\mathrm{HOCl}$ production in the range of the TRW calculations (Wong, personal communication). The results were again determined by difference from the reference atmosphere after a suitable period of integration demonstrated that steady state had been reached.

\section{Results}

\section{Cold Plume Advection Model}

The cold plume advection calculations follow the plume evolution under representative episodic conditions for four seasons. Figures 1 and 2 above showed the horizontal winds for the selected time periods. Figure 4 shows the locations of the advected parcels from the launch time at 6 am local solar time to 12 hours after launch. The parcel traces are numbered in ascending order with altitude. The launch point is indicated by a square, and the longitudinal coordinate has been adjusted in the figures to be commensurate in distance with the latitude. One degree in both directions is roughly $100 \mathrm{~km}$. The prevailing zonal winds move the plume generally to the east in all seasons except summer (July), most rapidly away from the launch longitude in winter (January) and summer. The upper parcels generally move more rapidly than the lower segments and can cover more than $1000 \mathrm{~km}$ in the first 12 hours. More importantly for the consideration of spatially coherent "holes" in the vertical, the plume spread top to bottom over the first 12 hours varies from a few hundred kilometers in October to $1500 \mathrm{~km}$ in January.

Figure 5 shows the tracks of the "shadows" the parcels make on the surface as they move and are illuminated by the sun over the daylight period following launch. These 
calculations use the plane parallel approximation which is less reasonable at solar zenith angles exceeding 85 degrees, so no projections were made under these grazing incidence conditions. The atmospheric pathlength under these conditions is long and little ultraviolet reaches the surface in any case, so that this is not a problematic assumption. Comparing Figures 4 and 5, the effect of the changing solar zenith angle is seen in October, when the plume lingers around the launch point. The parcel footprints travel from west to east as the apparent solar location travels from east to west.

The footprint of the entire plume at the surface is formed by linearly connecting the "shadows" of the vertically adjacent parcels, producing a series of linked rectangles at the surface, with length determined by the parcel "shadow" locations and width determined, in the absence of diffusion, by the plume radius as a function of altitude. Figures 6 a-e through 9 a-e depict the time-evolving plume footprints. The specified cold plume radius increases with altitude and this is indicated by greater line thickness for the higher altitude plume segments (although not to scale). Latitude and longitude are not necessarily plotted to the same distance scale in these plots.

Each plume segment represents a fraction of the vertical overhead column of ozone (i.e. 10\%), and, if sufficiently aligned in azimuth and zenith angle with the sun, the projected shadowed area for that segment could potentially be depleted in ozone to that corresponding extent (10\%). For each segment, the area affected and the ozone loss potentially realized will also be inversely related. If sunlight passes through a segment at an oblique angle, the potential fractional ozone loss is related to the ratio of the plume thickness along the path of the direct beam to the vertical layer thickness that the segment represents. Additionally, the projections of different plume segments can intersect on the surface, producing an area subject to ozone depletion from more than one vertical segment.

From the combination of azimuths and zenith angles for the plume and the sun, we calculated the areas subject to potential ozone loss for a series of hourly intervals for the four seasons. The assumption was made, discussed further below, that the plume is devoid of ozone and that ozone outside the plume was unaffected. These results are shown in Figures 10 a-e through 13 a-e. As expected, the area affected grows as the plume segments are stretched, but the magnitude of the corresponding potential ozone loss diminishes with time. As also expected, the peak potential ozone losses occur for the April and October launches, when lower wind speeds allow the plume to remain more compact. The peak potential depletions are on the order of $1 \%$ occurring in the first few hours after launch, and affecting areas of a few square kilometers. In general, by several hours after launch, the peak potential depletion is about $0.1 \%$ over an area less than 10 square kilometers. At a potential depletion level of $0.01 \%$, the area affected is between 100 and 1000 square kilometers. The effect of alignment of a plume segment with the solar position can be seen in the October calculation, where at 7 hours after launch (Figure 13d), the peak magnitude increases to between 0.3 and $0.4 \%$ because of the position of the sixth plume segment (Figure 9d). 
Although these calculations are merely representative of four episodic atmospheric states and can not rule out the possibility of an alignment of multiple plume segments with the sun that would produce a significant ozone hole, they do indicate that such an event is apparently unlikely and increasingly so beyond a few hours after launch. A potential depletion of $1 \%$ is significantly smaller than the naturally occurring variability in overhead ozone column at both seasonal and shorter time scales, and the transient nature of the plume effect further reduces any related effects to below a reasonable level of concern.

There are several relevant considerations in the interpretation of these results. The data assimilation model that generates the winds used here is coarsely gridded in the horizontal ( 400 by $500 \mathrm{~km}$ ) relative to the plume dimensions in the early hours after launch. It is also coarsely gridded in the vertical relative to sharp features (100 meter thickness) in the stratosphere often observed by in situ instruments that are presumably related to vertical shears in the horizontal winds. A more finely resolved picture of the stratospheric winds might increase the area affected by increasing the length of the more tortuous plume footprint, but might not increase the peak potential depletion as the likelihood of solar/plume alignment extending over a significant depth would be reduced in the more structured plume.

Growth of the plume radius by diffusion and the accompanying entrainment of ambient air into the spreading plume has not been considered here. Observations of plumes in the stratosphere appear to show a degree of integrity over the few hour time scale while they are sheared by the winds (Prather, private communication), so this assumption may be justified. Estimation of diffusion coefficients related to stratospheric small scale eddy turbulence is difficult and the time scales obtained tend to be short (order of minutes, Denison et al, 1994), in contrast to the apparent integrity of plumes in the stratosphere. When the plume has dispersed over the $1000 \mathrm{~km}$ scale after a day or two, Prather and coworkers have shown that the contribution of the chlorine from the exhaust has dropped to the $1 \%$ level over background and will be mostly tied up as inactive $\mathrm{HCl}$. At early times, the very high initial levels of atomic chlorine can rapidly deplete ozone in the plume, so that these calculations, assuming total ozone loss, may represent a "worst_case". Whether the competing time scales of shearing and diffusing could produce a plume a few hours old that is enlarged in radius, devoid of ozone through fast catalytic destruction, and compact with respect to shear can not be answered with the model used here. But the results of Denison and coworkers (1994) seem to show that photochemical ozone-destroying processes are too slow to keep ambient ozone from entraining and refilling the plume even after just a few minutes. Additionally, the lifetime of atomic chlorine with respect to reaction with methane and conversion to $\mathrm{HCl}$ is on the order of minutes. These considerations would indicate that a non-diffusing plume scenario might indeed be conservative in assessing the risks of ozone depletion.

\section{Global Steady State Cl Perturbation and Response}

The effect on stratospheric ozone of an indefinitely continuing constant rate of launches will reach a steady state when the transport-driven removal of the injected chlorine 
(by the irreversible transfer of $\mathrm{HCl}$ from stratosphere to troposphere) balances the rate of input. In this steady state condition, a seasonally varying but annually periodic enhancement exists in the abundance of stratospheric inorganic chlorine species. As noted above, the current level of $\mathrm{Cl}_{\mathrm{y}}$ in the mid and upper stratosphere is about 3,500 ppt and results mostly from CFC photolysis. The distribution calculated by the model in a steady state representation of current CFC surface abundances is shown in Figure $14 \mathrm{a}$ and $\mathrm{b}$ for northern hemisphere winter and summer. The shape results from higher average illumination at the equator, yielding greater $\mathrm{Cl}$ release there, and the mean downward and poleward circulation in each hemisphere. To this background a continuous constant injection of $\mathrm{HCl}$ in the latitude bin $25-30 \mathrm{~N}$ distributed in altitude between 15 and $42 \mathrm{~km}$ was added. After 5 years of integration a steady state was effectively reached. The stratospheric lifetime of the added $\mathrm{HCl}$, determined by dividing the stratospheric burden of excess $\mathrm{Cl}_{\mathrm{y}}$ by the injection rate, gives a value of 2.3 years. The amount of the enhancement at steady state thus corresponds to the input from about 23 motors in this scenario (note that a single launch may involve more than one motor).

Figures $15 \mathrm{a}$ and $\mathrm{b}$ show the resulting distribution of $\mathrm{Cl}_{\mathrm{y}}$ enhancement in ppt for the calculated scenario of ten Titan motor launches per year. Seven ppt corresponds to $0.2 \%$ increase above the reference stratospheric $\mathrm{Cl}_{\mathrm{y}}$. The effects of seasonal changes in circulation can be seen by comparing the summer and winter enhancements. The peak January enhancement is between 5 and 6 ppt over a 30 degree range north of the launch latitude. Meridional circulation is stronger in the winter and moves the injected $\mathrm{Cl}_{\mathrm{y}}$ downward and poleward. The weaker circulation in the northern hemisphere summer allows the additional $\mathrm{Cl}_{\mathrm{y}}$ to remain longer at the launch latitude, increasing the local peak value to more than $7 \mathrm{ppt}$ and leading to noticeable interhemispheric transport in the upper stratosphere. The southern hemisphere enhancement at steady state is about half of the northern hemisphere values.

The distribution of the change in ozone depends not only on the $\mathrm{Cl}_{\mathrm{y}}$ perturbation, but also on transport and photochemical time constants and on interaction of the radical families. The maximum January destruction of $-0.07 \%$ occurs at the northern and upper edge of the $\mathrm{Cl}_{\mathrm{y}}$ peak (Figure 16a). Photochemical destruction of ozone is continuing as the air moves north through the region of high $\mathrm{Cl}_{\mathrm{y}}$, but is eventually slowed by the loss of solar illumination. In the southern hemisphere summer, the maximum loss is at the sunlit pole and is about half of the northern value, consistent with the $\mathrm{Cl}_{\mathrm{y}}$ enhancement. In July (Figure 16b) the ozone loss is spread over a greater portion of the northern hemisphere and the maximum of about $-0.06 \%$ occurs at the pole. Little depletion occurs in either season in the mid and lower stratosphere, where the $\mathrm{Cl}_{\mathrm{y}}$ increase is smaller and other ozone loss processes dominate. These local responses are quite similar to the results of Prather and coworkers (1990), after scaling for their somewhat larger injection rate.

Figure 17 shows the change in total column ozone at all latitudes and seasons. The global and annual average depletion is $-0.006 \%$. The peak column losses are in the polar latitudes in the respective spring, about $-0.025 \%$ in the northern hemisphere and somewhat 
smaller in the southern. Depletion between $60 \mathrm{~N}$ and $60 \mathrm{~S}$ is between -0.005 and $-0.010 \%$, with little seasonal or latitudinal variation.

\section{Global Steady State $\mathrm{ClONO}_{2}$ /Aluminum Oxide Reaction and Response}

Deorbiting debris is found mostly in the form of $\mathrm{Al}_{2} \mathrm{O}_{3}$ particles, at a density of perhaps 0.1 - 1 particle per cubic meter (Wong, private communication) evenly dispersed throughout the stratosphere. Laboratory studies (Molina, 1996) have indicated that these particles may serve as sites for activation of $\mathrm{ClONO}_{2}$, that is production of active $\mathrm{Cl}$ species by reaction of $\mathrm{ClONO}_{2}$ on collision with the particle surface. This process occurs in the reference model atmosphere on the surface of sulfuric acid aerosol particles in the reaction $\mathrm{ClONO}_{2}+\mathrm{H}_{2} \mathrm{O}$ (particle $)=\mathrm{HOCl}+\mathrm{HNO}_{3}$.

The $\mathrm{HOCl}$ is rapidly photolyzed, releasing the $\mathrm{Cl}$ to participate in ozone-destroying catalytic cycles. The presence of additional particles will augment this process, particularly at mid and low latitudes, where the sulfate aerosol particles are less efficient partners (because of lower water activity at higher temperatures). Wong has estimated that each of these particles can activate between $2 \mathrm{E} 4$ and $2 \mathrm{E} 6 \mathrm{Cl}$ per second, for a production rate of between $2 \mathrm{E} 3$ and $2 \mathrm{E} 6 \mathrm{Cl}$ per cubic meter per second. At the typical $\mathrm{ClONO}_{2}$ stratospheric density of around $4 \mathrm{E} 14 \mathrm{ClONO}_{2}$ per cubic meter, a first order rate constant of about $5 \mathrm{E}-9$ $\mathrm{s}^{-1}$ gives a processing rate of $2 \mathrm{E} 6 \mathrm{~m}^{-3} \mathrm{~s}^{-1}$. This first order rate constant value was specified throughout the stratosphere (designated as Case A). The actual distribution in March of $\mathrm{ClONO}_{2}$ activation through this process is shown in Figure 18 and can be compared to sulfate activation of $\mathrm{ClONO}_{2}$ in the reference atmosphere shown in Figure 19. Debris particle activation is between 1 and 4E6 $\mathrm{Cl} \mathrm{m}^{3} \mathrm{~s}^{-1}$ through much of the stratosphere. It is higher in the northern hemisphere polar spring, where polar stratospheric cloud activation of $\mathrm{HCl}$ has produced high $\mathrm{ClONO}_{2}$ densities. It is lower in the upper stratosphere, where $\mathrm{ClONO}_{2}$ densities are diminished. A second case (B), was run in which the activation rate constant was increased an order of magnitude to $5 \mathrm{E}-8 \mathrm{~s}^{-1}$ to ensure a numerically significant perturbation result.

Figure 20 shows the change in overhead column ozone at steady state for Case A. The global annual average ozone loss is $-0.01 \%$. As expected for small perturbations, the effect is linearly proportional to the forcing. Case B shows an average loss of $-0.1 \%$, with an essentially identical distribution in latitude and season to Case $A * 10$. The largest losses occur in the polar springtimes, when $\mathrm{ClONO}_{2}$ levels are enhanced by wintertime processing of $\mathrm{HCl}$ in the polar vortices. For short days and high levels of $\mathrm{ClONO}_{2}$, activation by the debris particles is more competitive with $\mathrm{ClONO}_{2}$ photolysis and produces a larger relative enhancement of active $\mathrm{Cl}$ species. Overhead column ozone is reduced by up to $-0.07 \%$ at high southern latitudes in October. Northern hemisphere values in March are reduced by up to $-0.02 \%$. The effect is smaller in the northern hemisphere because the $\mathrm{NH}$ winter pole is warmer and polar activation of $\mathrm{HCl}$ is less efficient. 


\section{Conclusions}

None of the effects of rocket motor and spacecraft operation considered here produces a significant impact on stratospheric ozone. From the global standpoint, material injected into the stratosphere during launch or deorbit has stratospheric residence lifetimes of a few years or less, which serves to limit the steady state burden. A single motor launch per year is calculated to reduce globally and annually averaged ozone by $-0.0006 \%$, with a maximum column loss at the surface of about $-0.002 \%$. These values can probably be scaled to 1000 launches per year, at which the effect $(-0.6 \%$ globally and $-2 \%$ maximum) is on the order of current assessments for High Speed Civil Transport fleets. Deorbiting debris particles produce an effect through activation of existing stratospheric $\mathrm{Cl}$ on the same order of magnitude as the additional $\mathrm{Cl}$ injection of 10 motors launched per year. The debris contribution to $\mathrm{Cl}$ activation will be substantially overshadowed by volcanic activity. Additionally, as stratospheric Cly diminishes in the next century because of CFC controls, the availability of $\mathrm{ClONO}_{2}$ to activate will drop and the debris effect will diminish. The expected downward trend in ambient $\mathrm{Cl}_{\mathrm{y}}$ levels may enhance the importance of exhaust $\mathrm{Cl}_{\mathrm{y}}$, however. As the balance of ozone-controlling processes changes with reduced $\mathrm{Cl}_{\mathrm{y}}$, the exhaust contribution will become proportionally larger. This effect deserves continued analysis.

In consideration of local ozone loss under the exhaust plume, our calculations indicate that the plume is sheared and stretched rapidly in the horizontal over just a few hours, reducing the possibility of an ozone hole with a significant depth. Local effects at the surface of up to $-1 \%$ over regions of less than $10 \mathrm{~km}^{2}$ were calculated for the less dynamically active spring and fall periods. In summer and winter, the maximum line of sight loss was around $-0.5 \%$. Regions up to $1000 \mathrm{~km}^{2}$ are affected at levels of $-0.01 \%$ in all four seasons. A more highly resolved treatment of horizontal wind velocities is not likely to increase the extent of the line of sight ozone depletions. Consideration of turbulent eddy diffusion as the plume is sheared may increase the area affected and could increase the integrated total ozone loss through processing of entrained ambient air, but indications are that photochemical processes in an entraining plume are not fast enough to keep ozone completely depressed, while processes that deactivate chlorine are quite fast. This problem could also be analyzed further with a more sophisticated chemistry/diffusion/trajectory model. In any case, daily and seasonal natural variability in overhead ozone substantially exceed these calculated effects. 


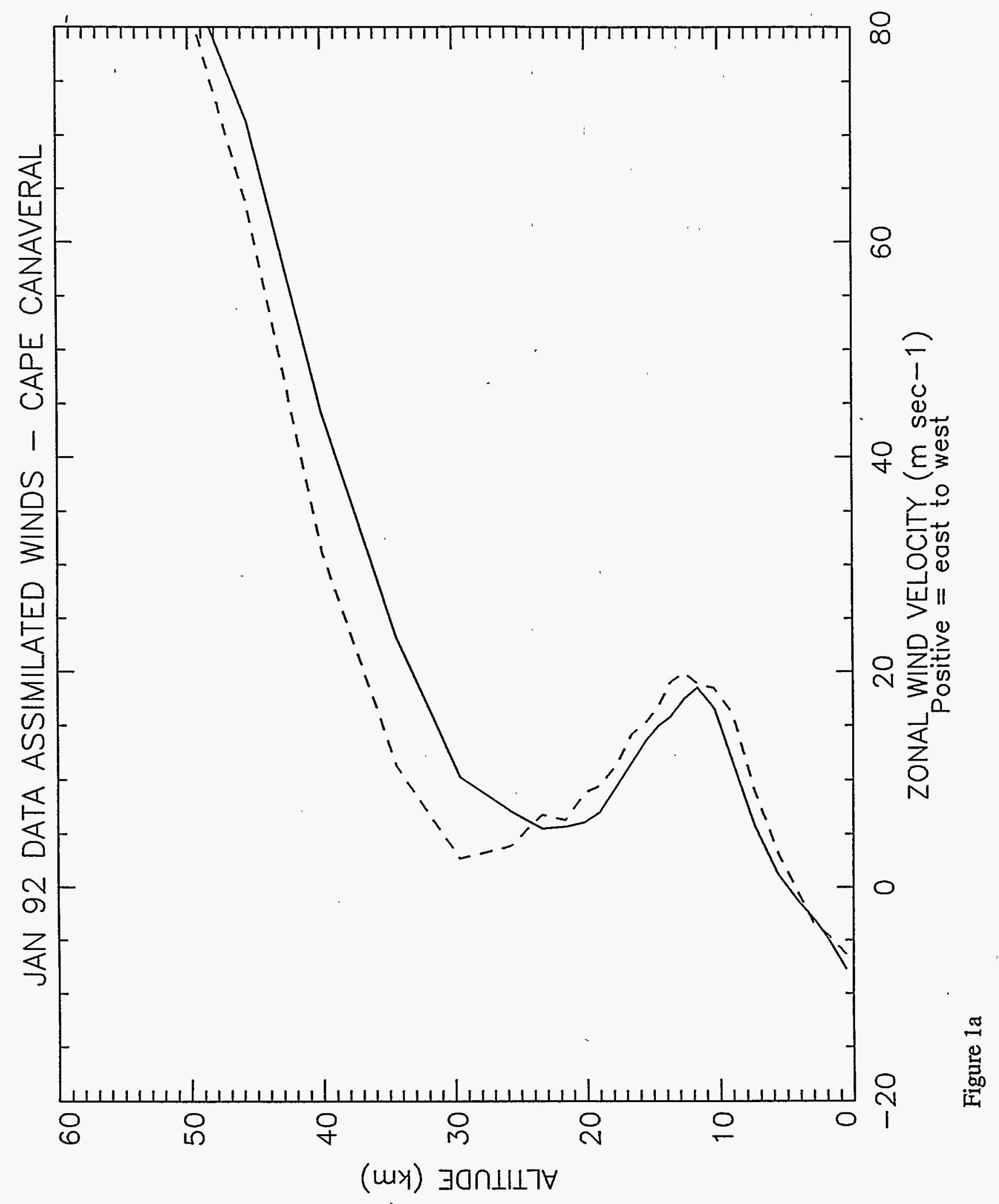




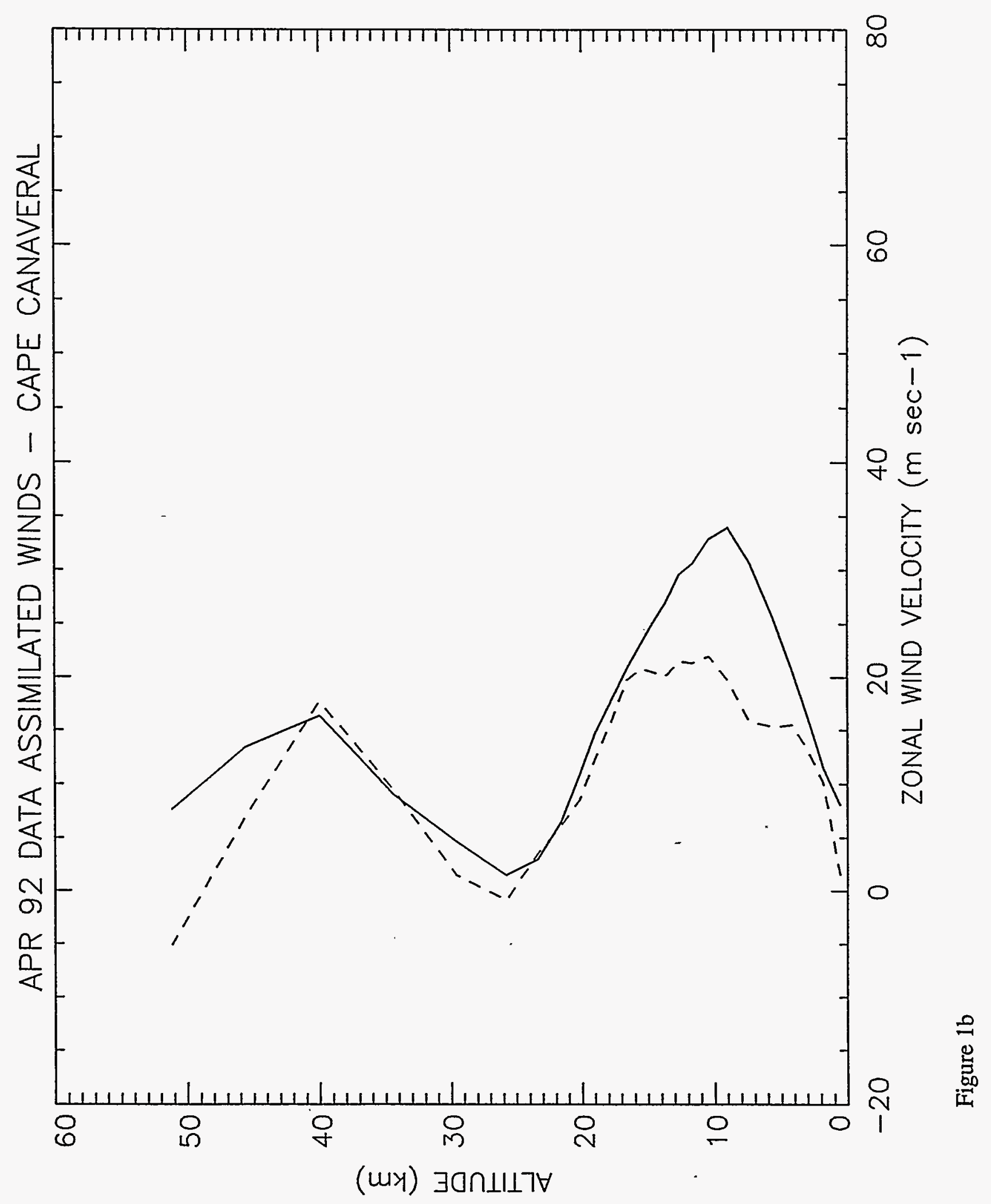




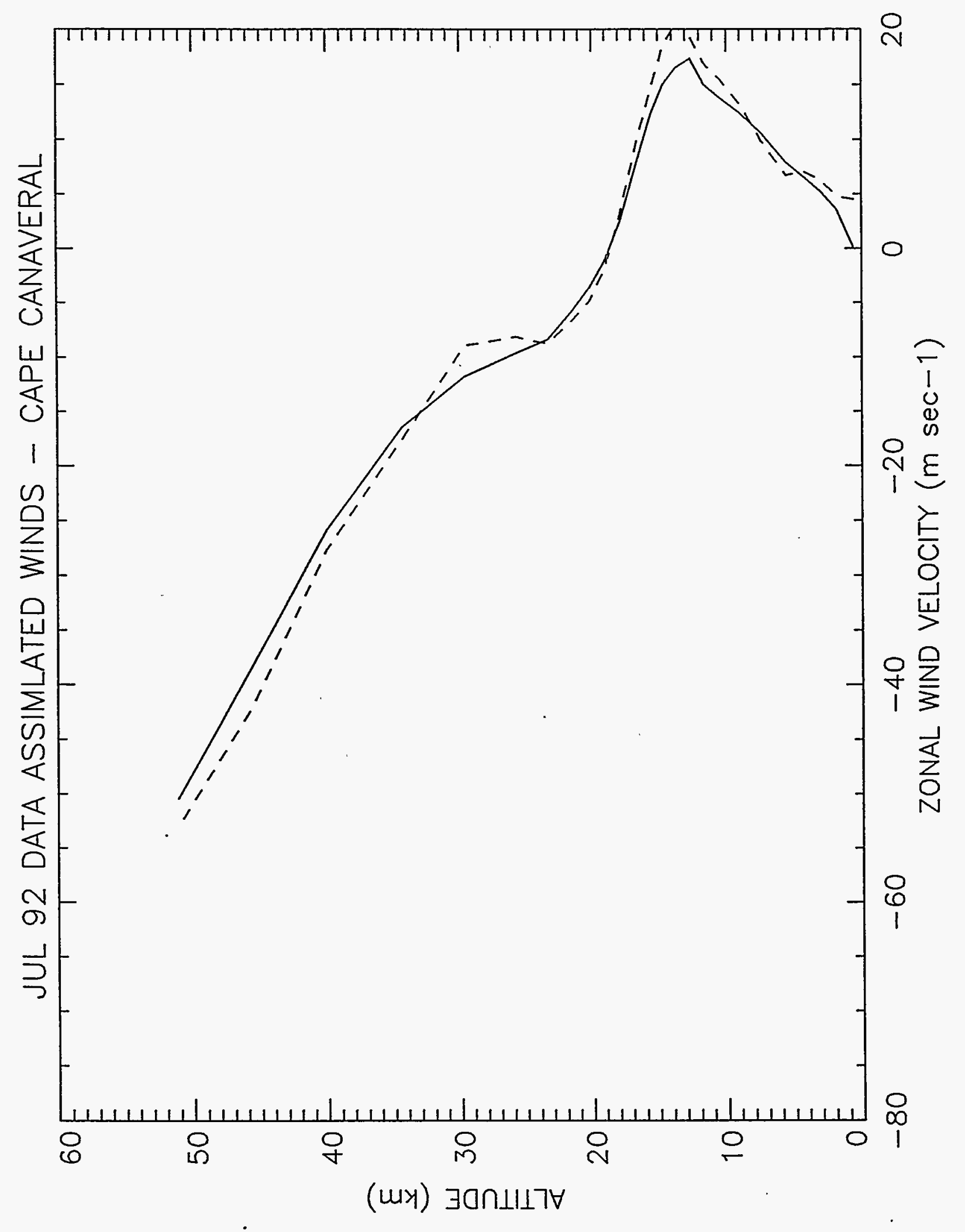

足 


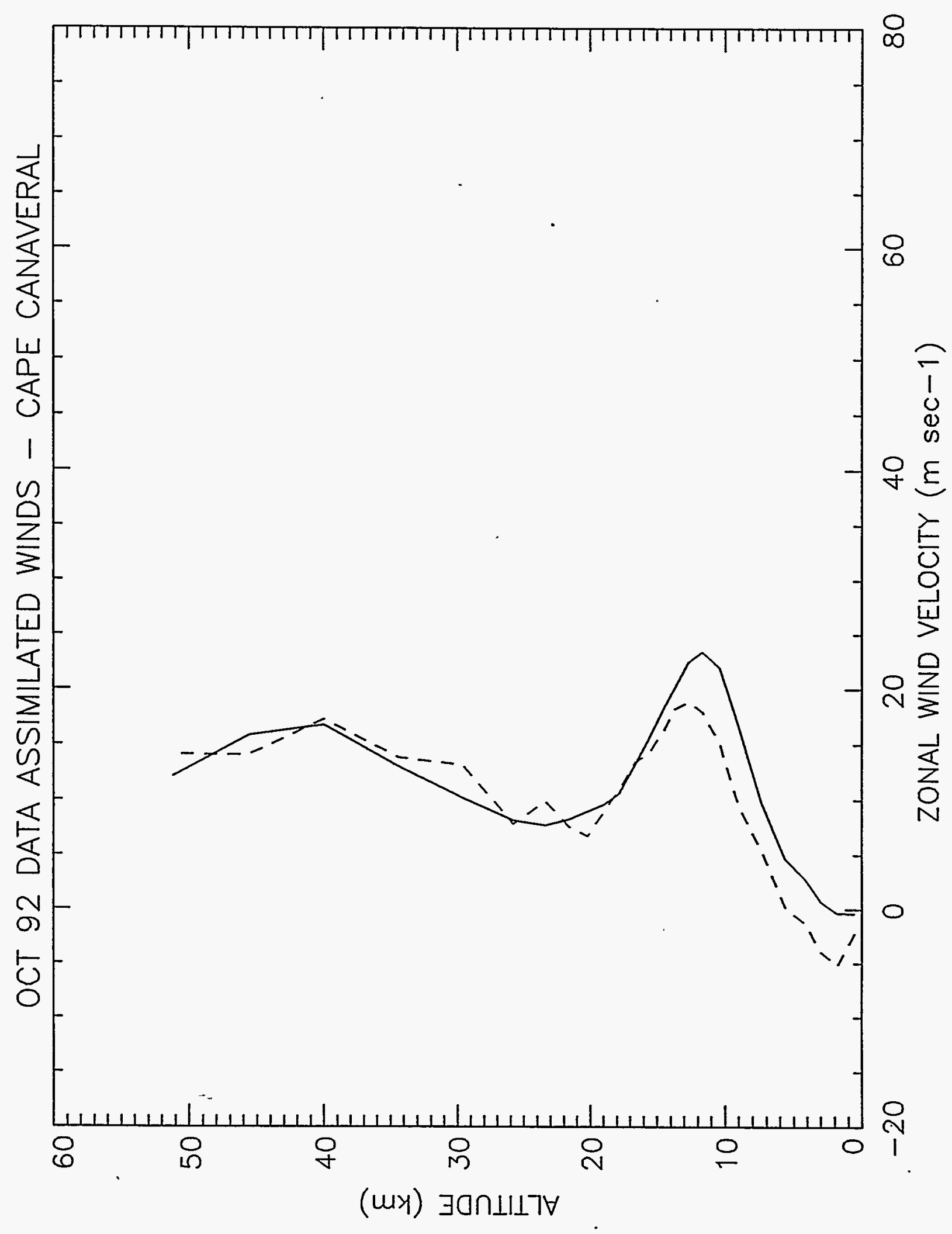

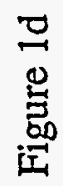




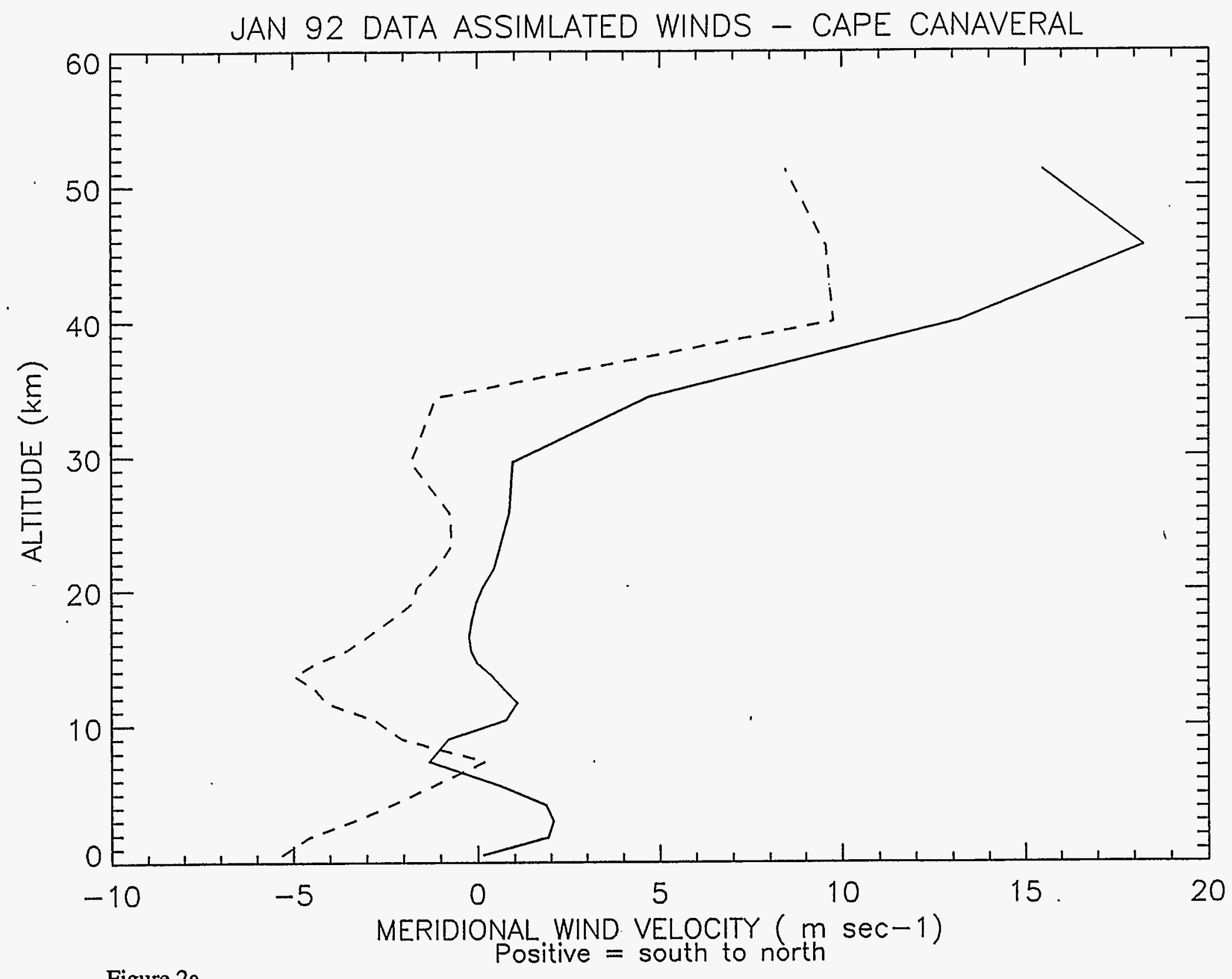

Figure $2 \mathrm{a}$ 


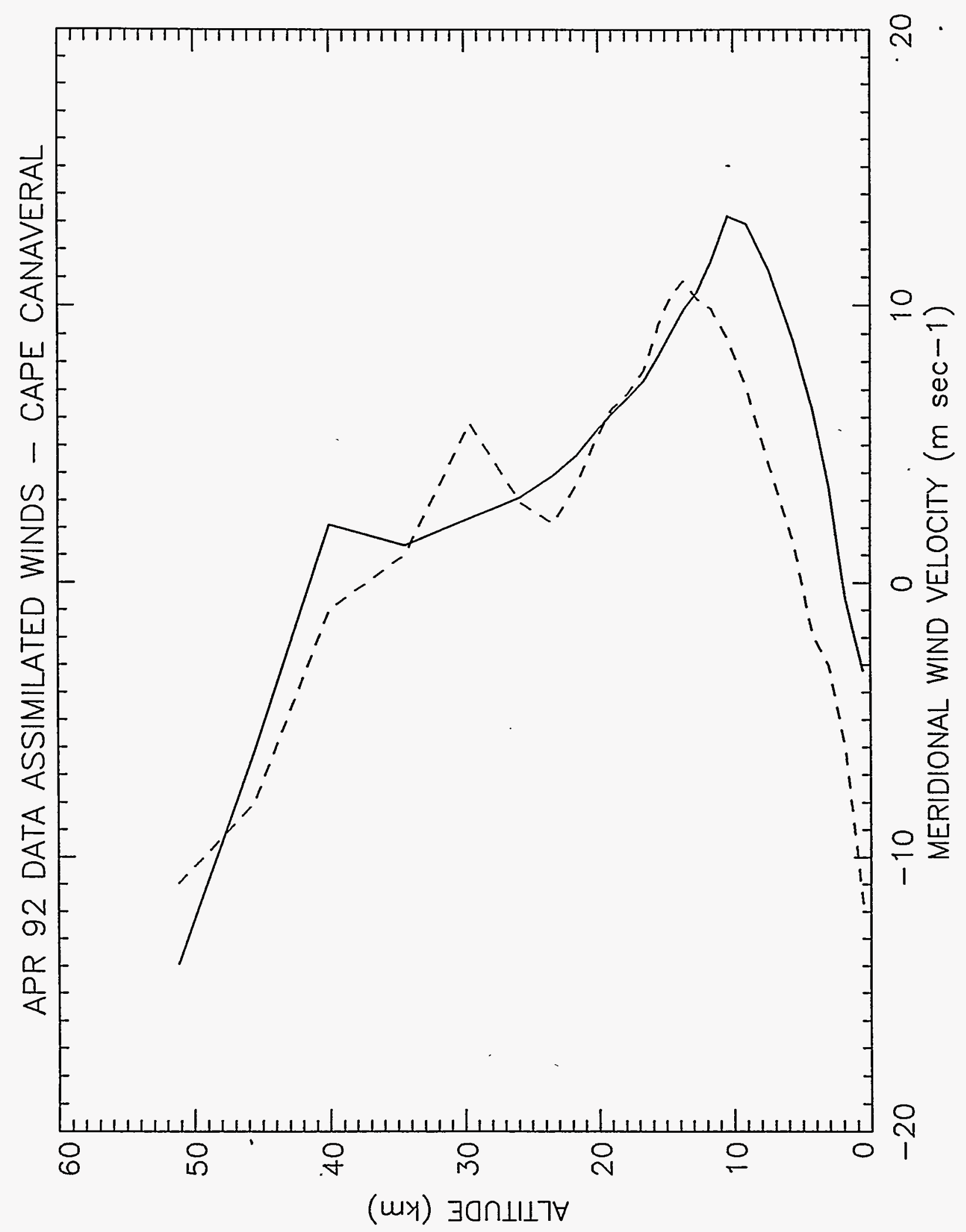

울 


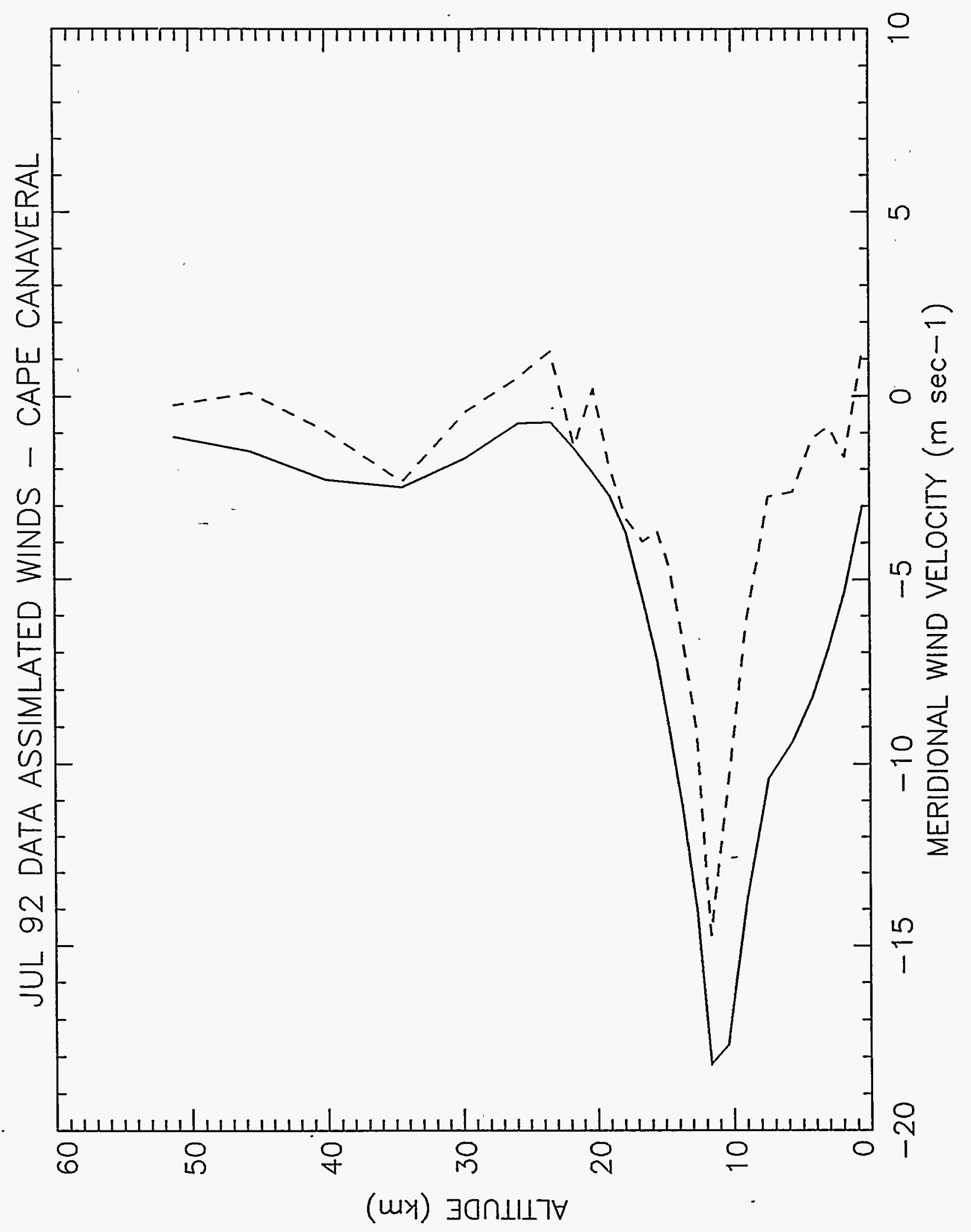

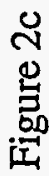




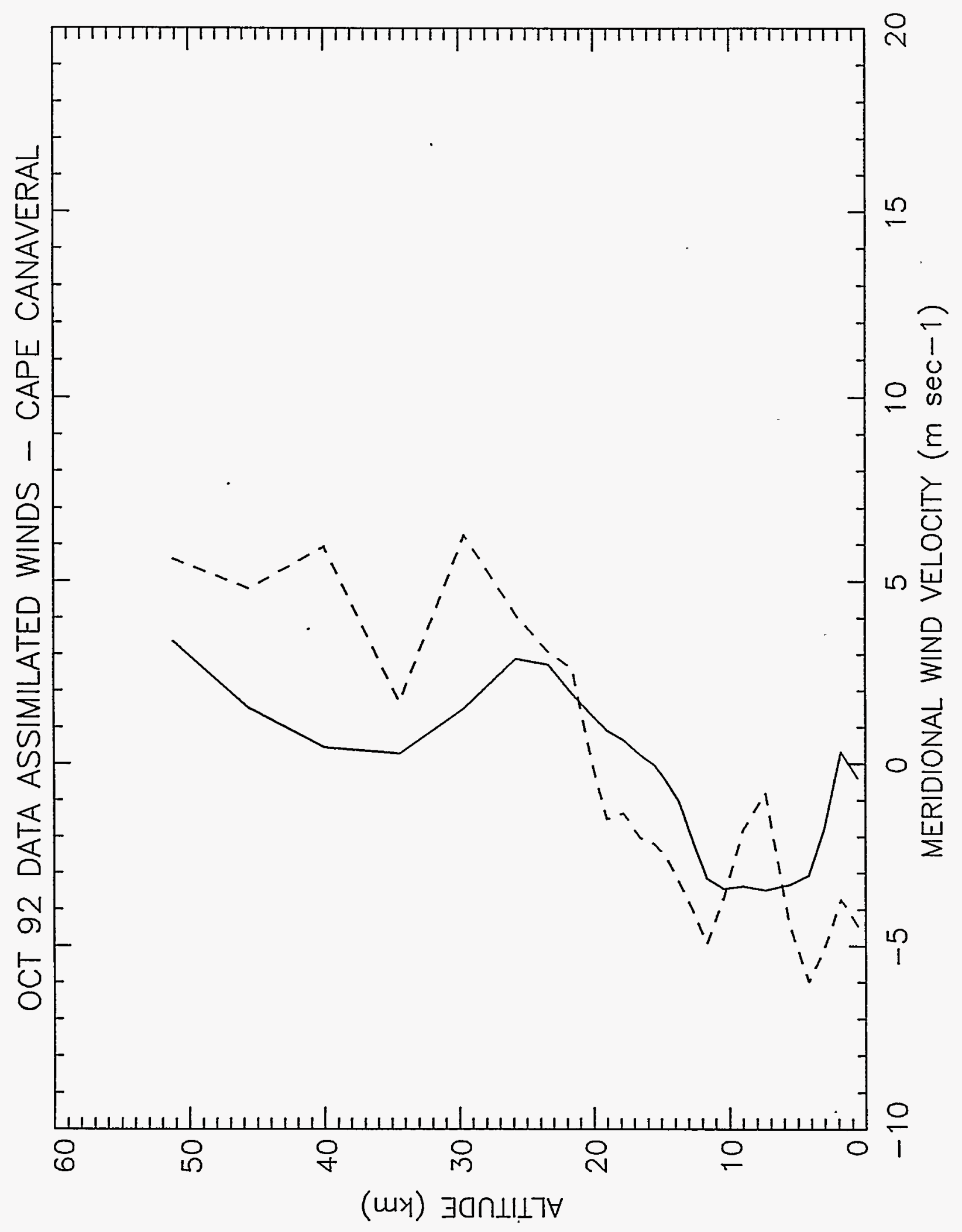

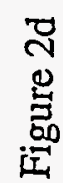




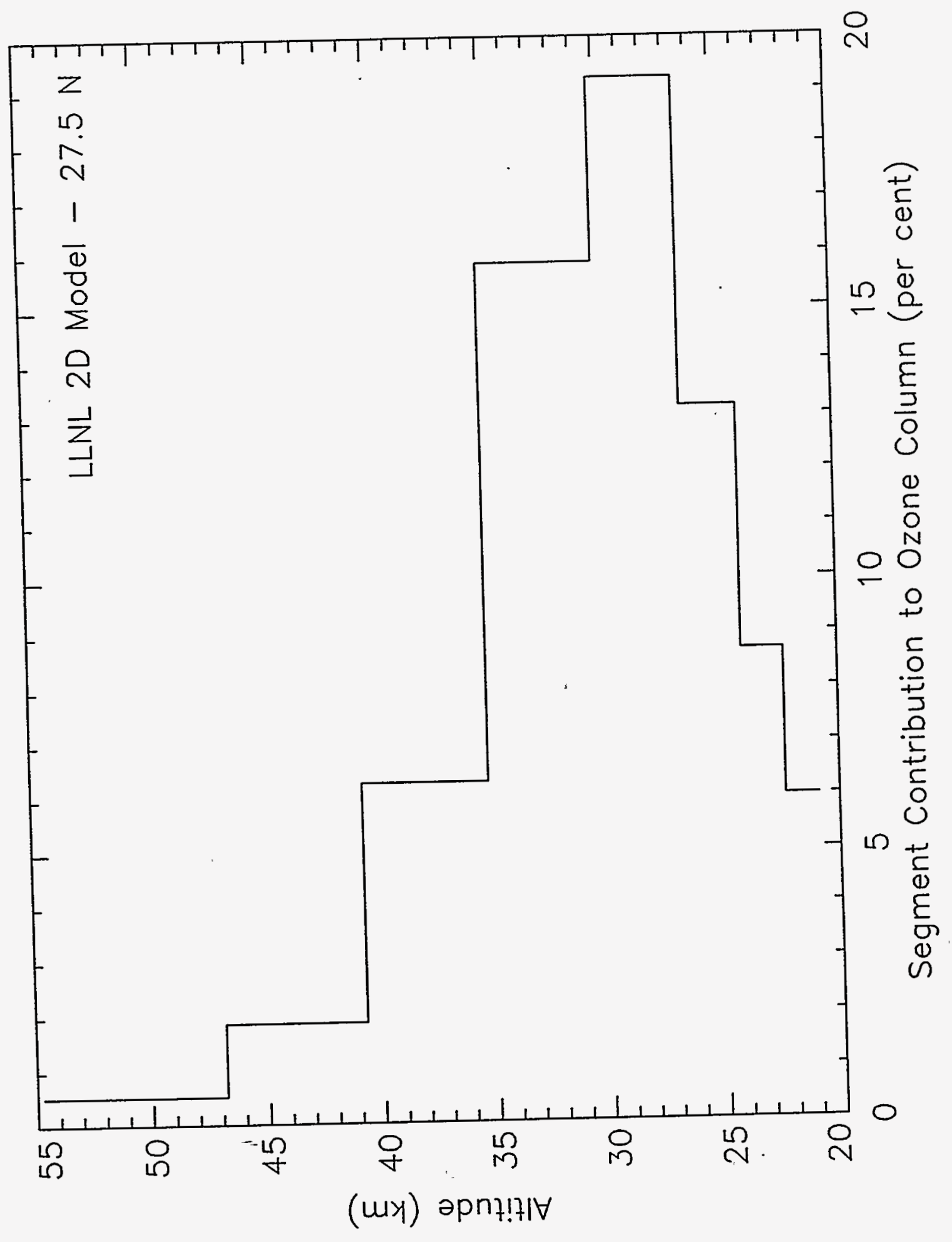

$m$
0
总
它 

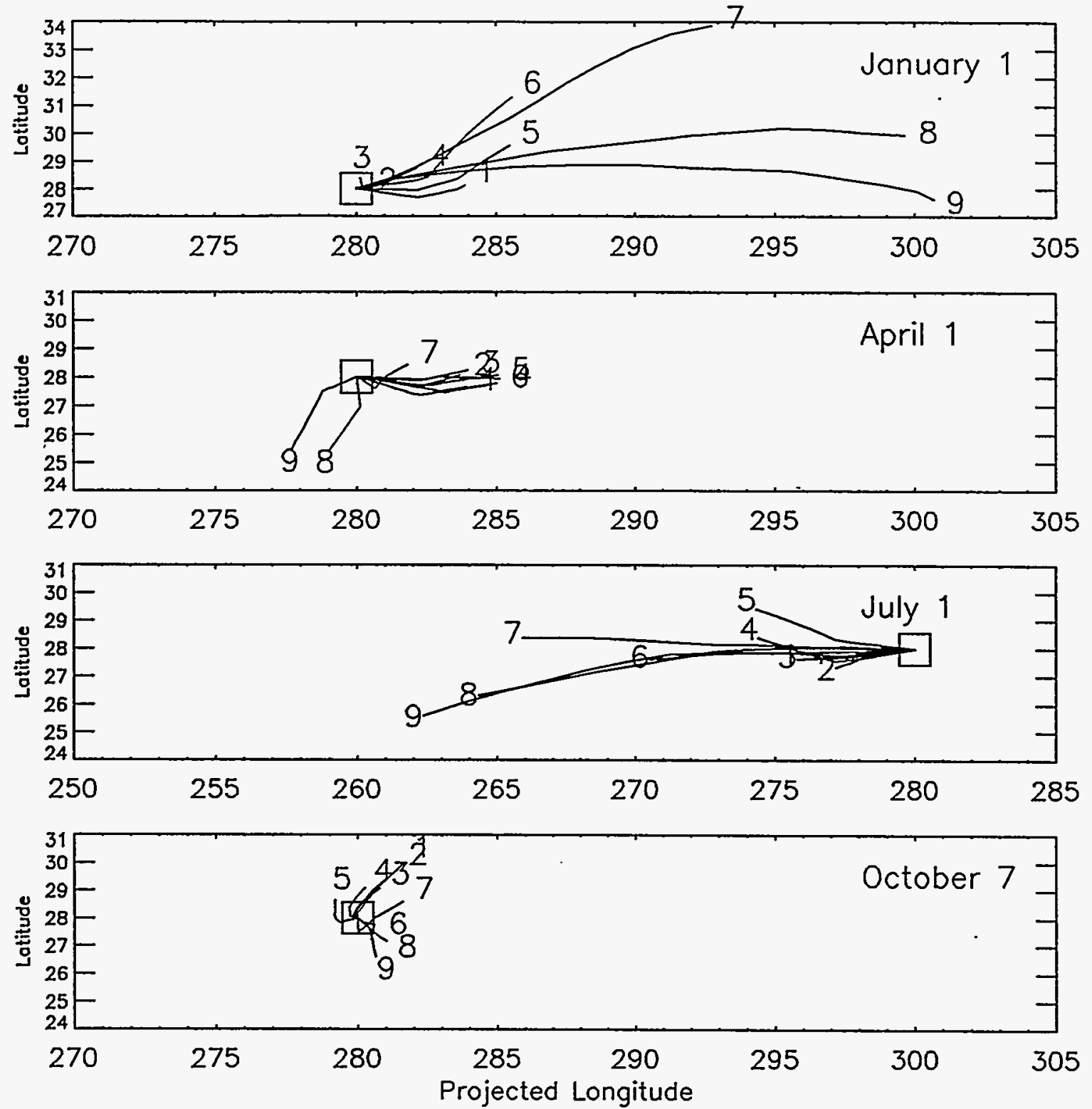

Figure 4 

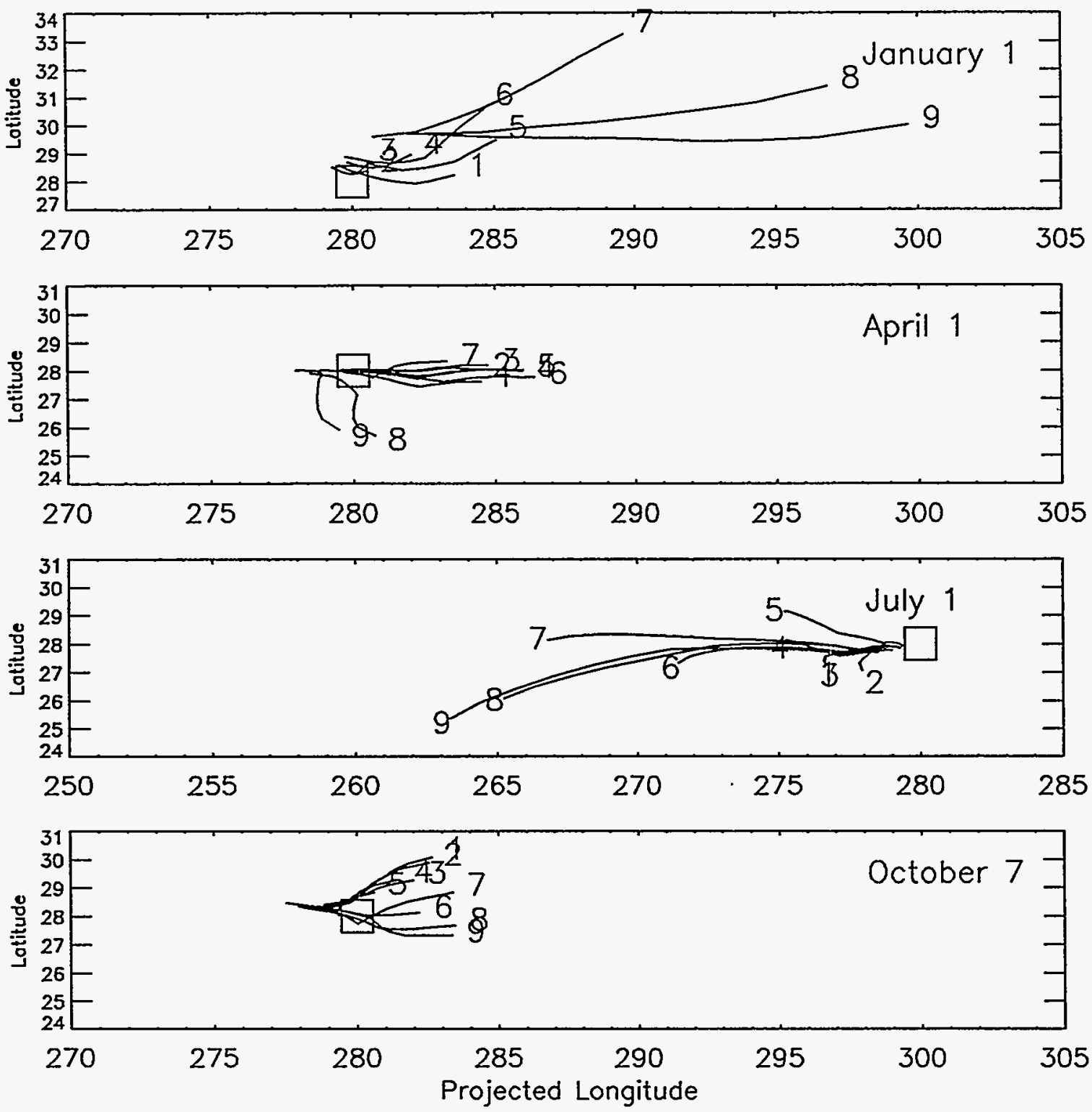

Figure 5 


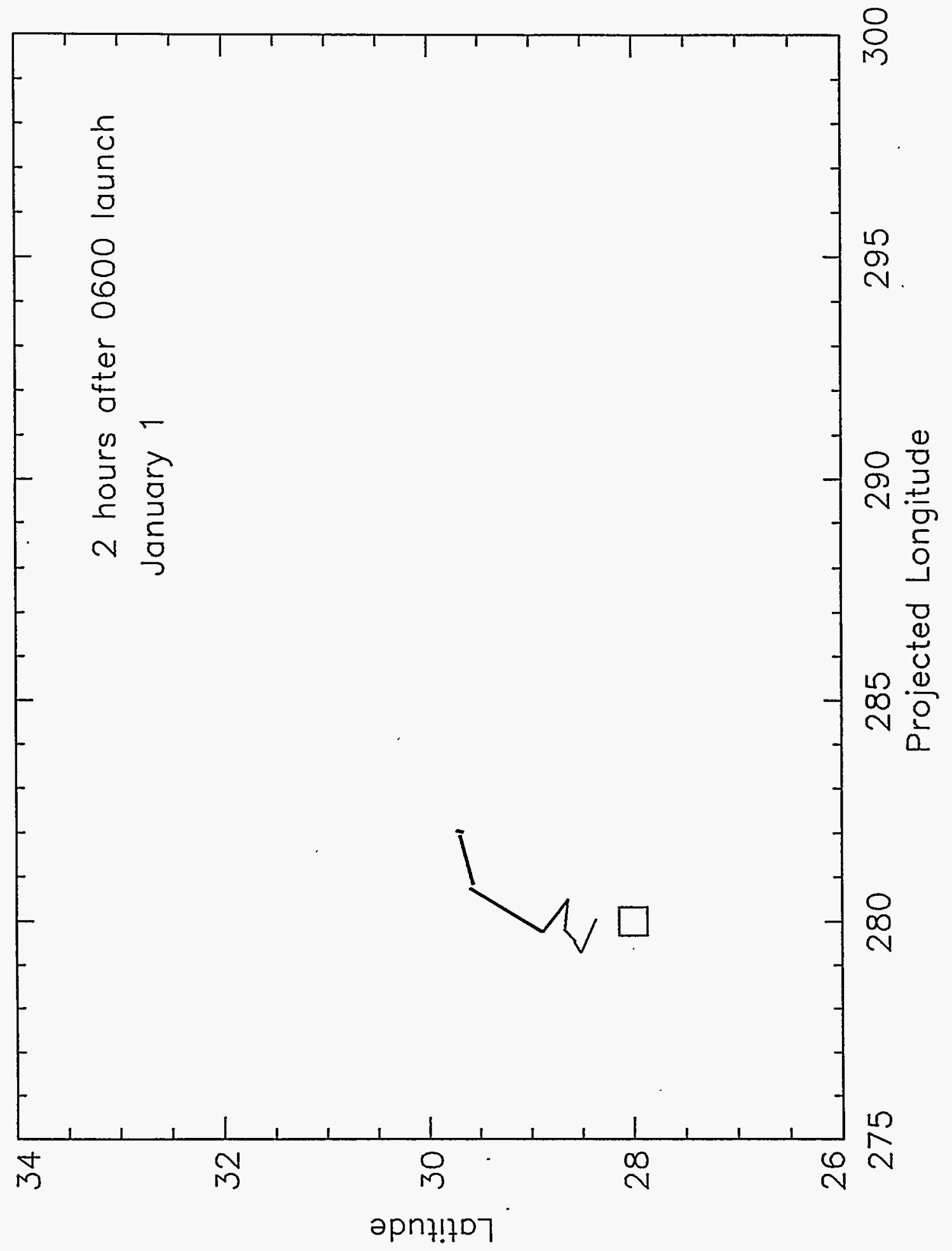

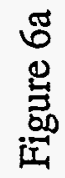




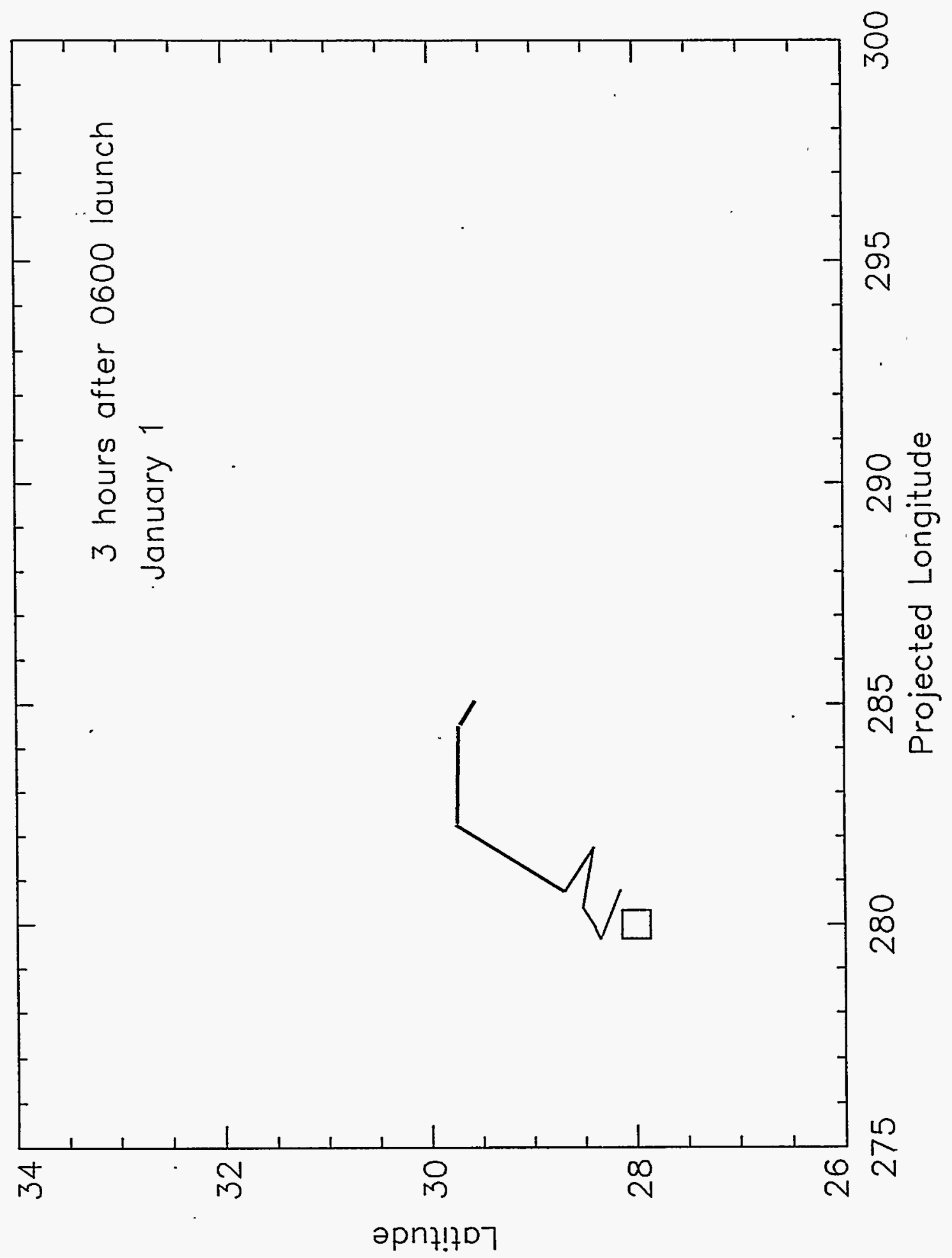

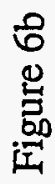




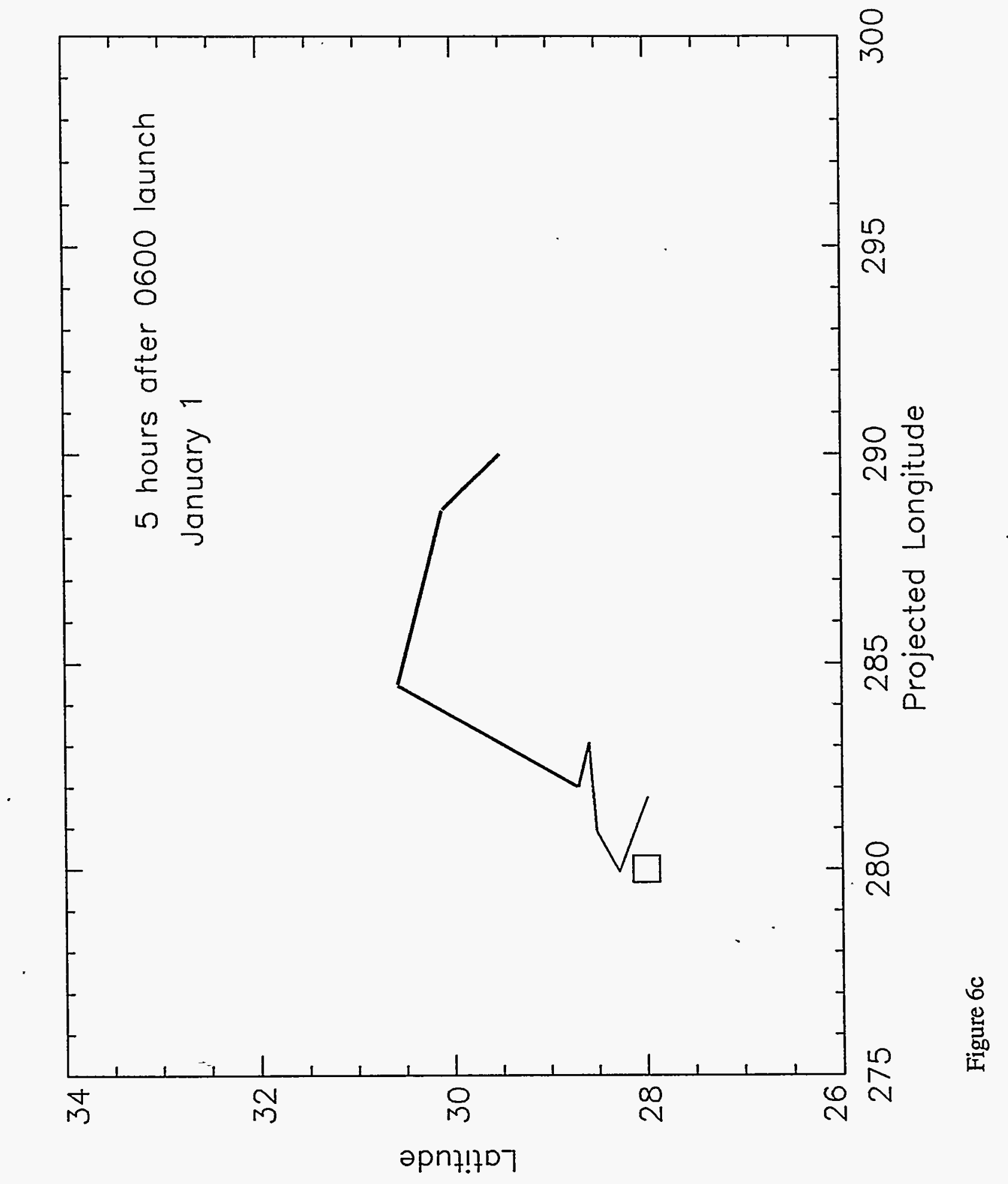




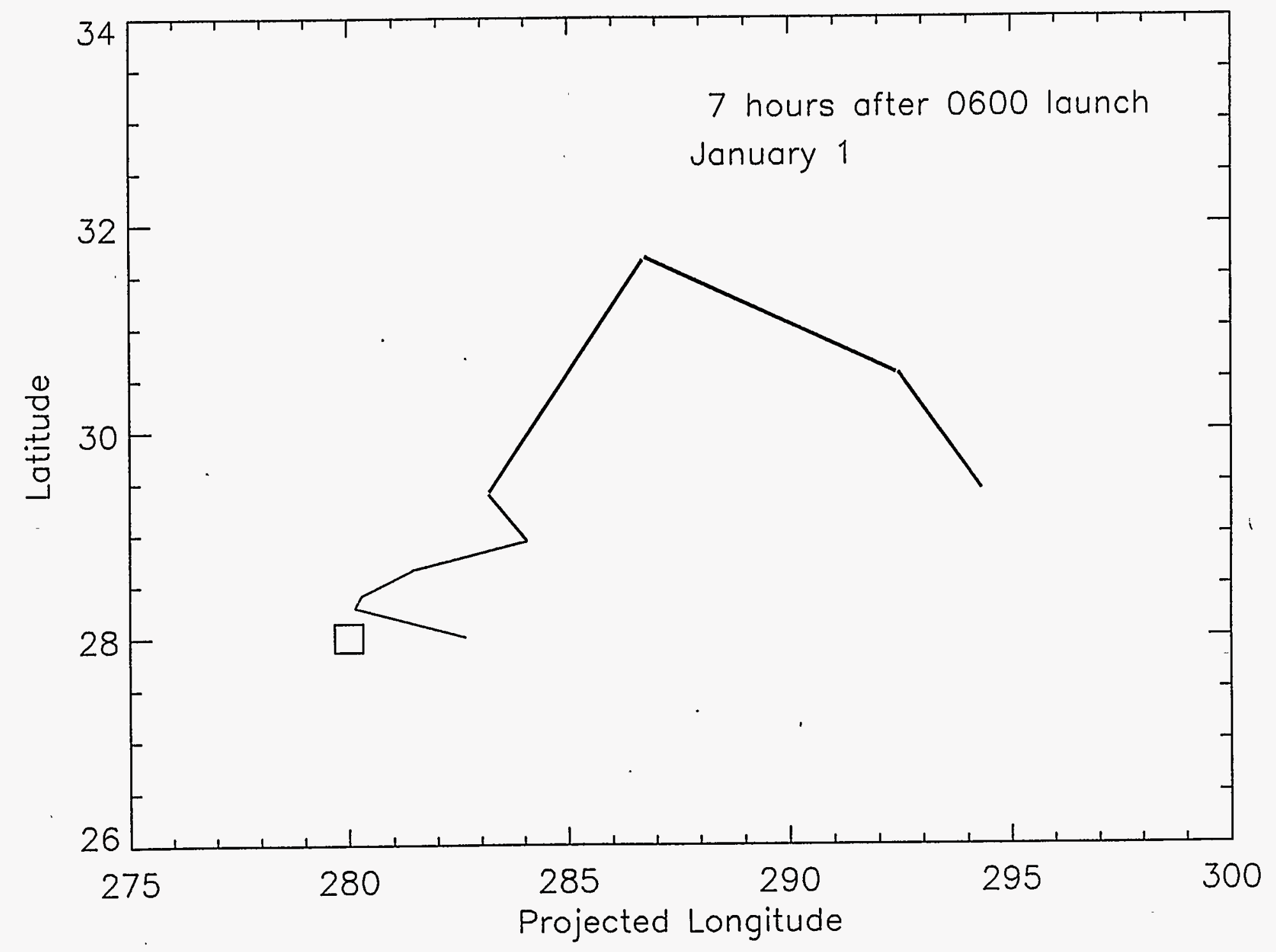

Figure 6d 


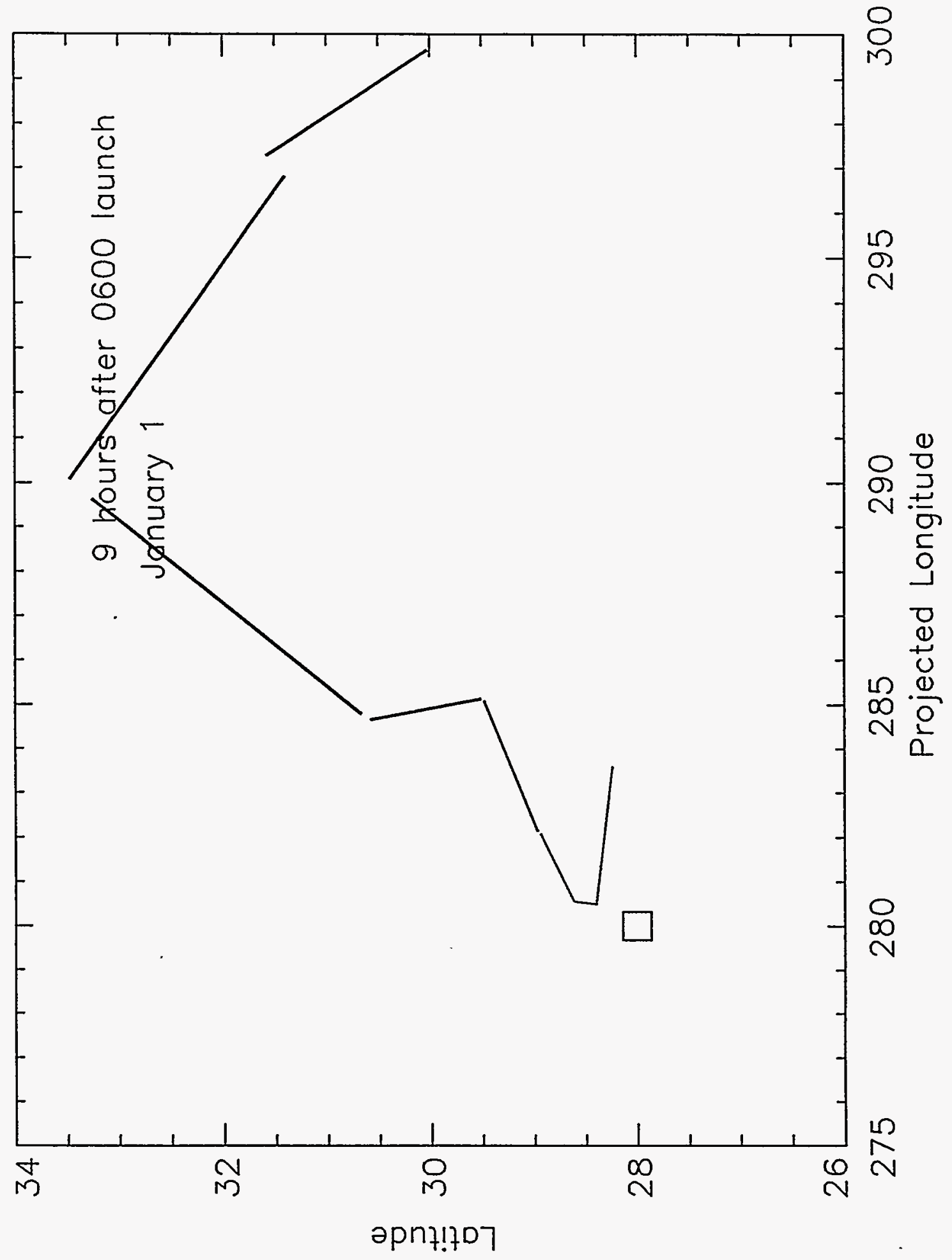

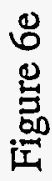




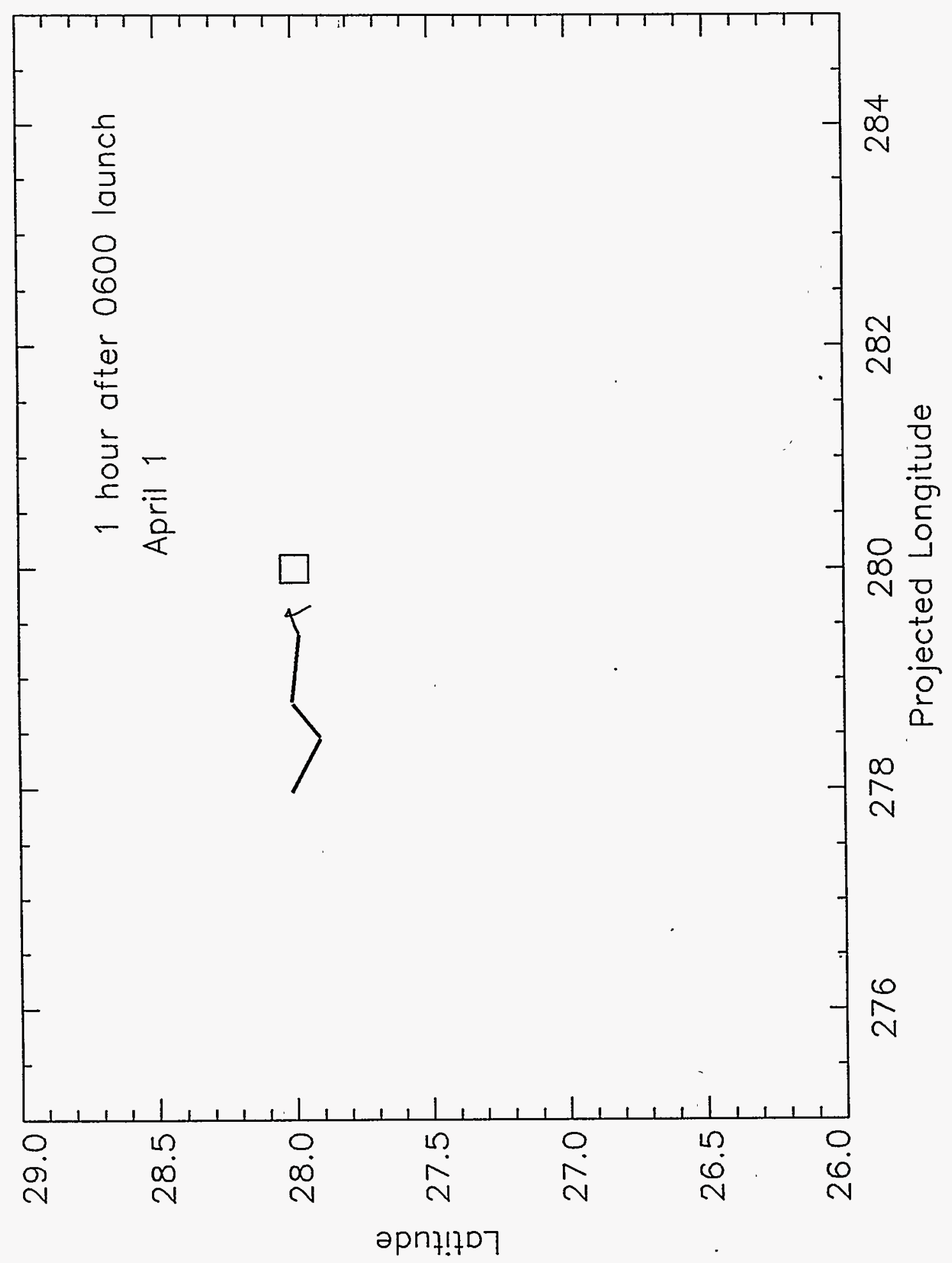

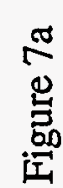




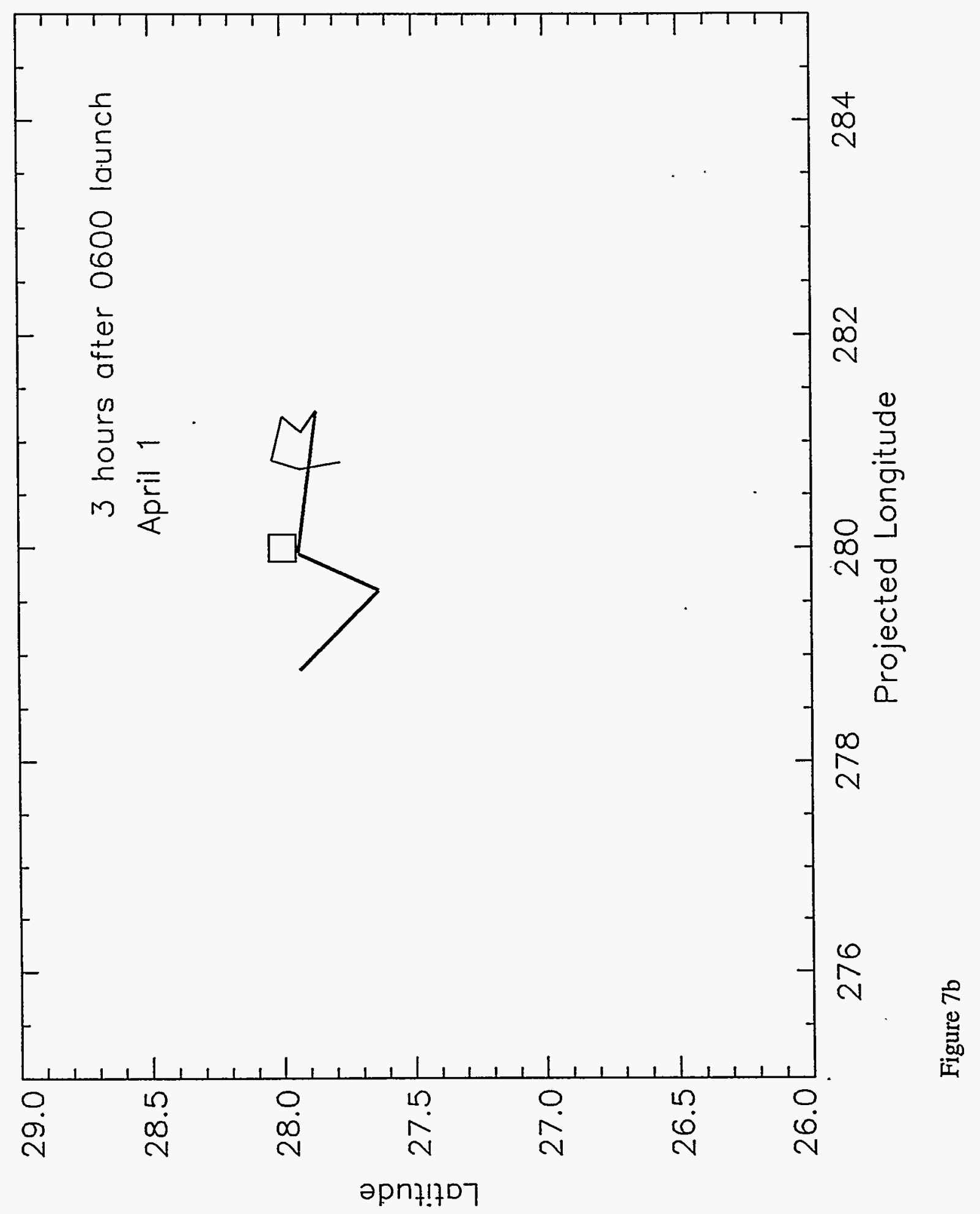




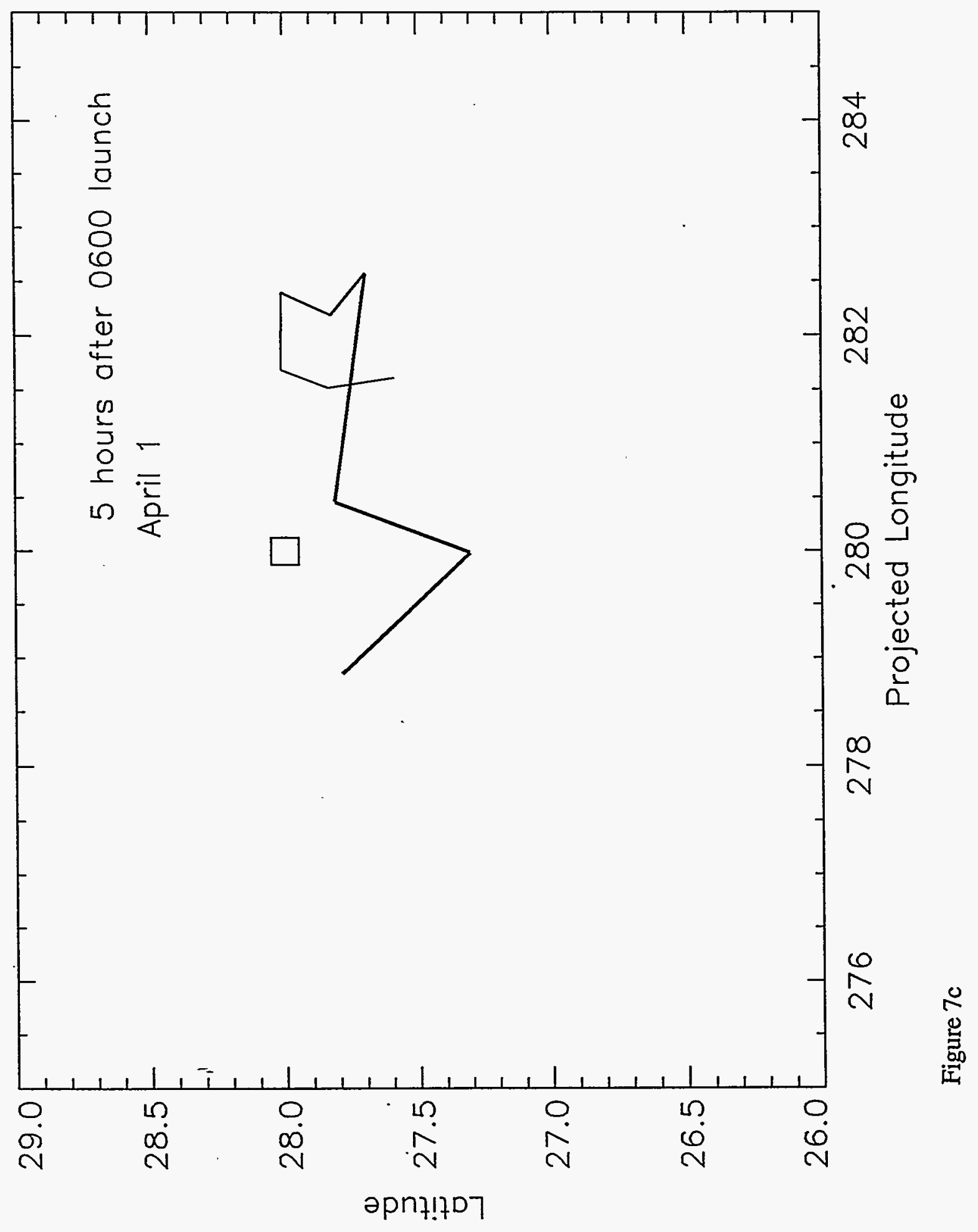




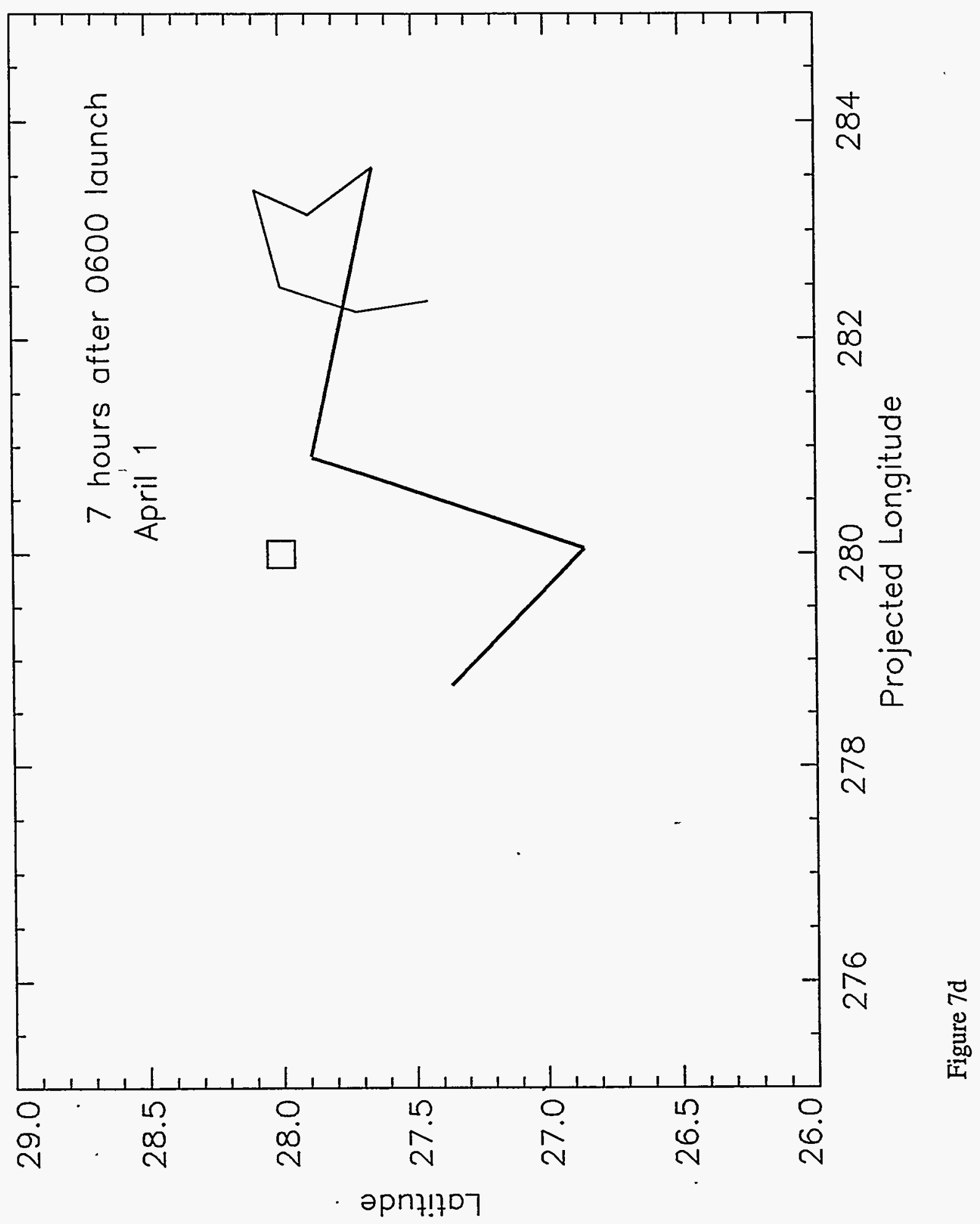




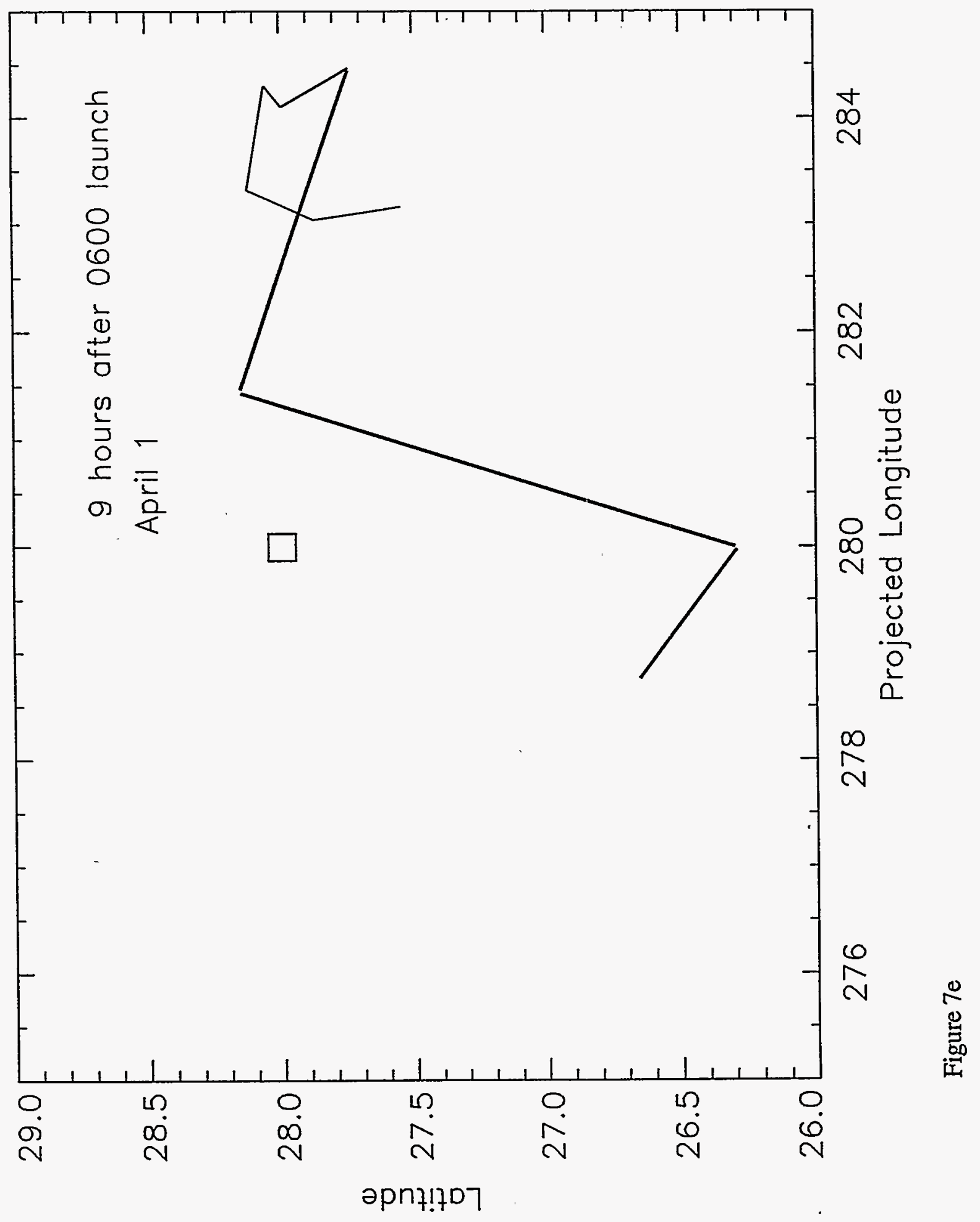




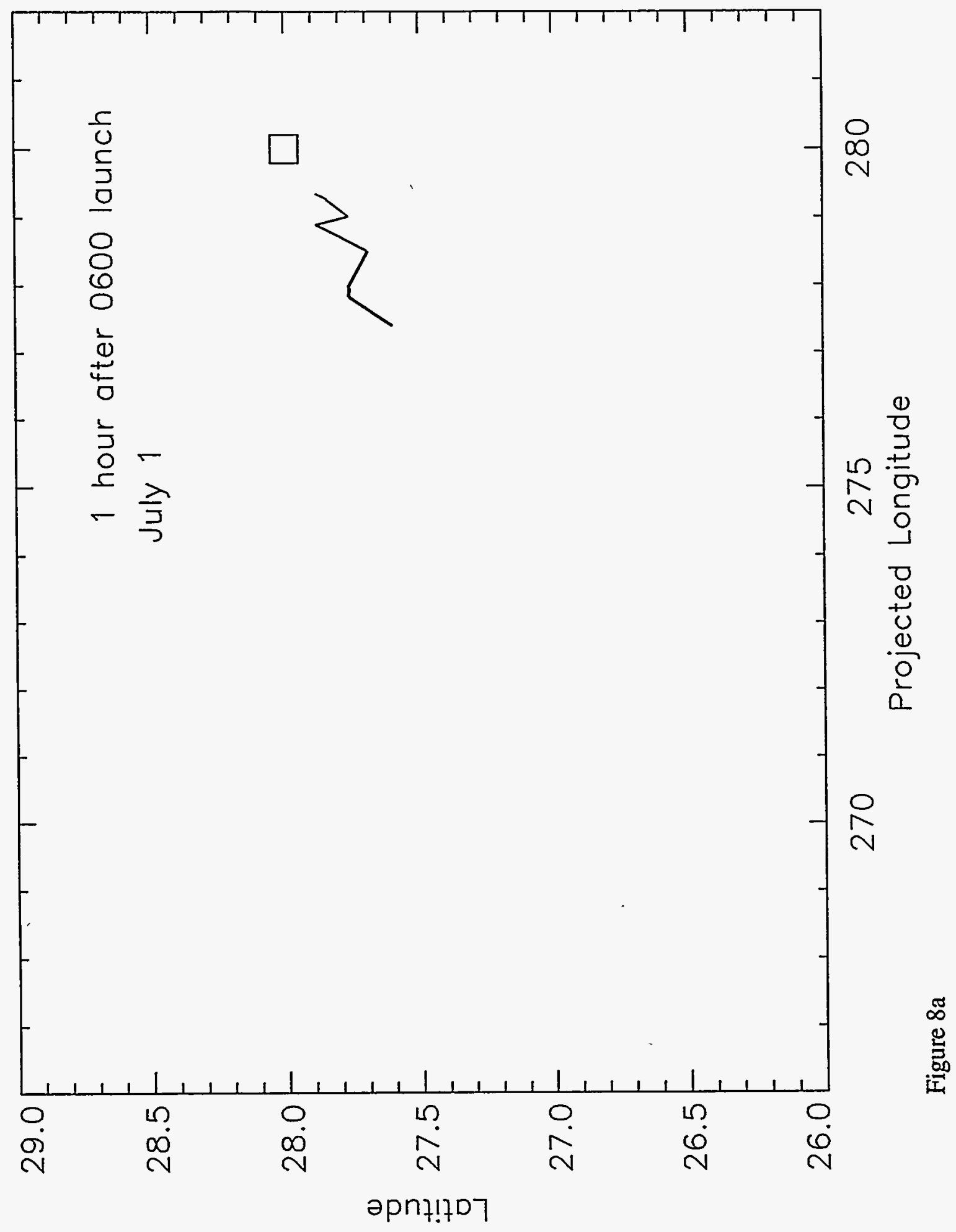




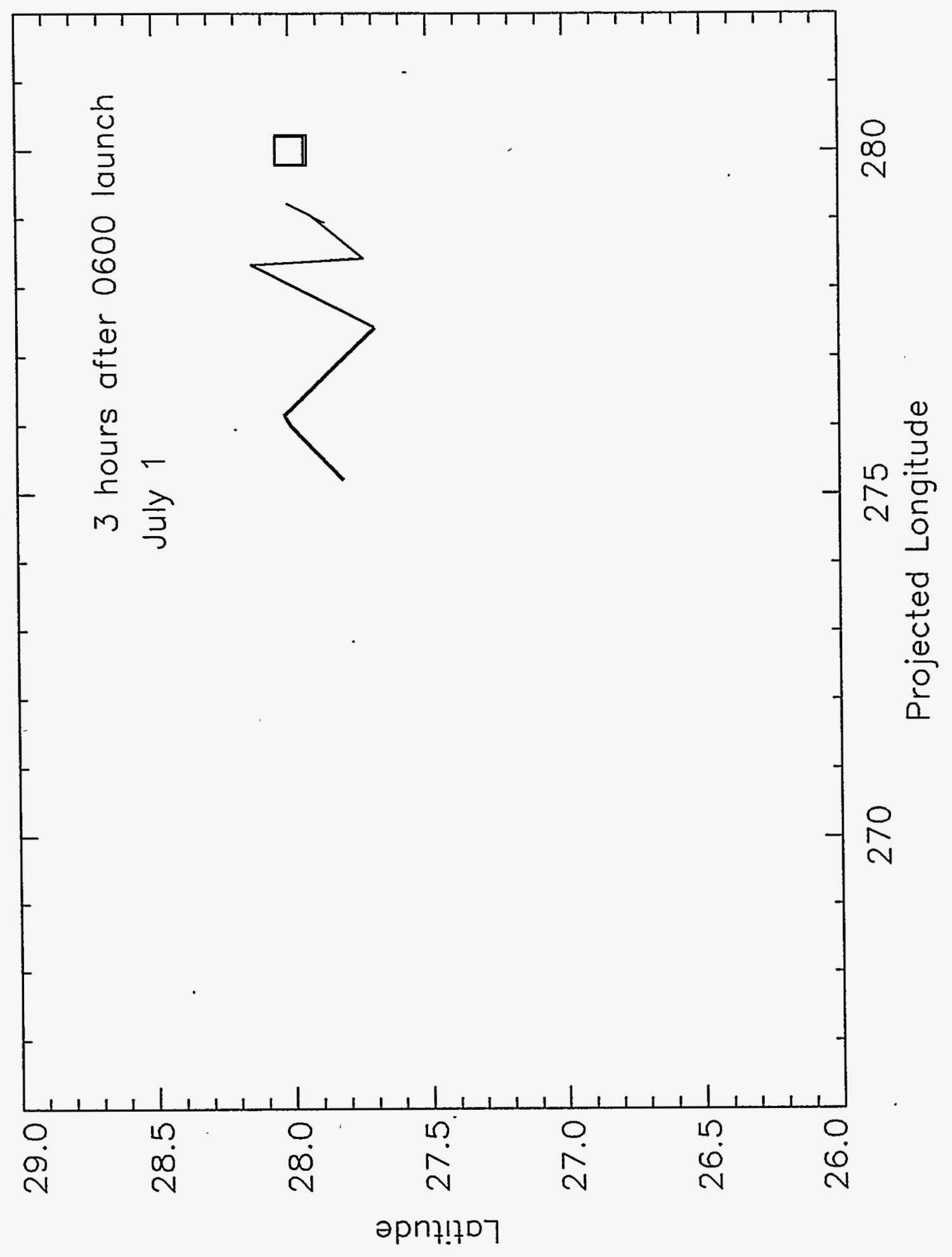

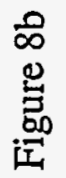




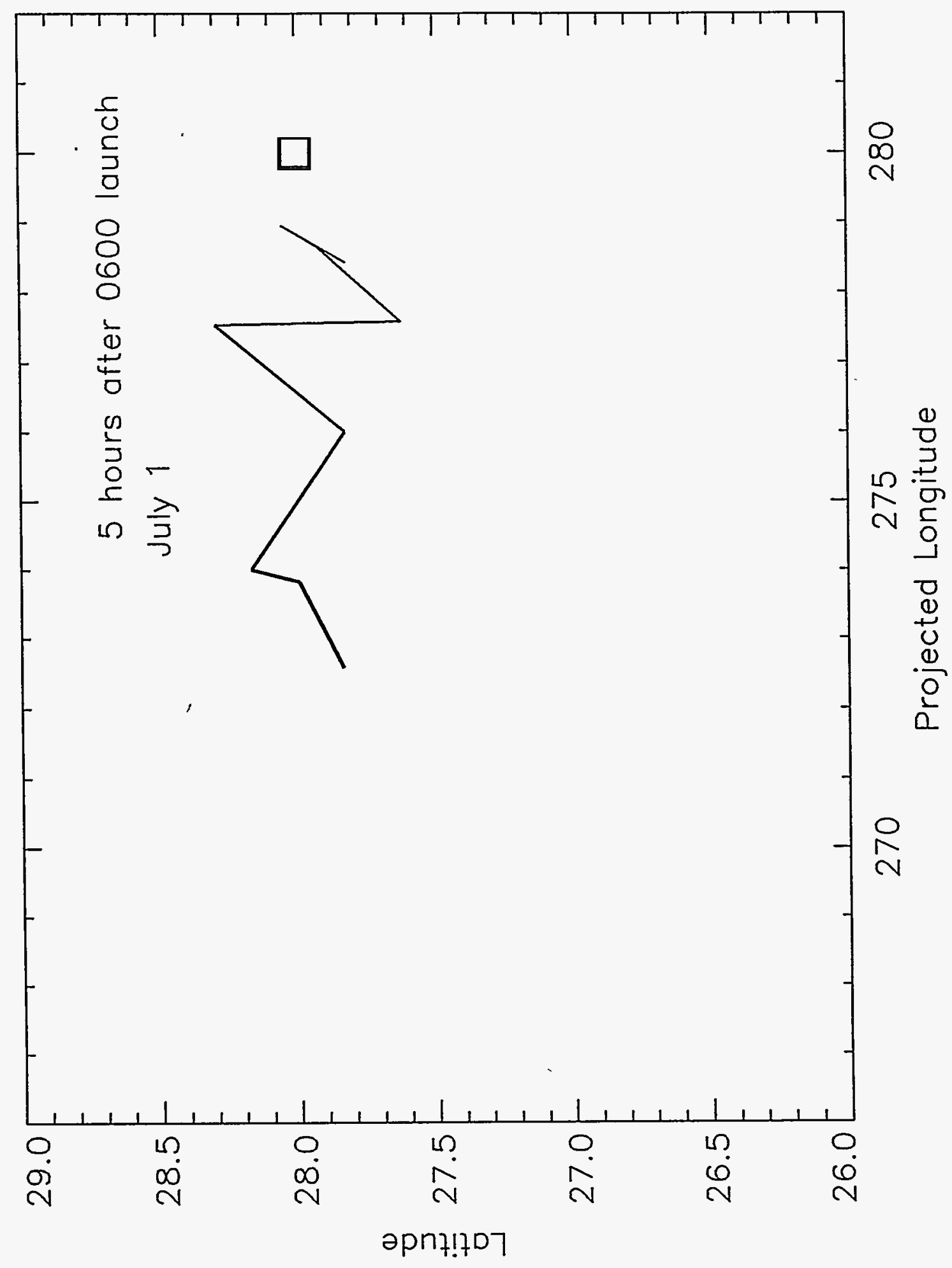

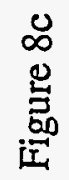




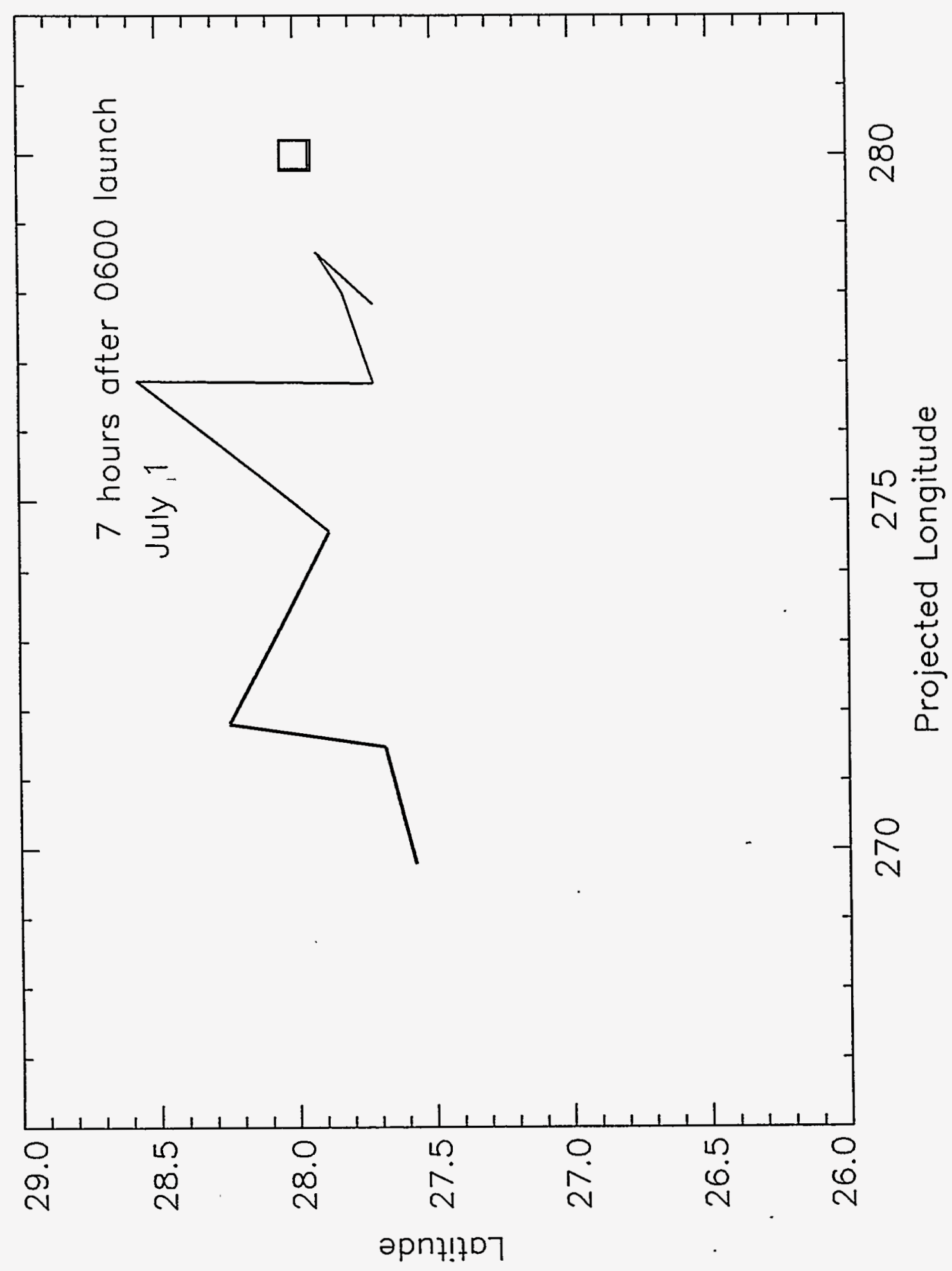

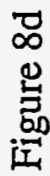




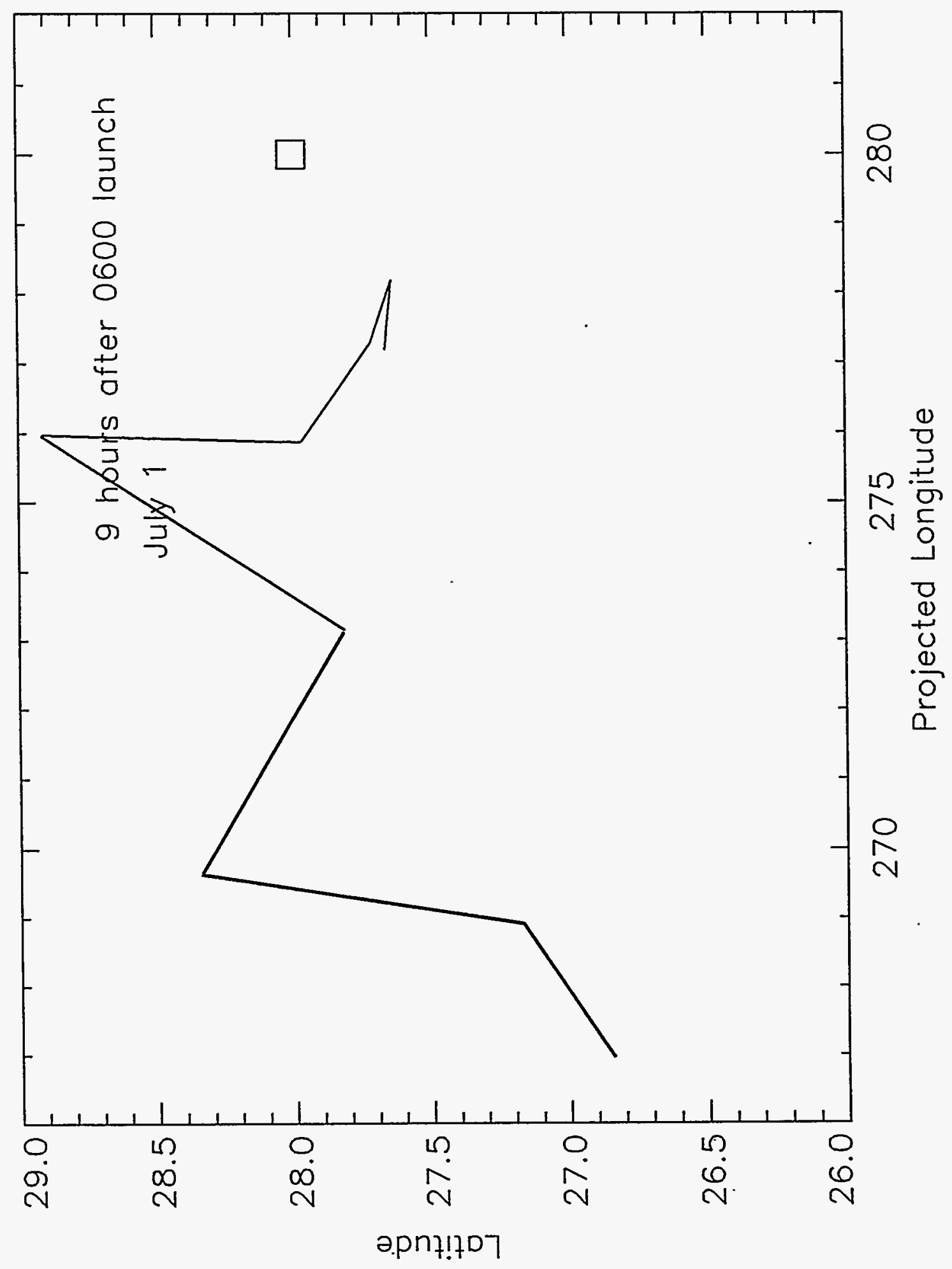

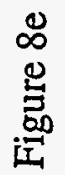




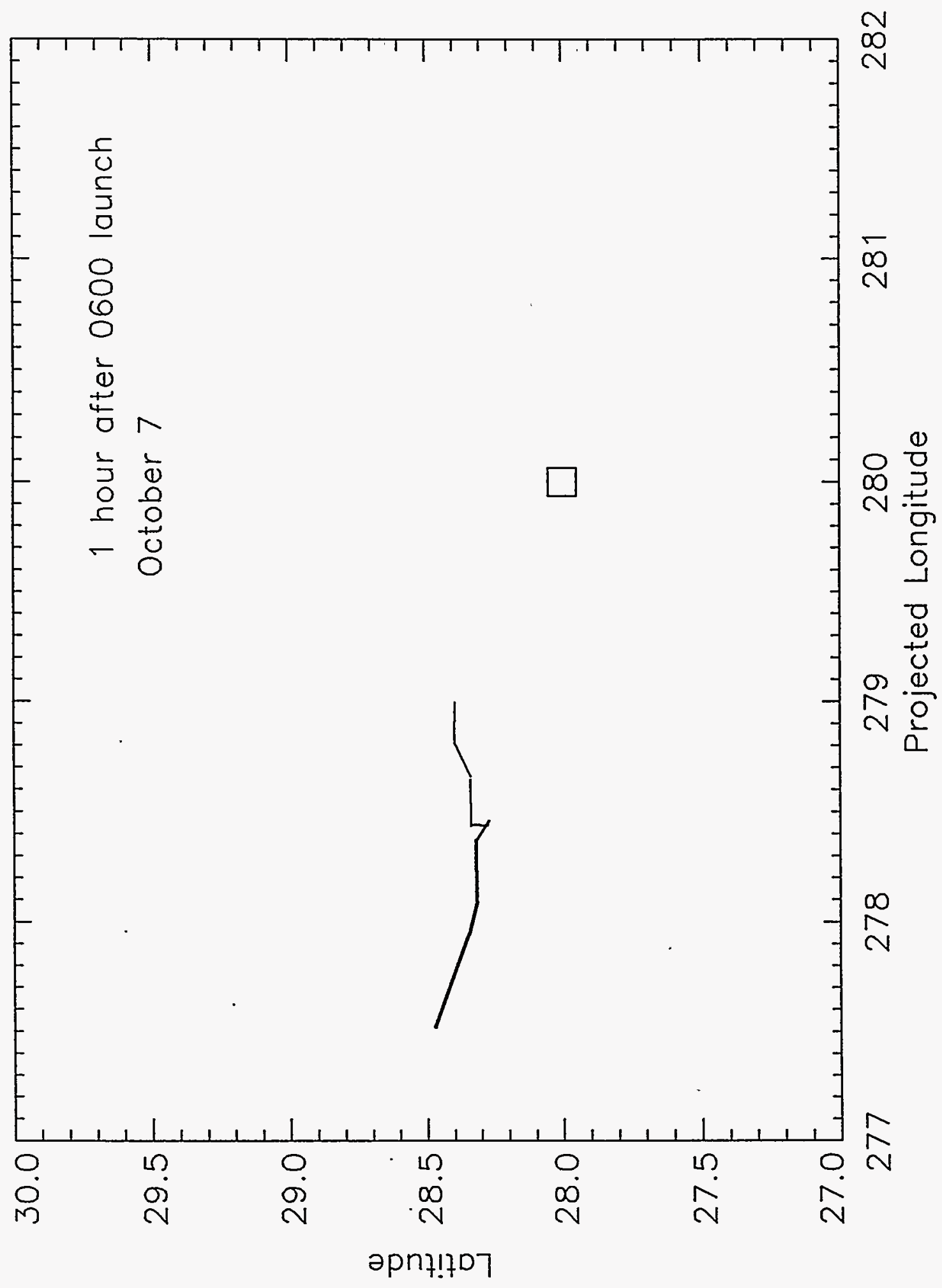

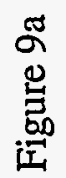




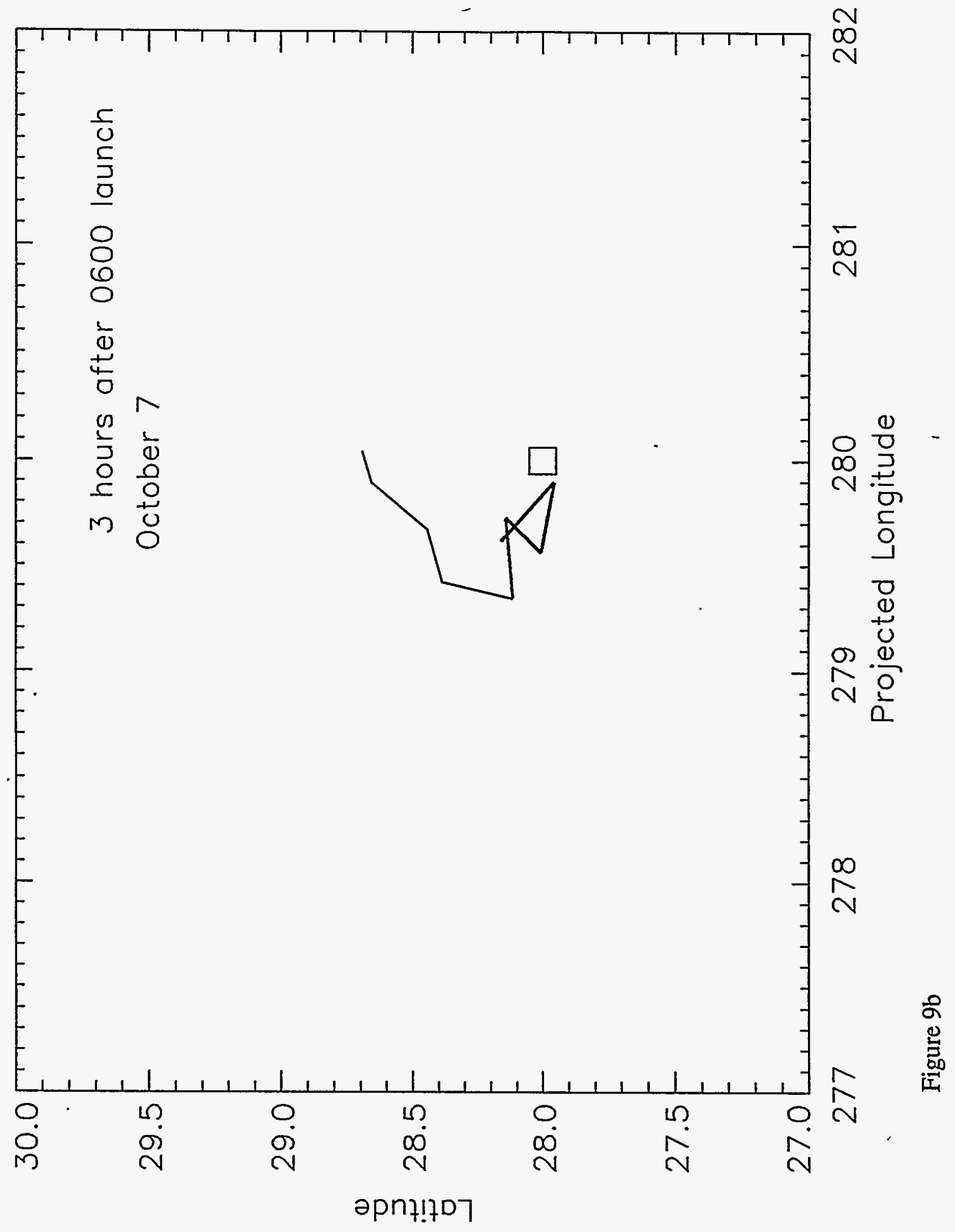




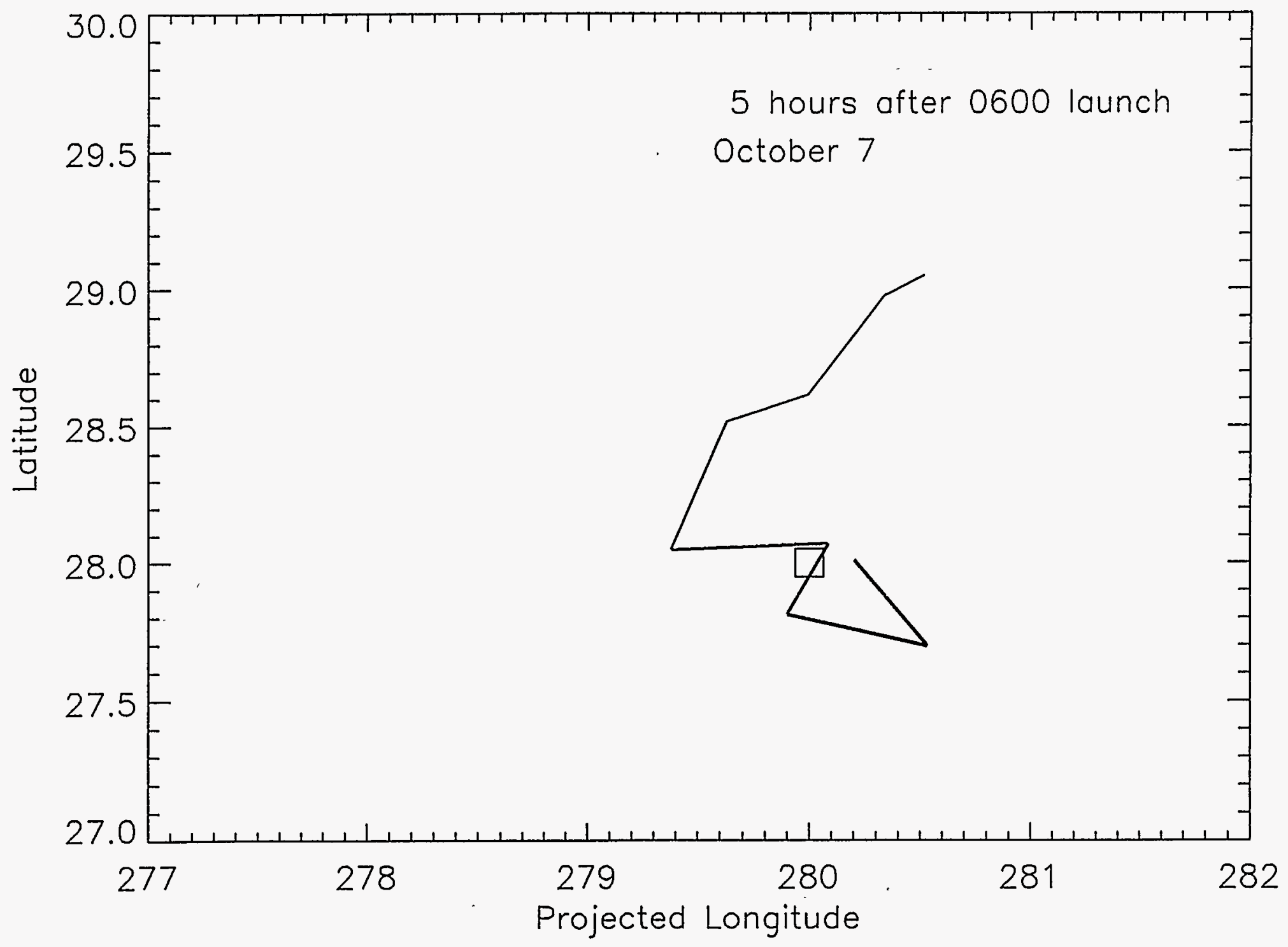

Figure 9c 


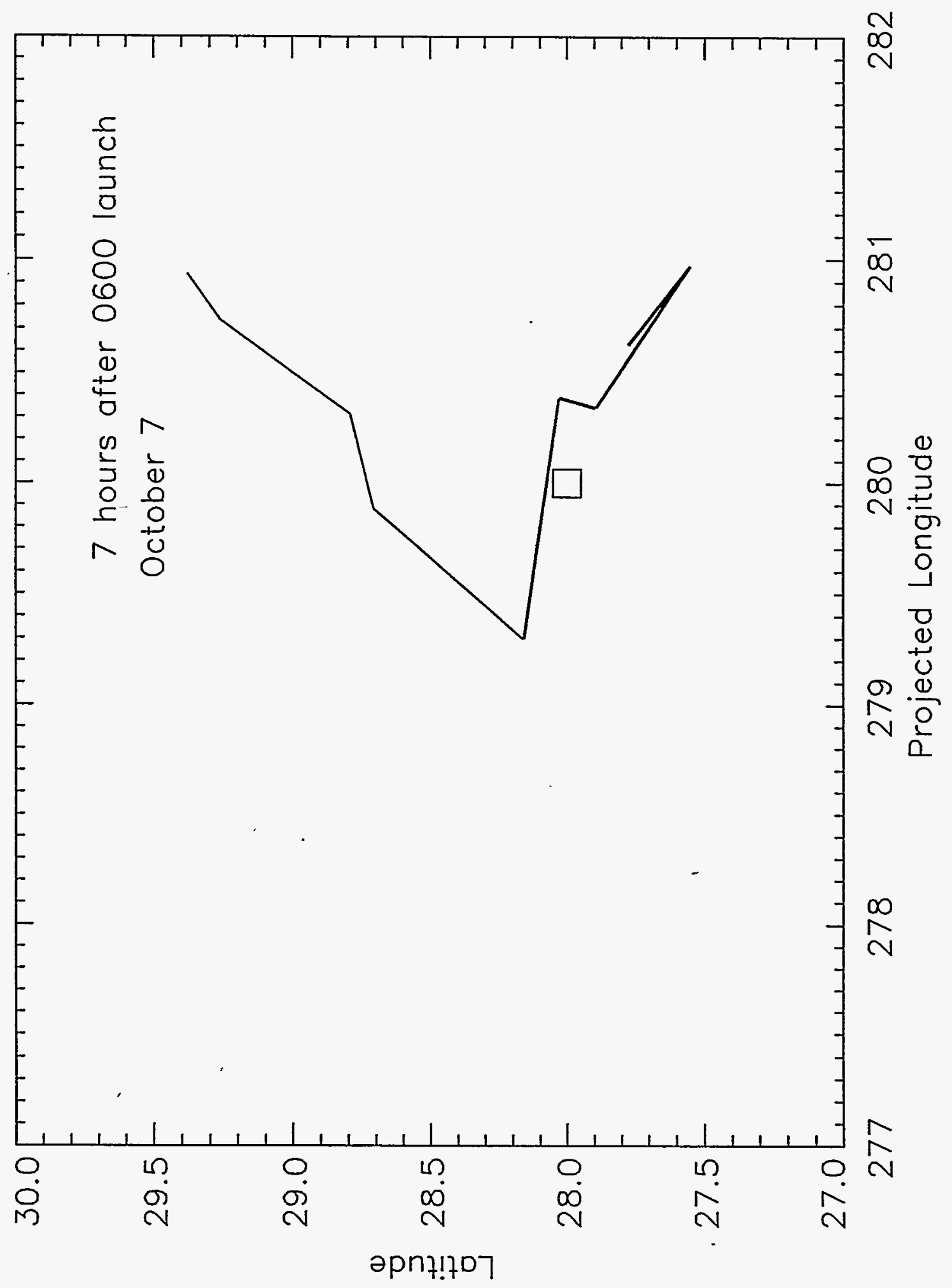

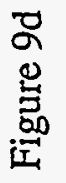




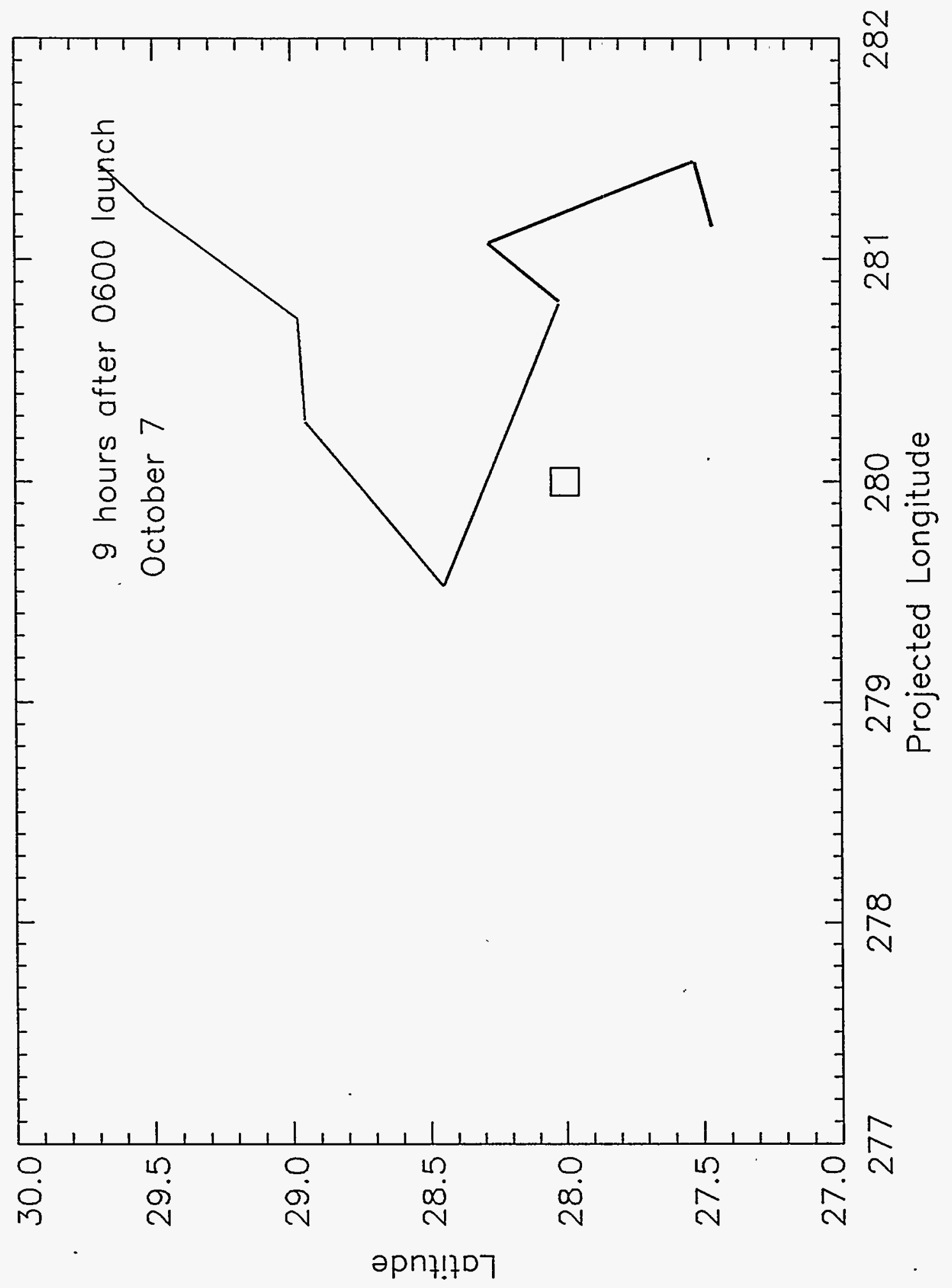

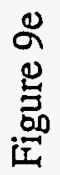




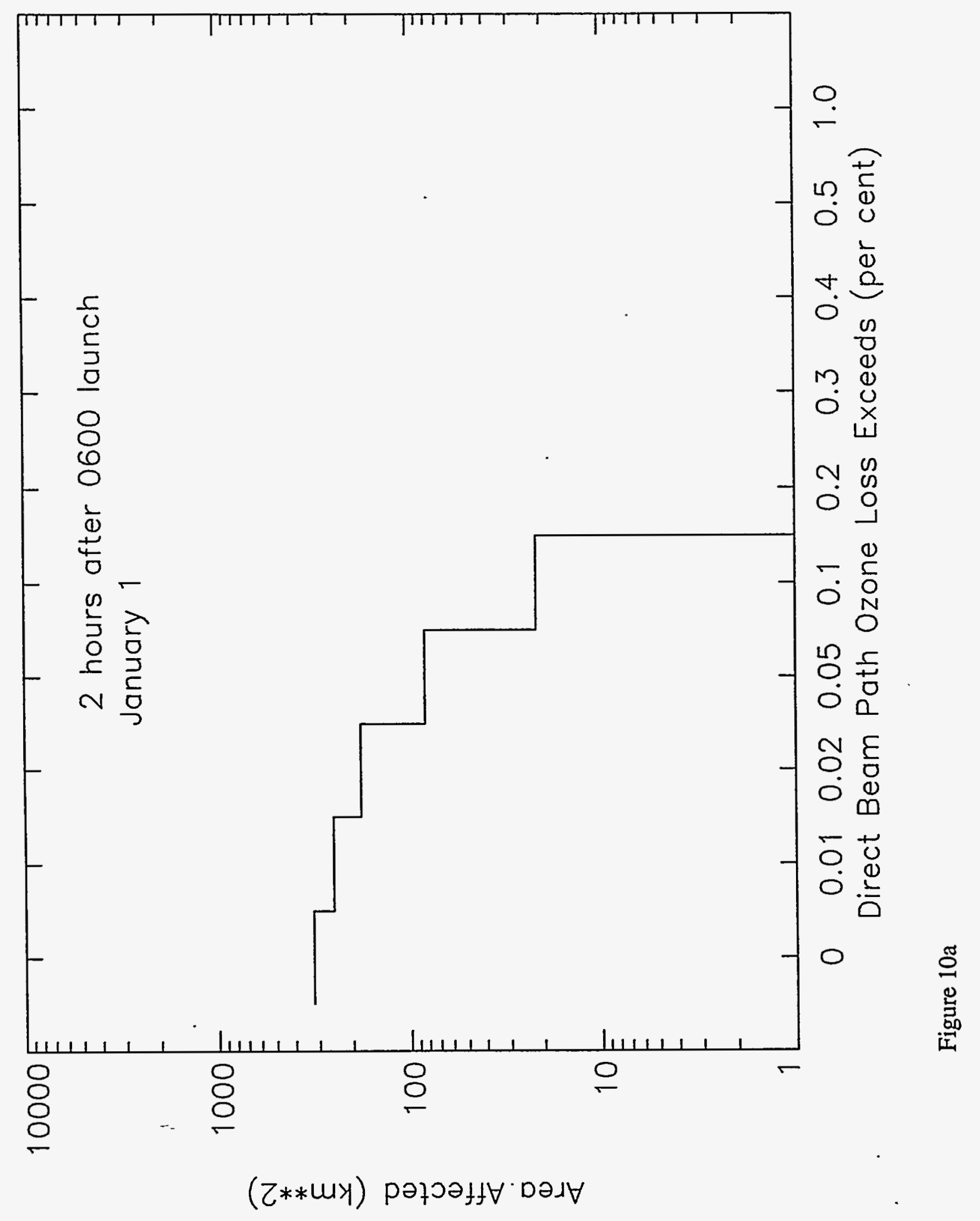




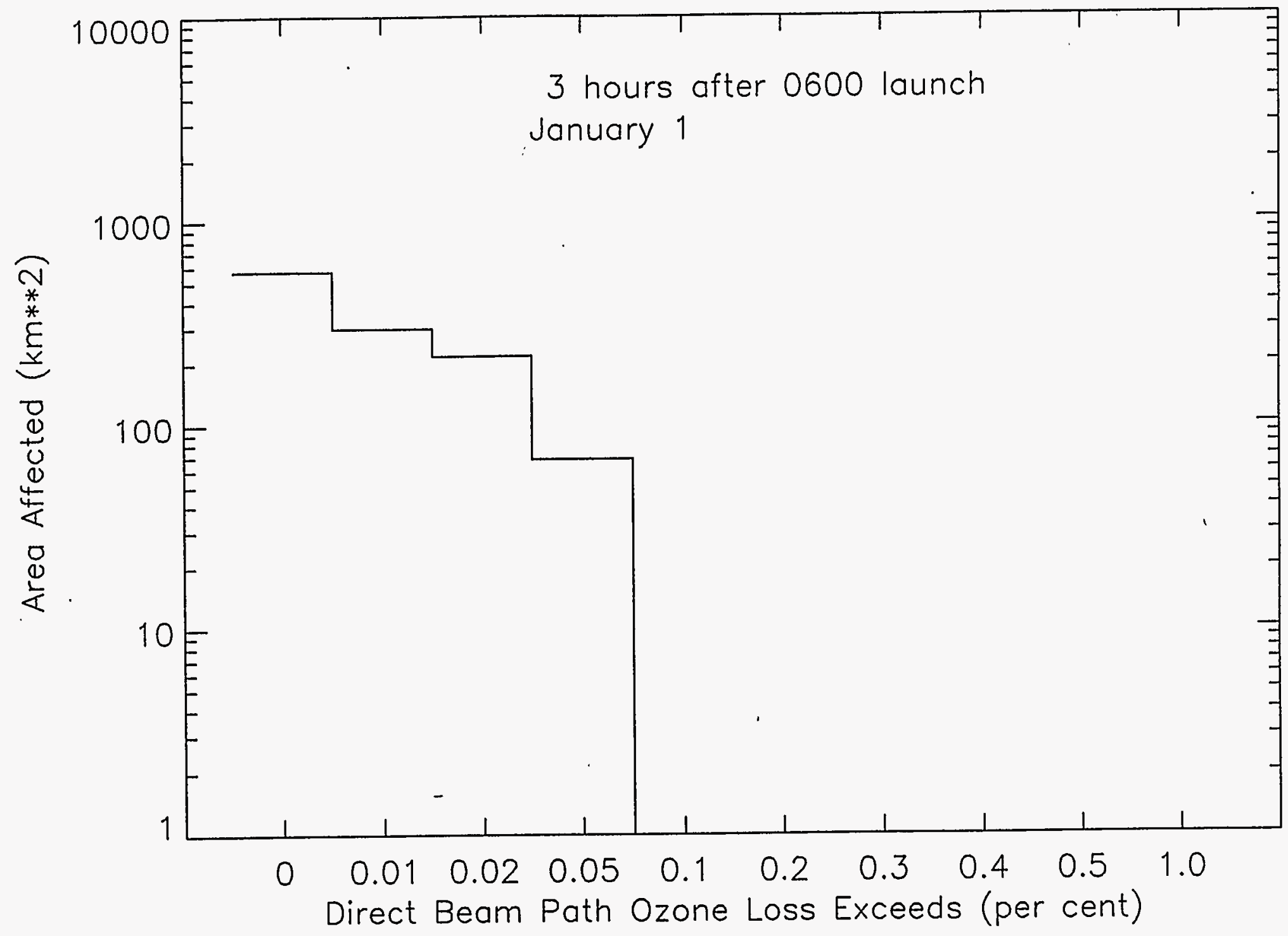

Figure 10b 


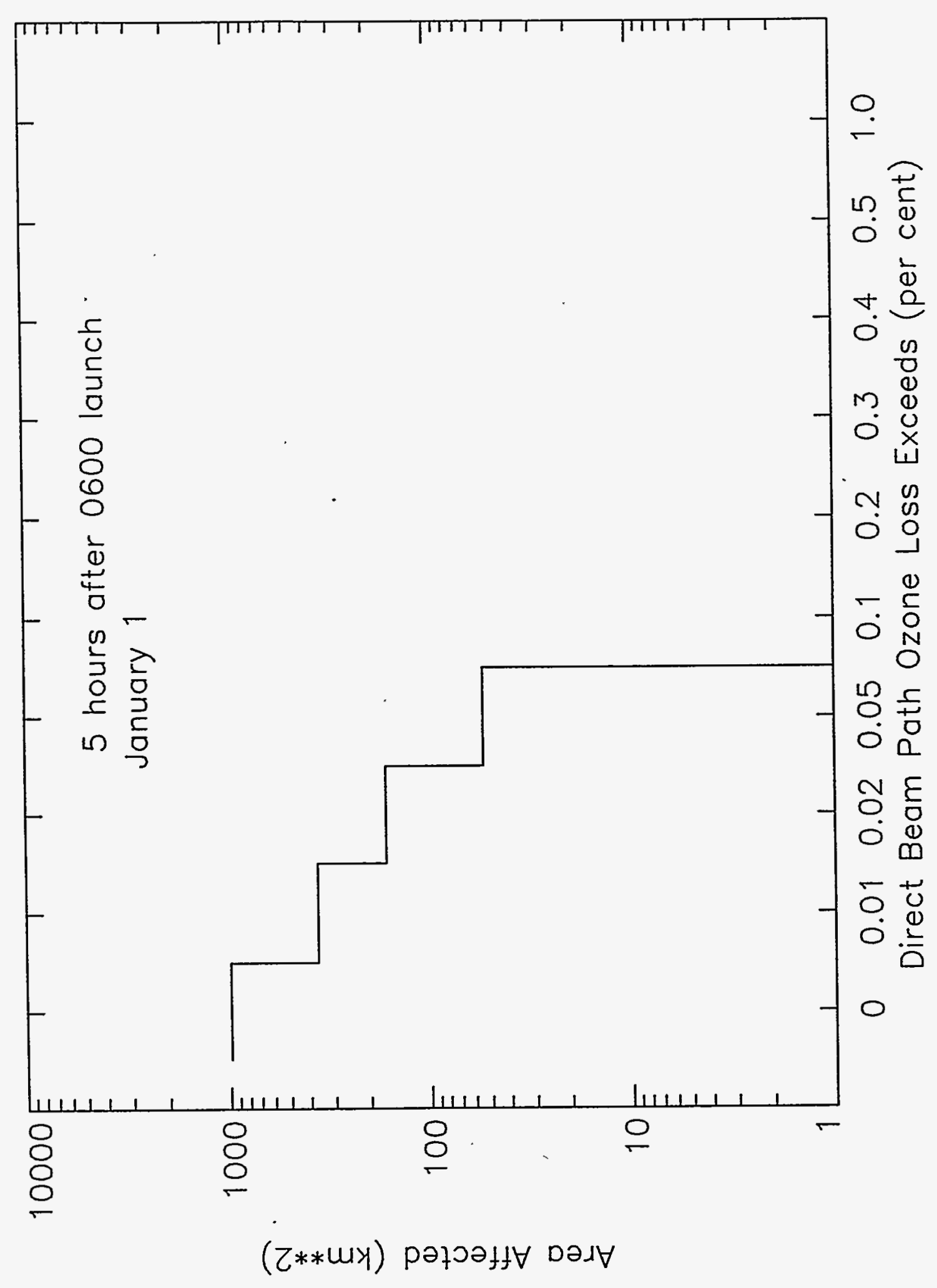




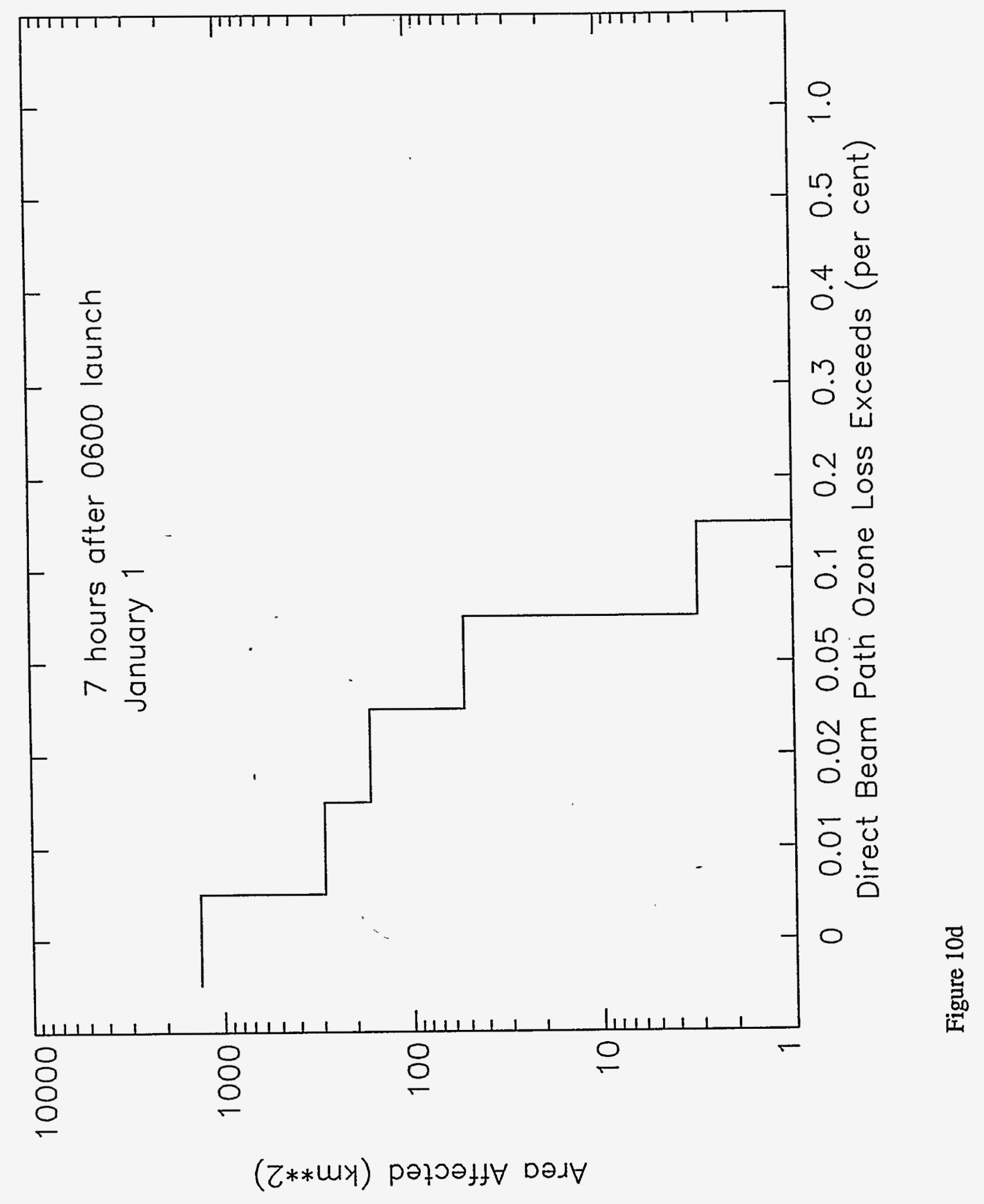




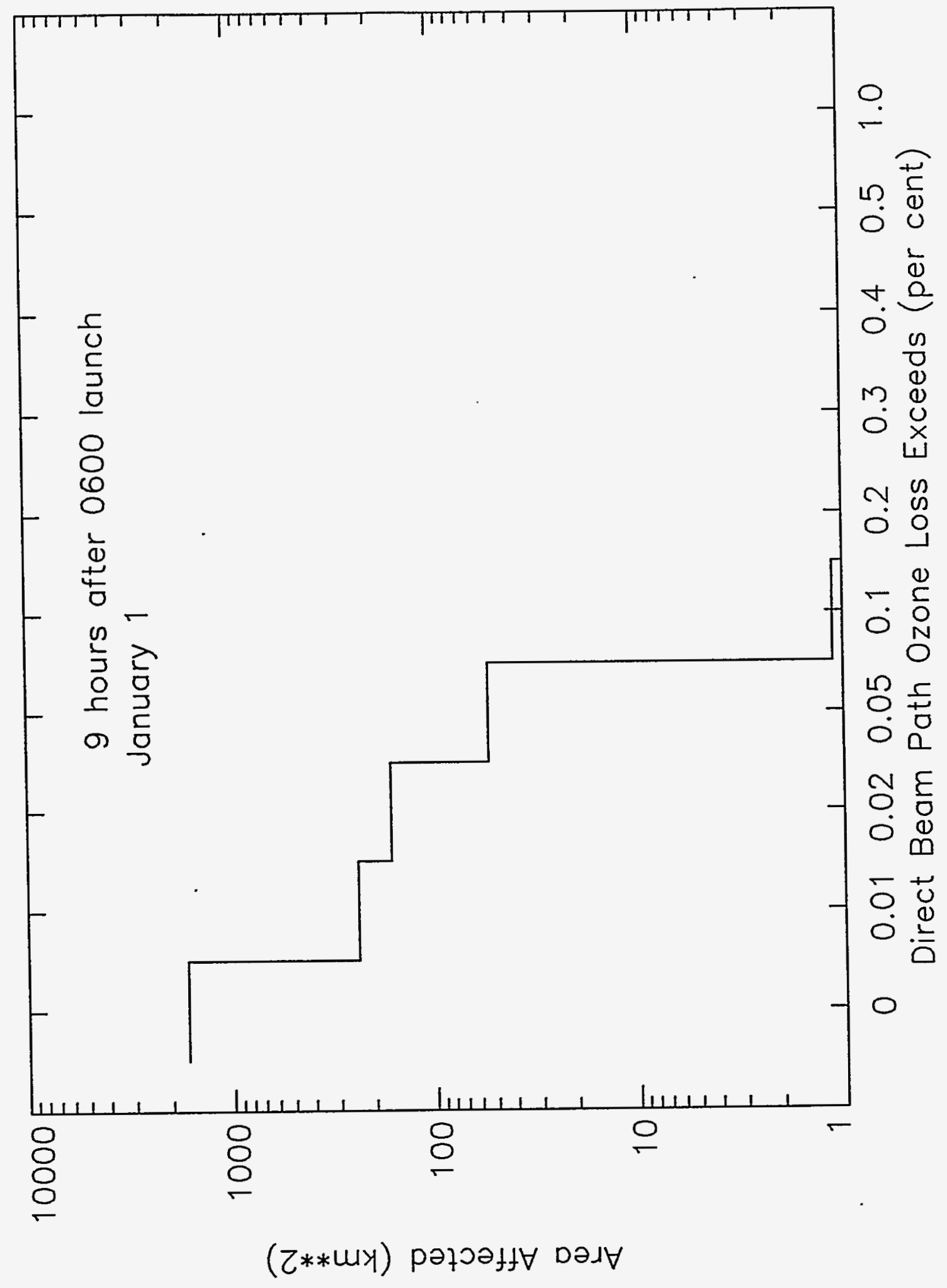

$\underset{0}{\stackrel{0}{0}}$ 


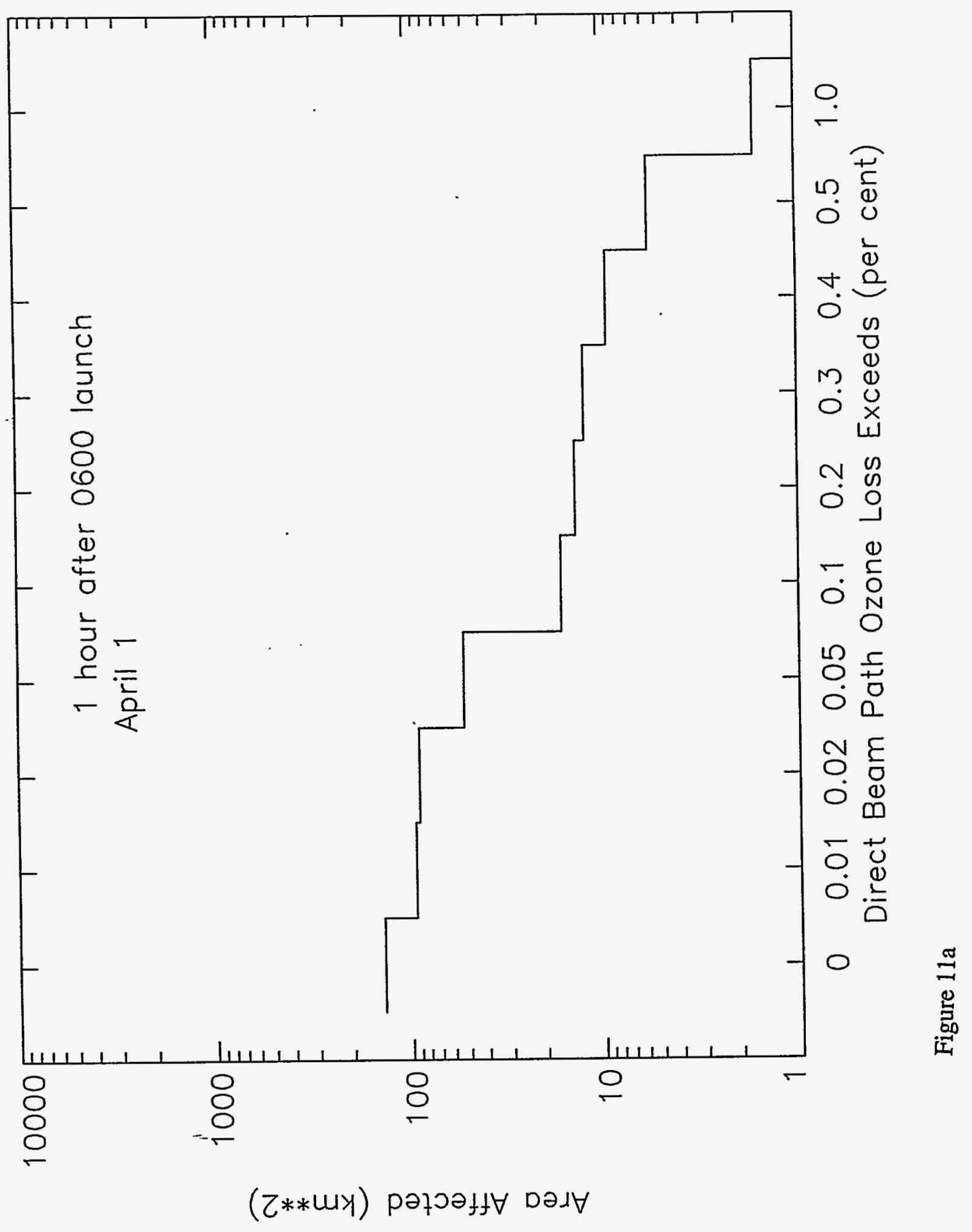




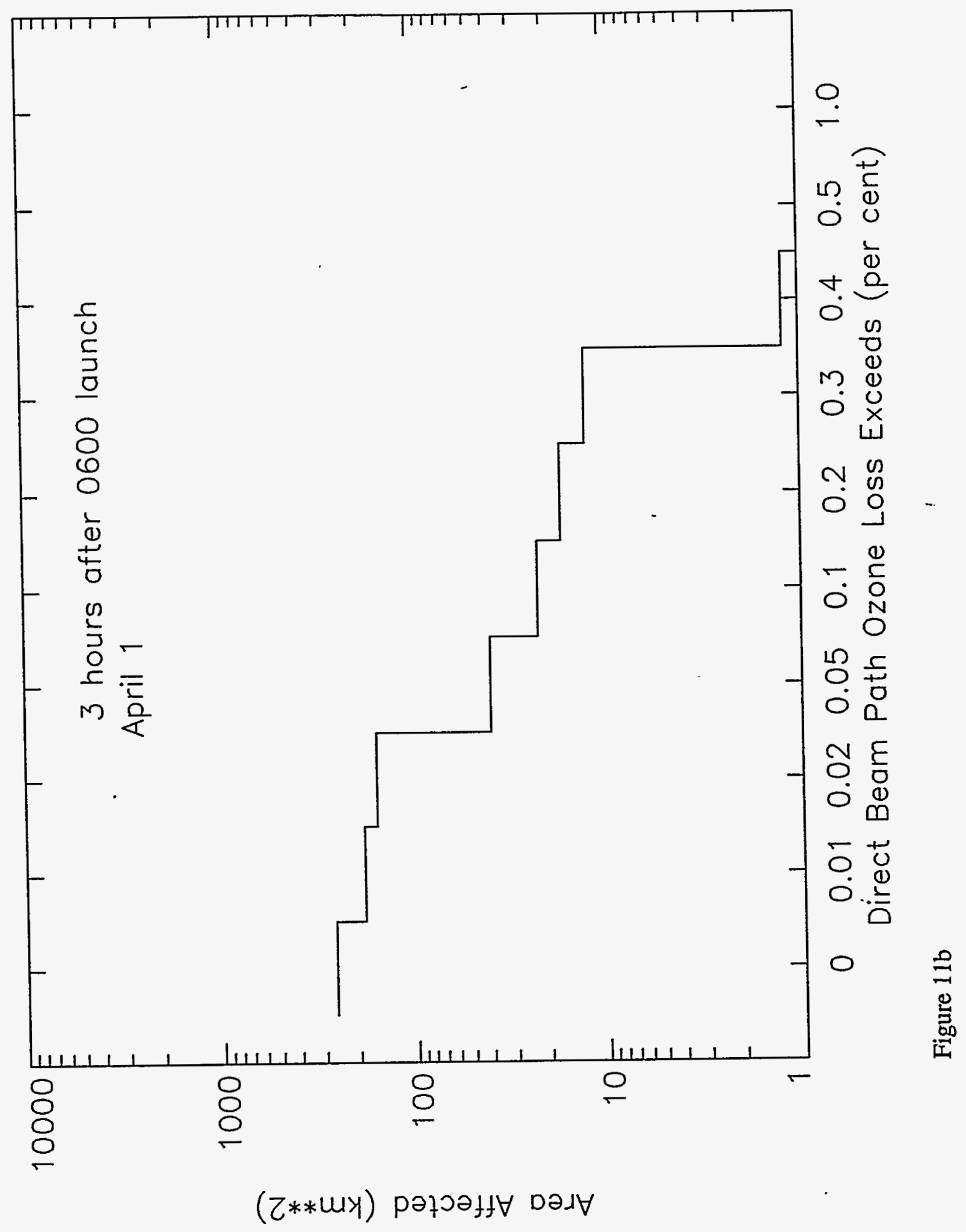




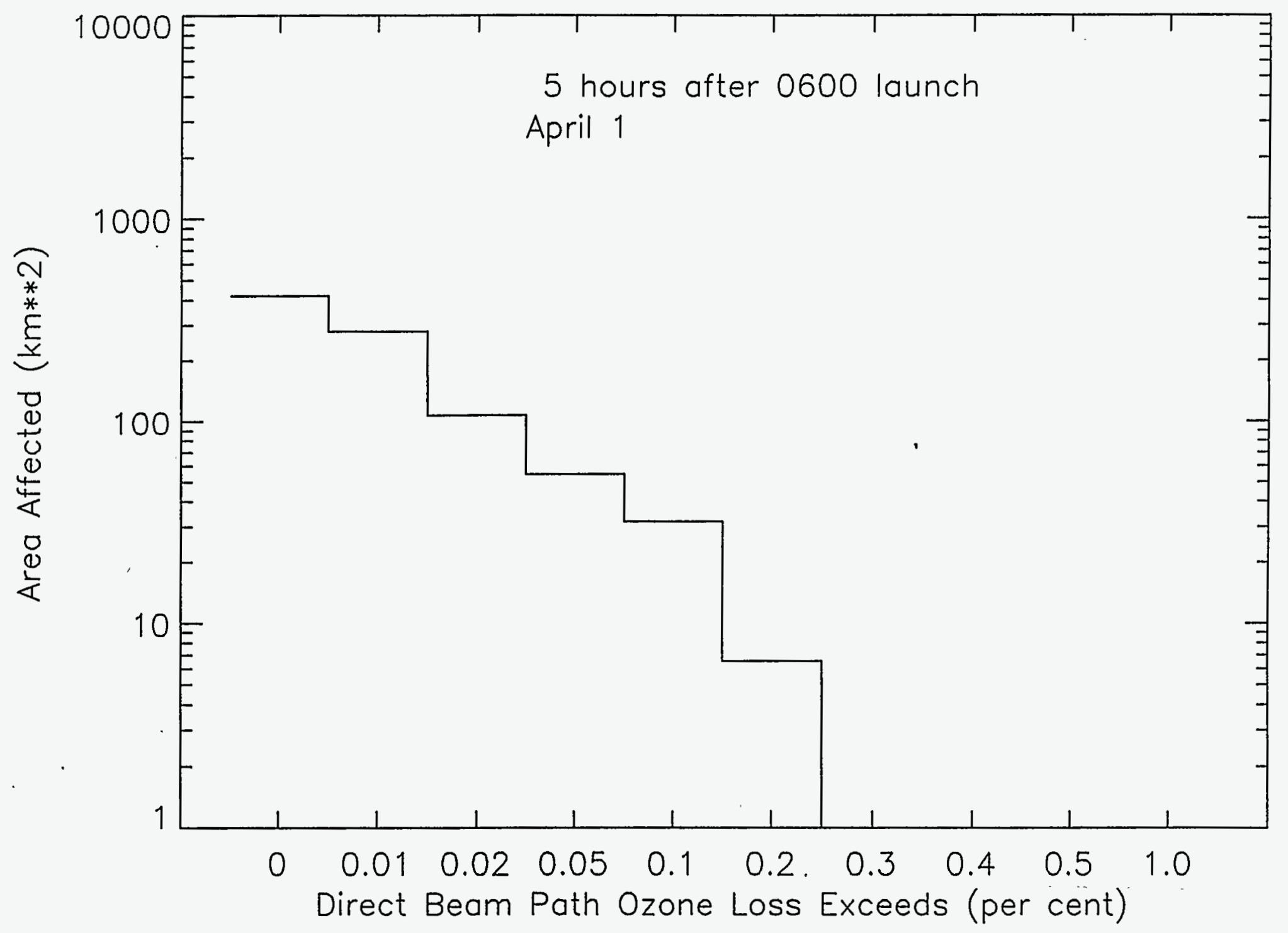

Figure 11c 


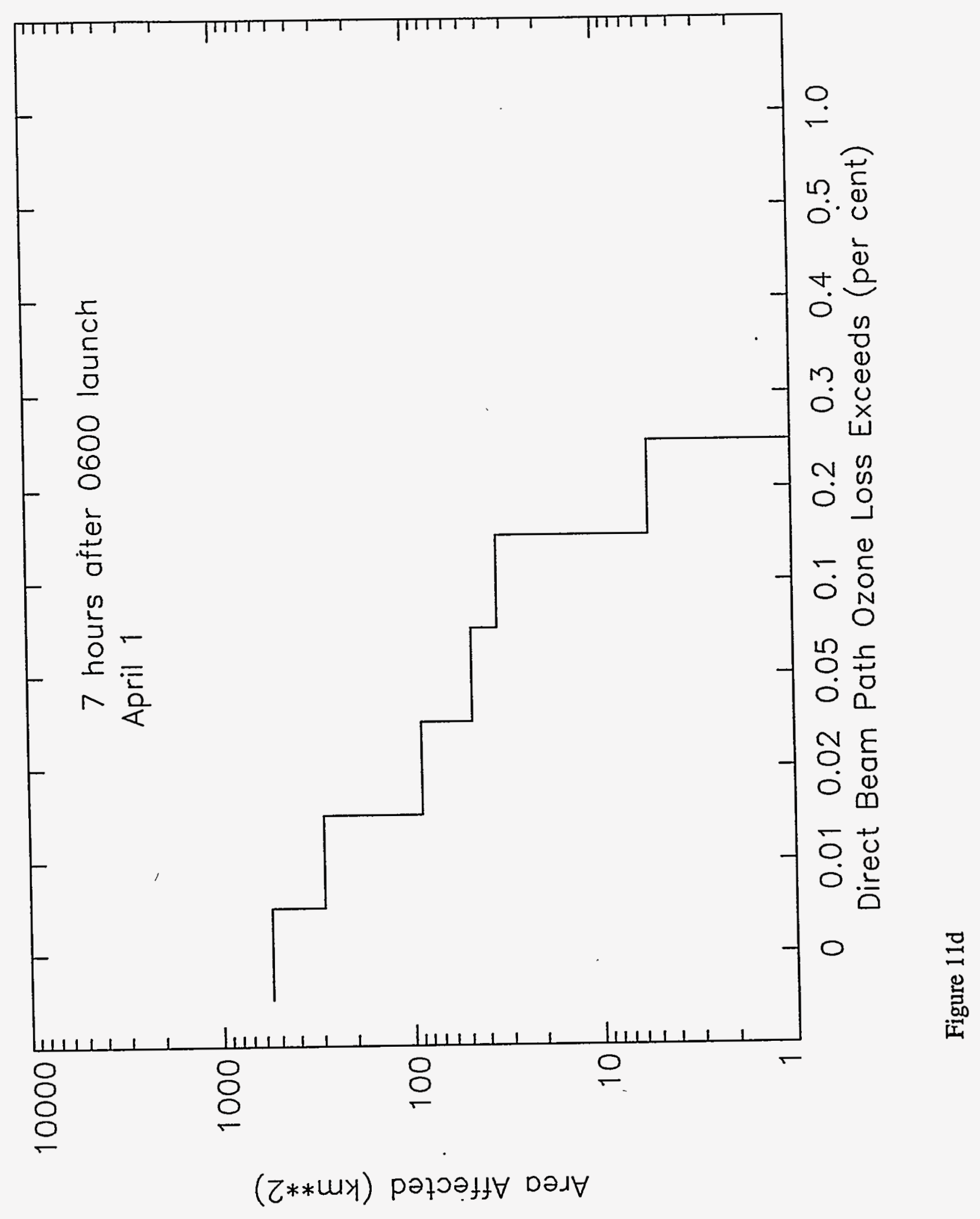




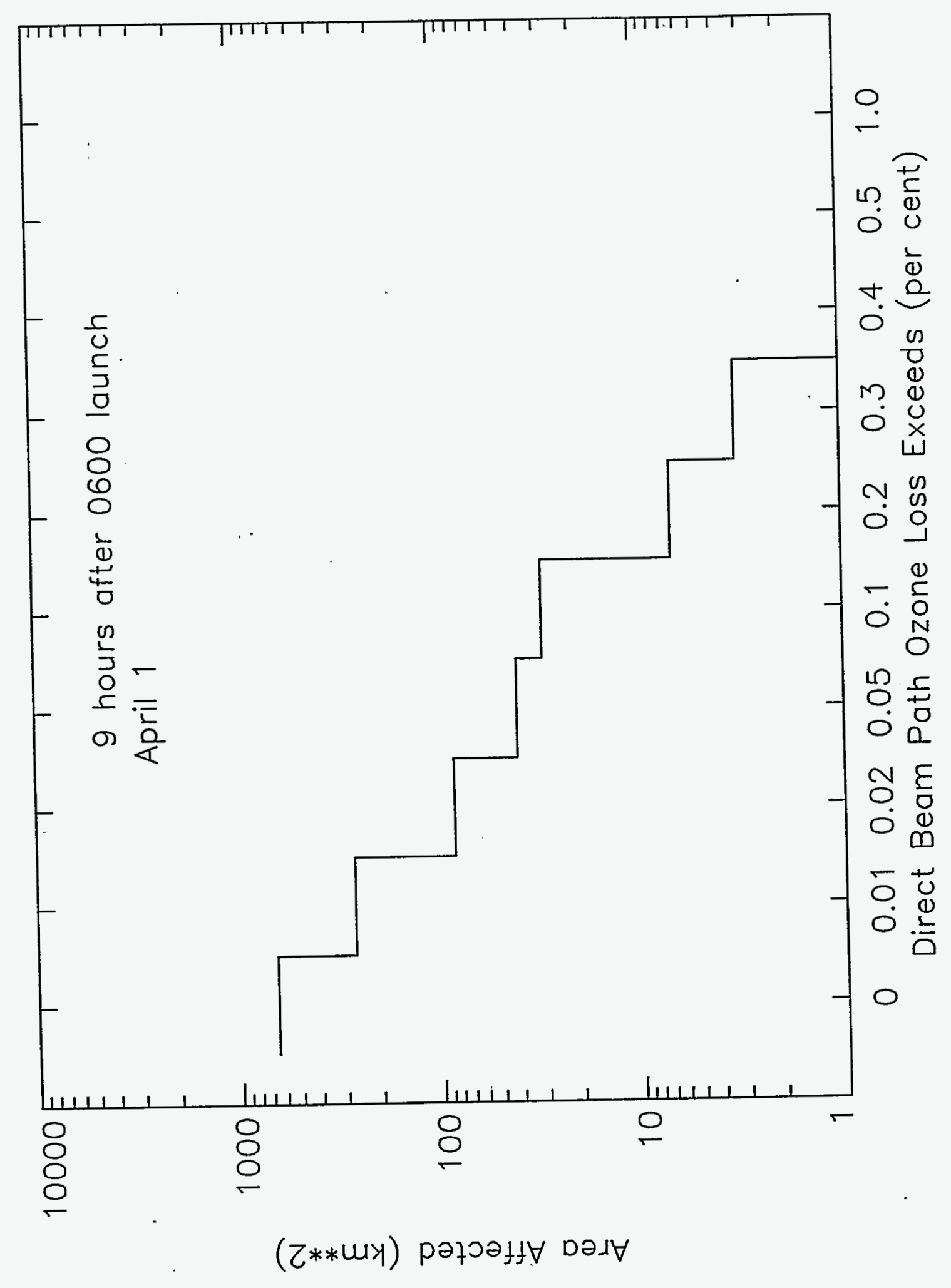

$\stackrel{0}{\stackrel{0}{ \pm}}$ 


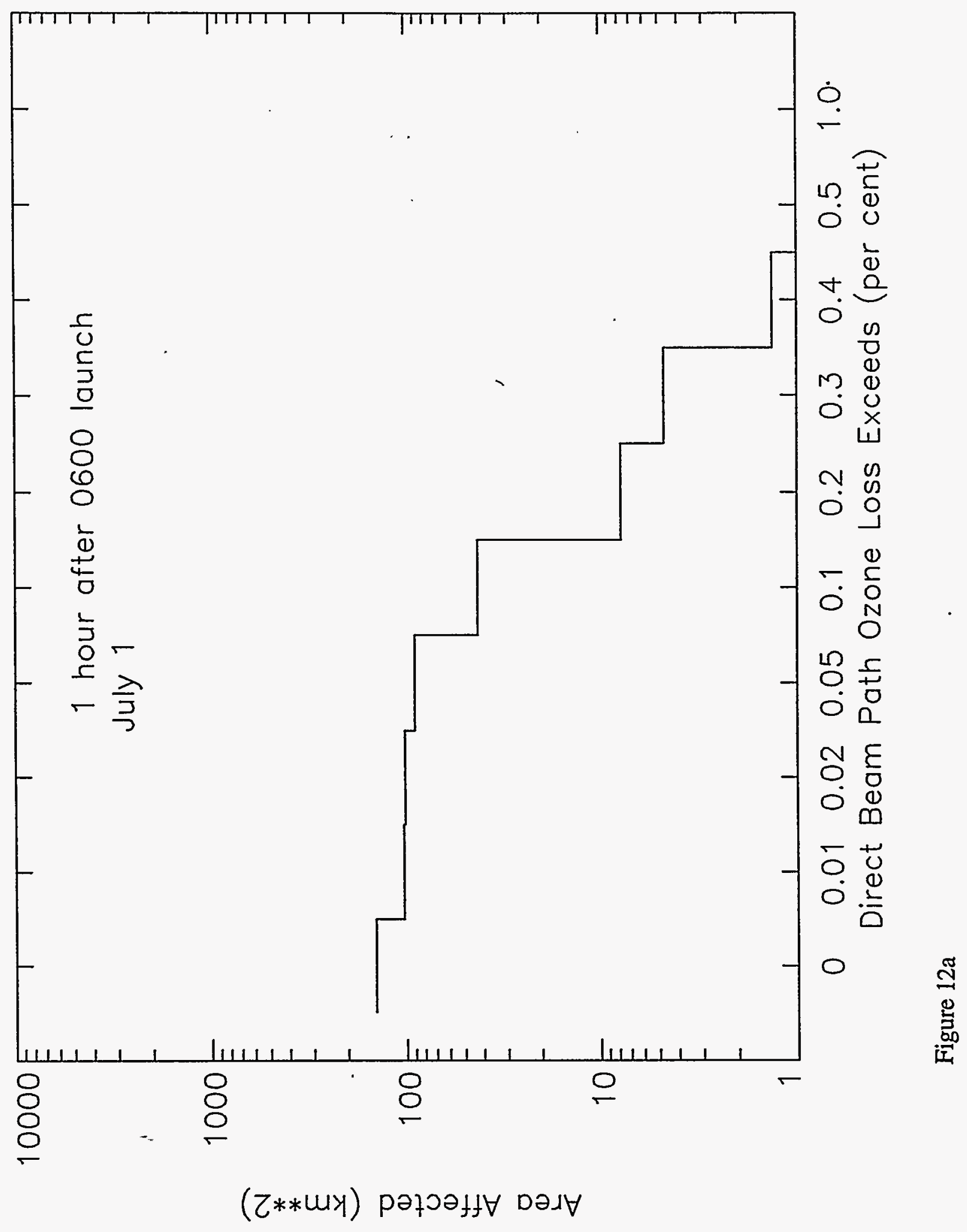




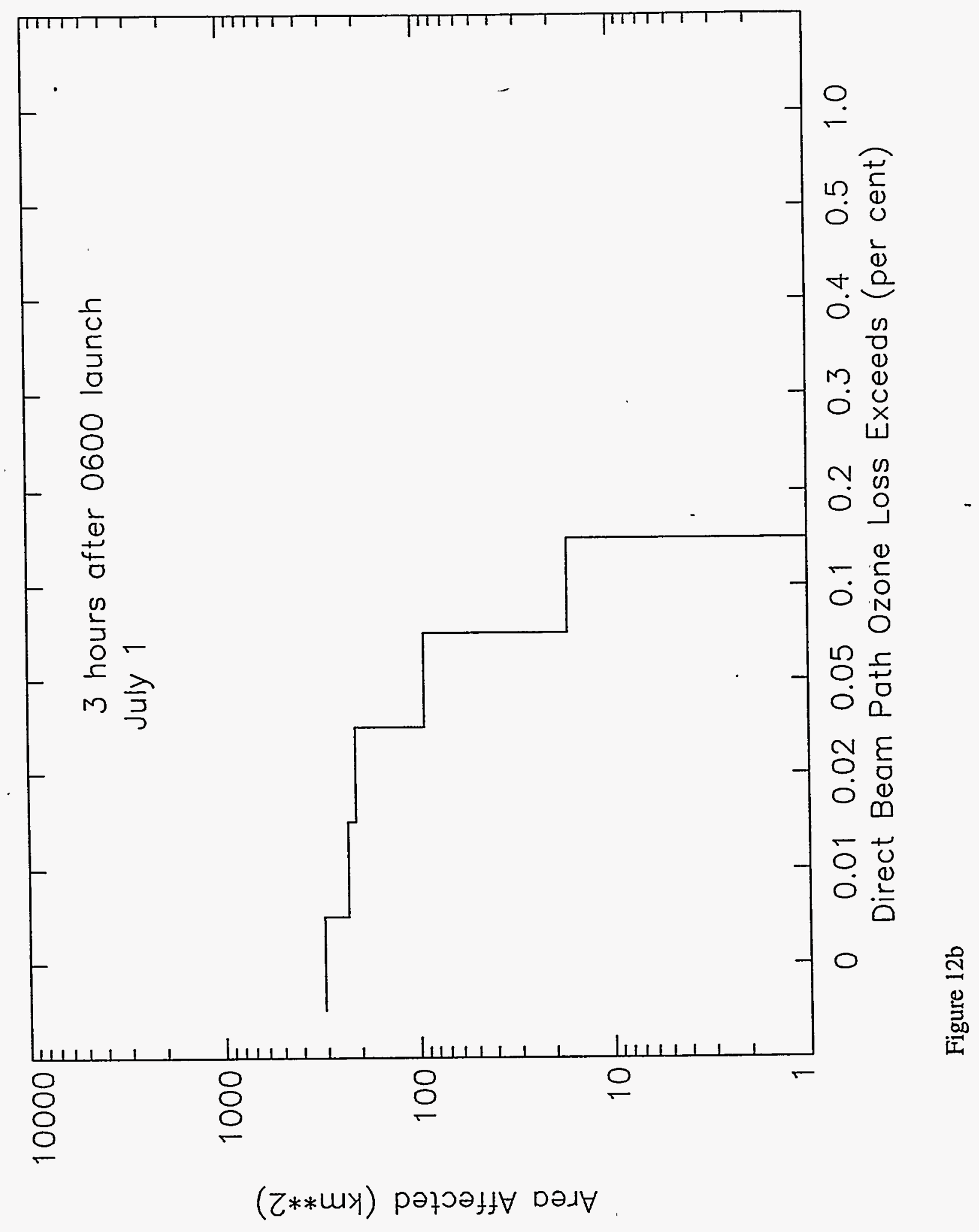




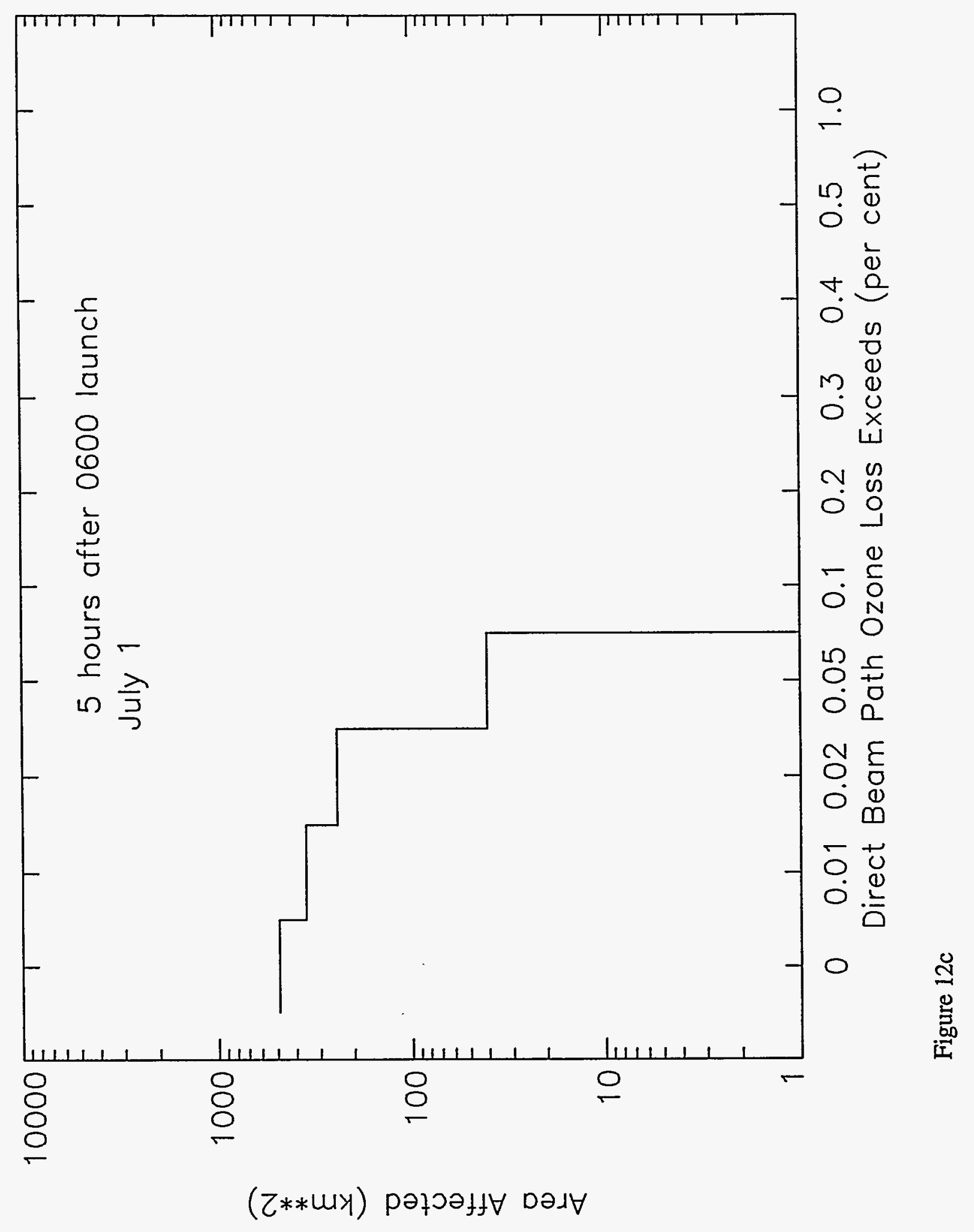




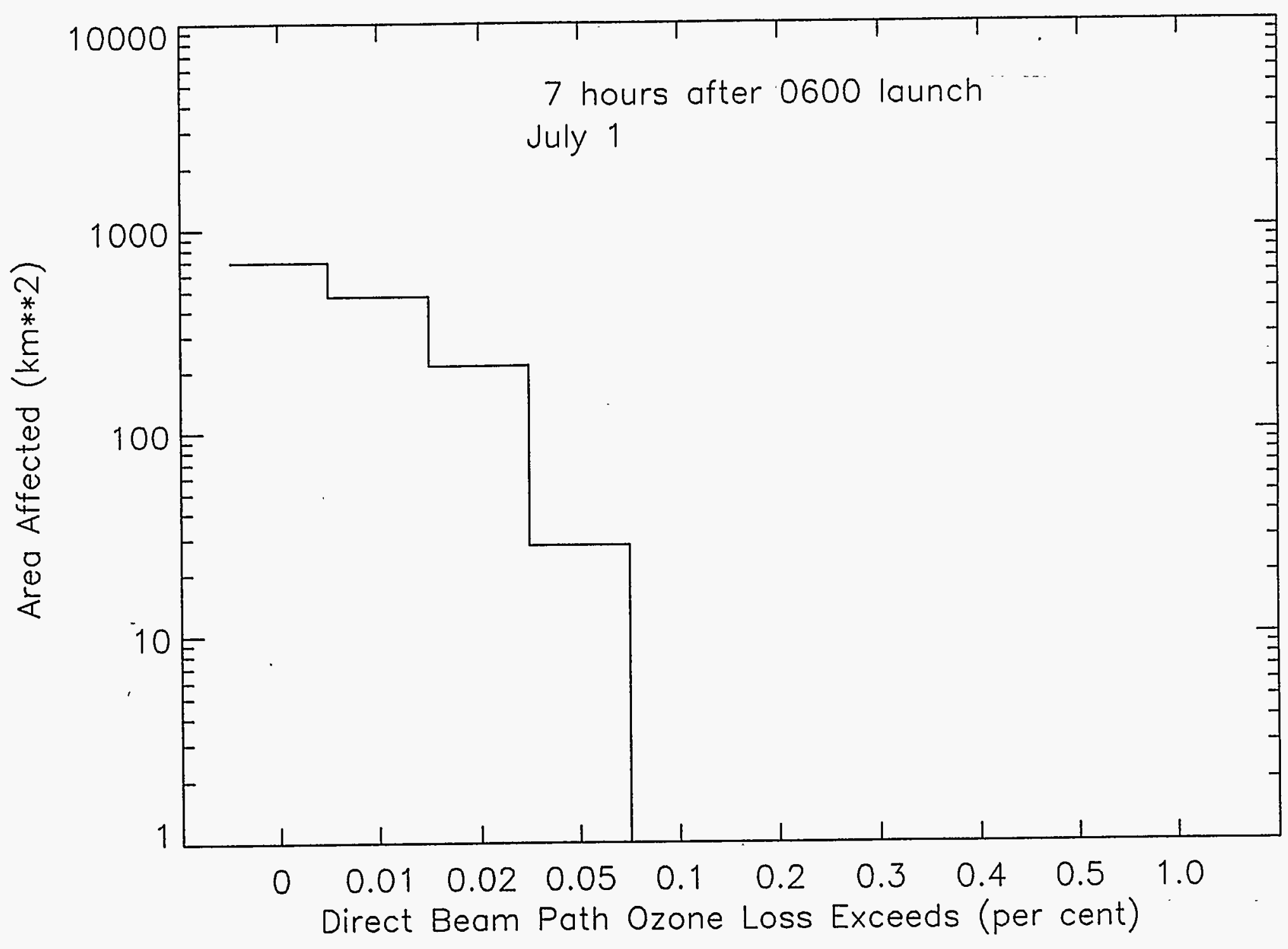

Figure 12d 


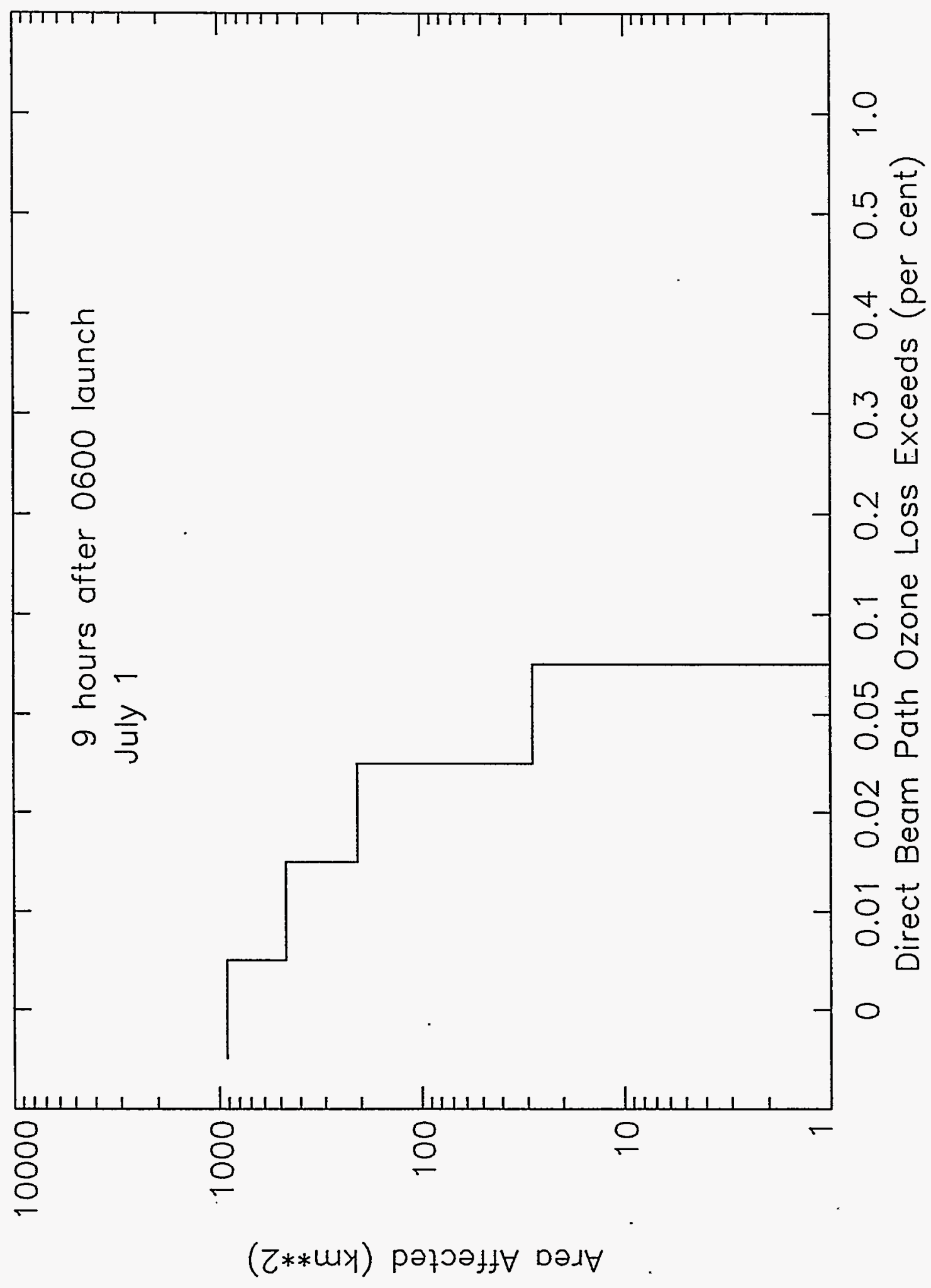

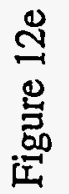




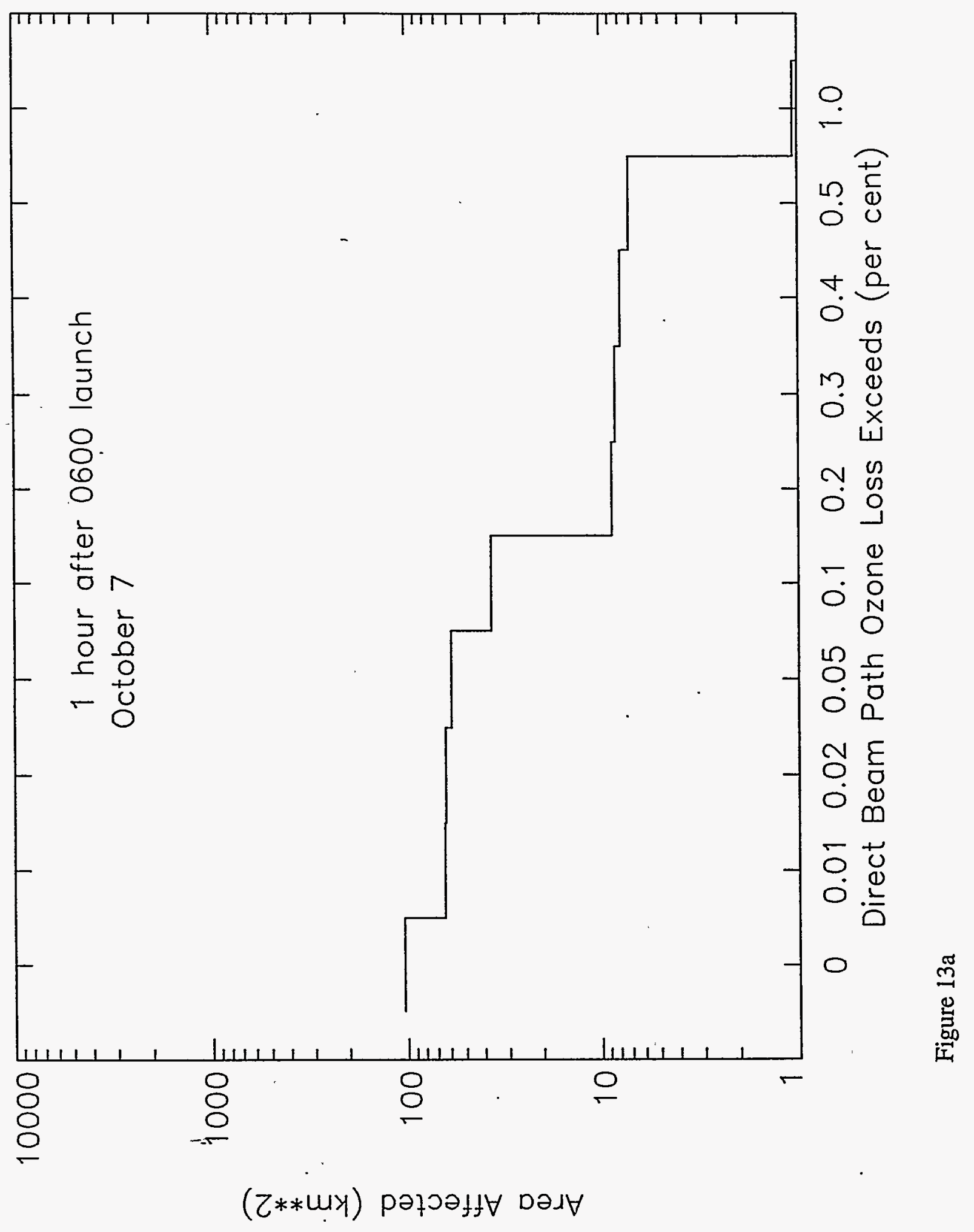




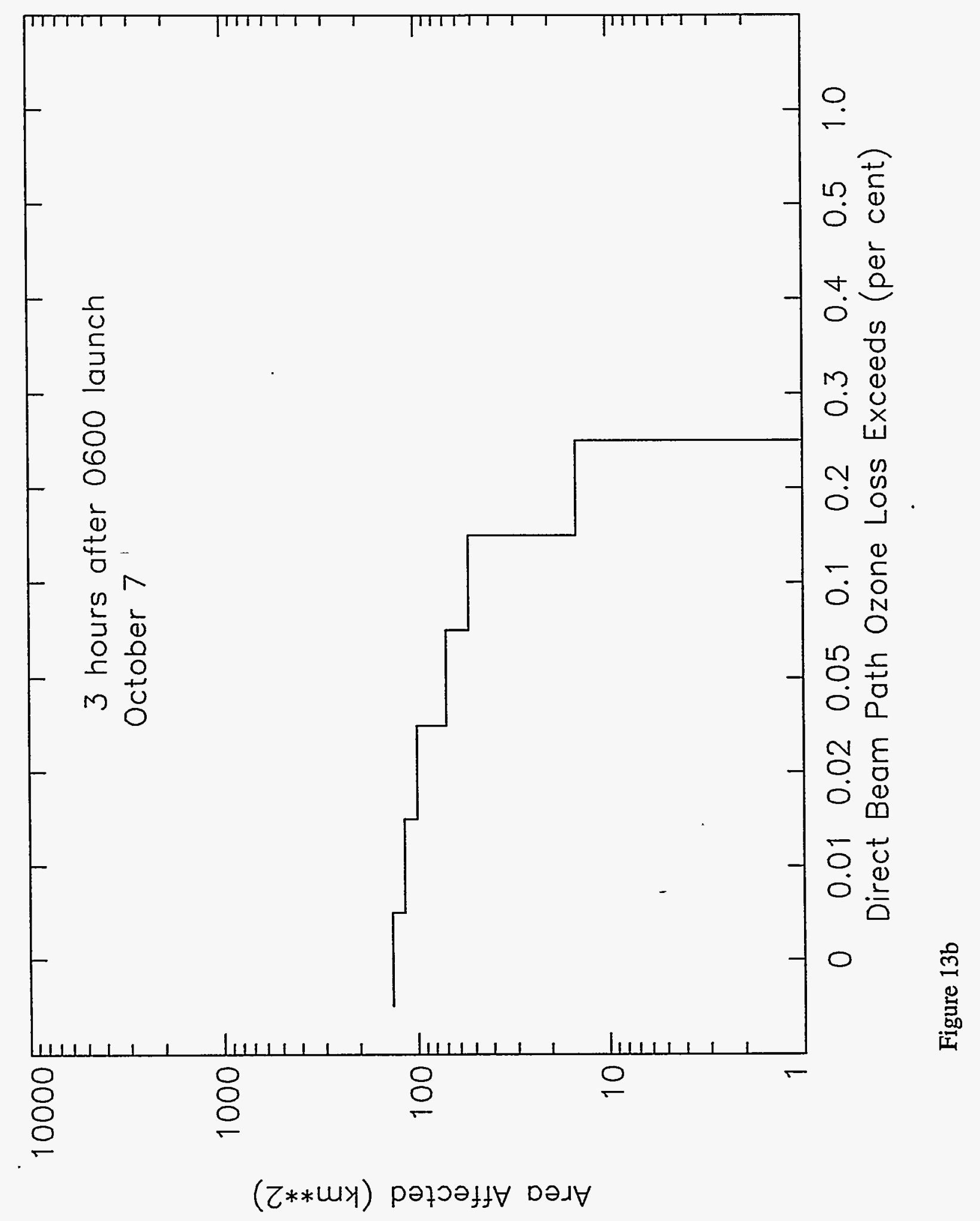




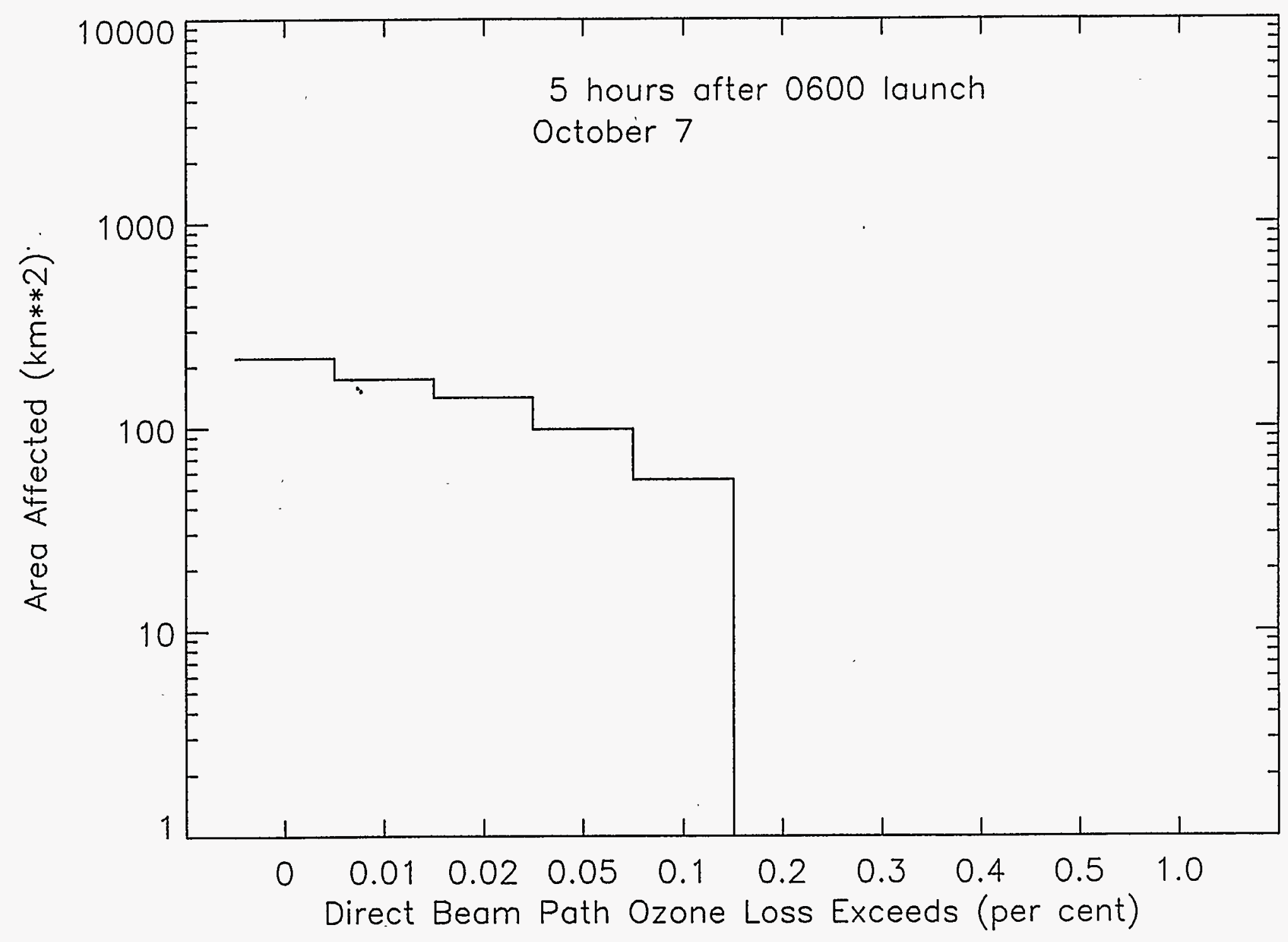

Figure 13c 


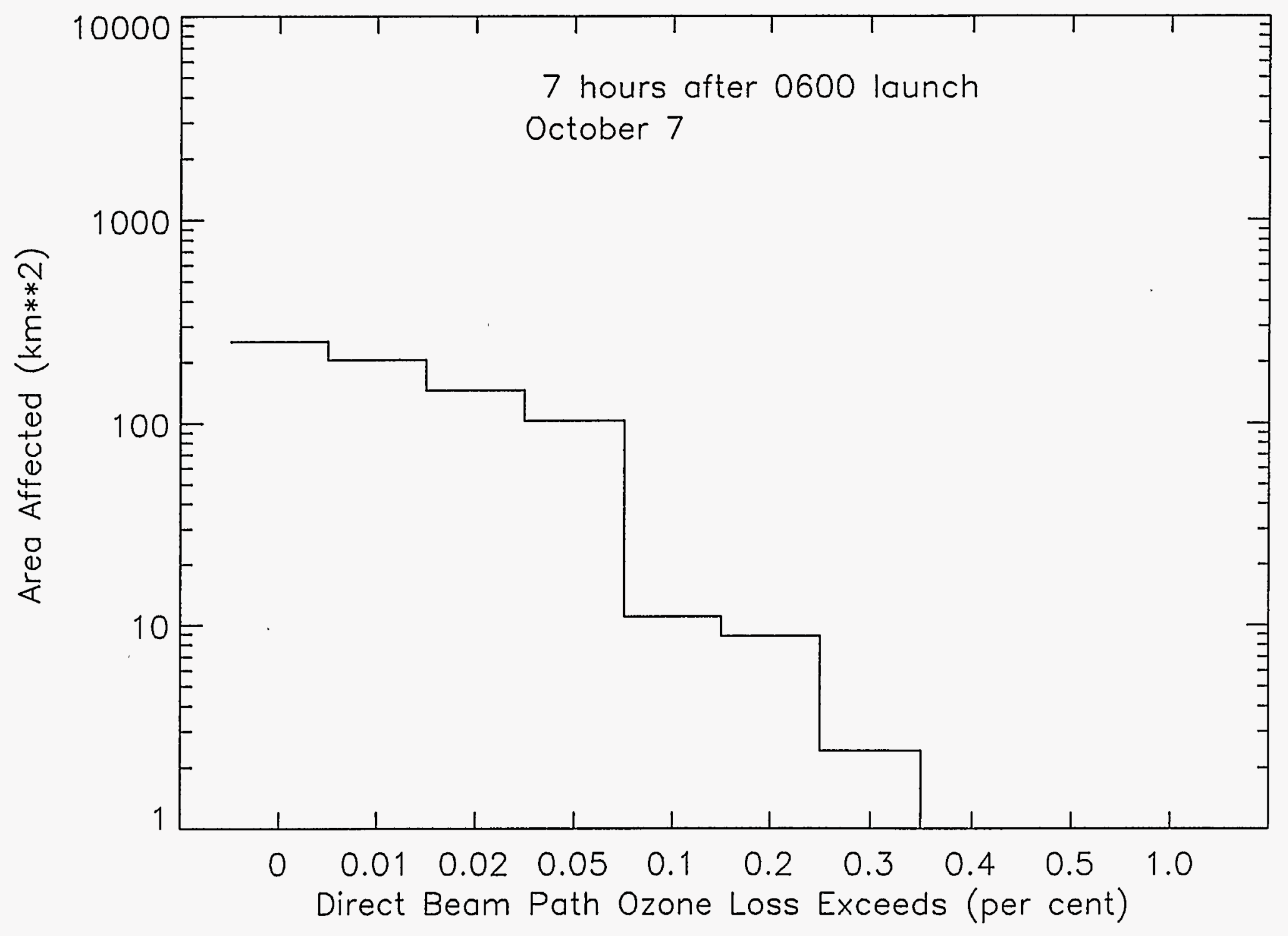

Figure 13d 


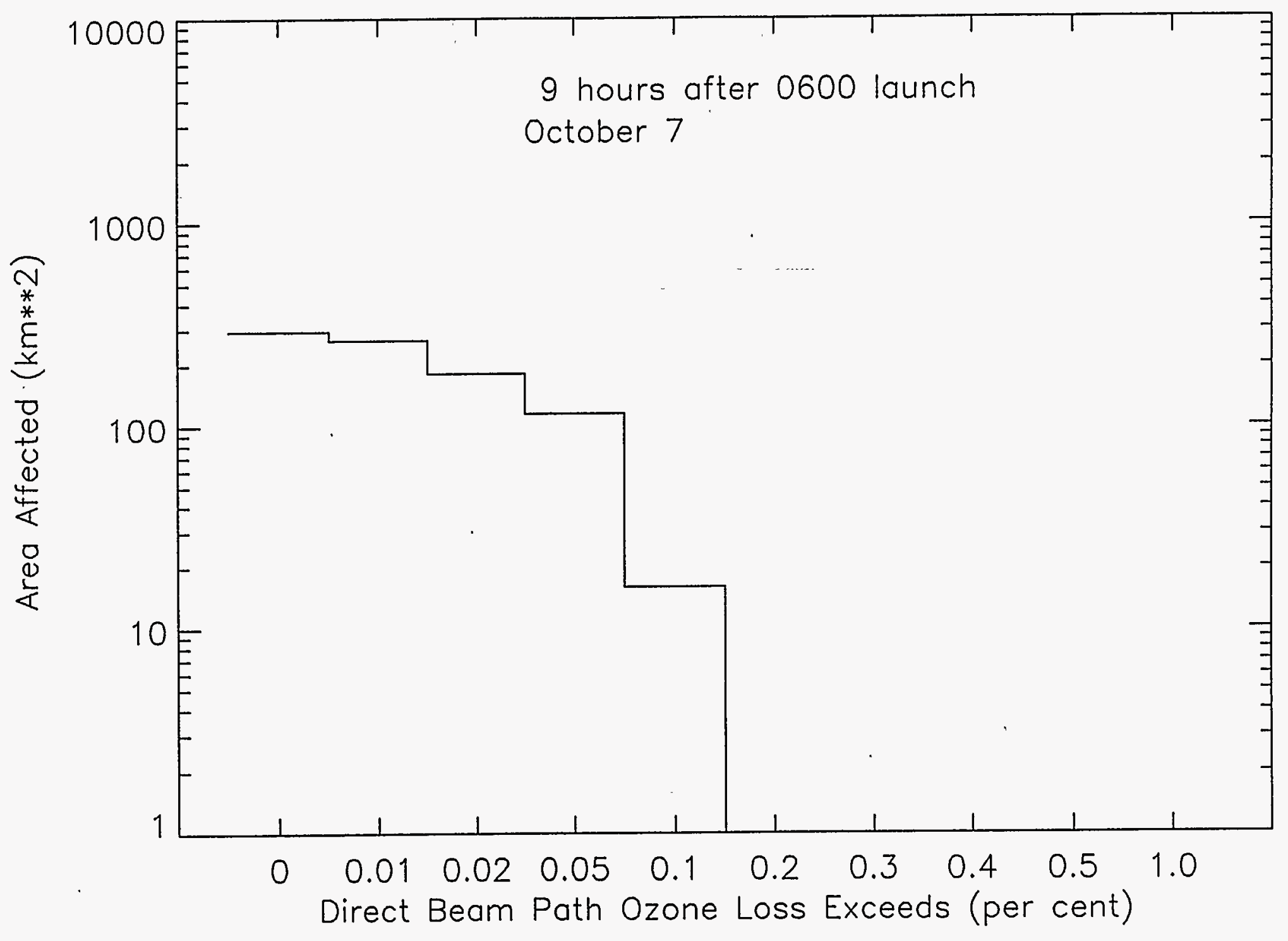

Figure 13e 


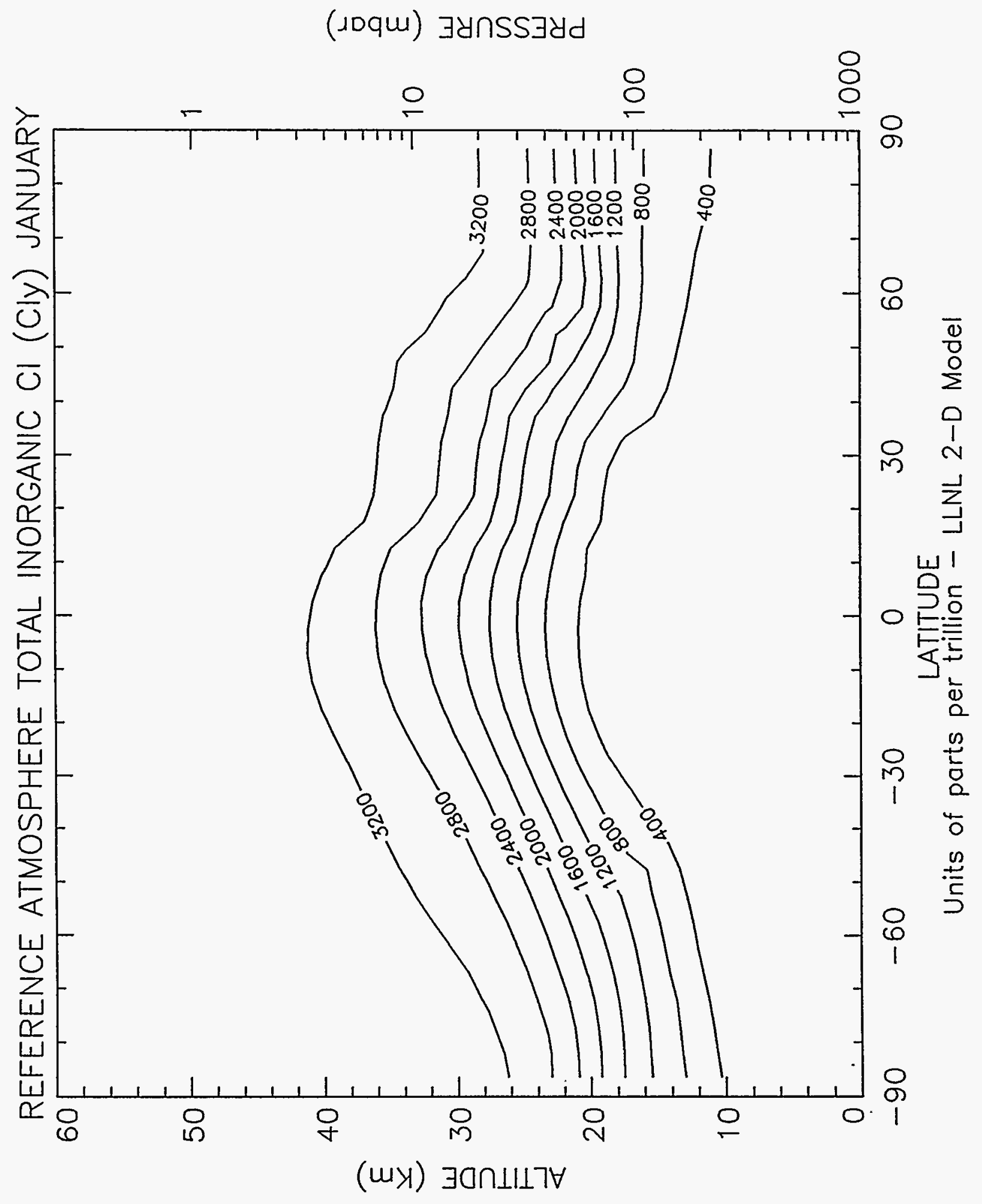

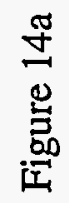




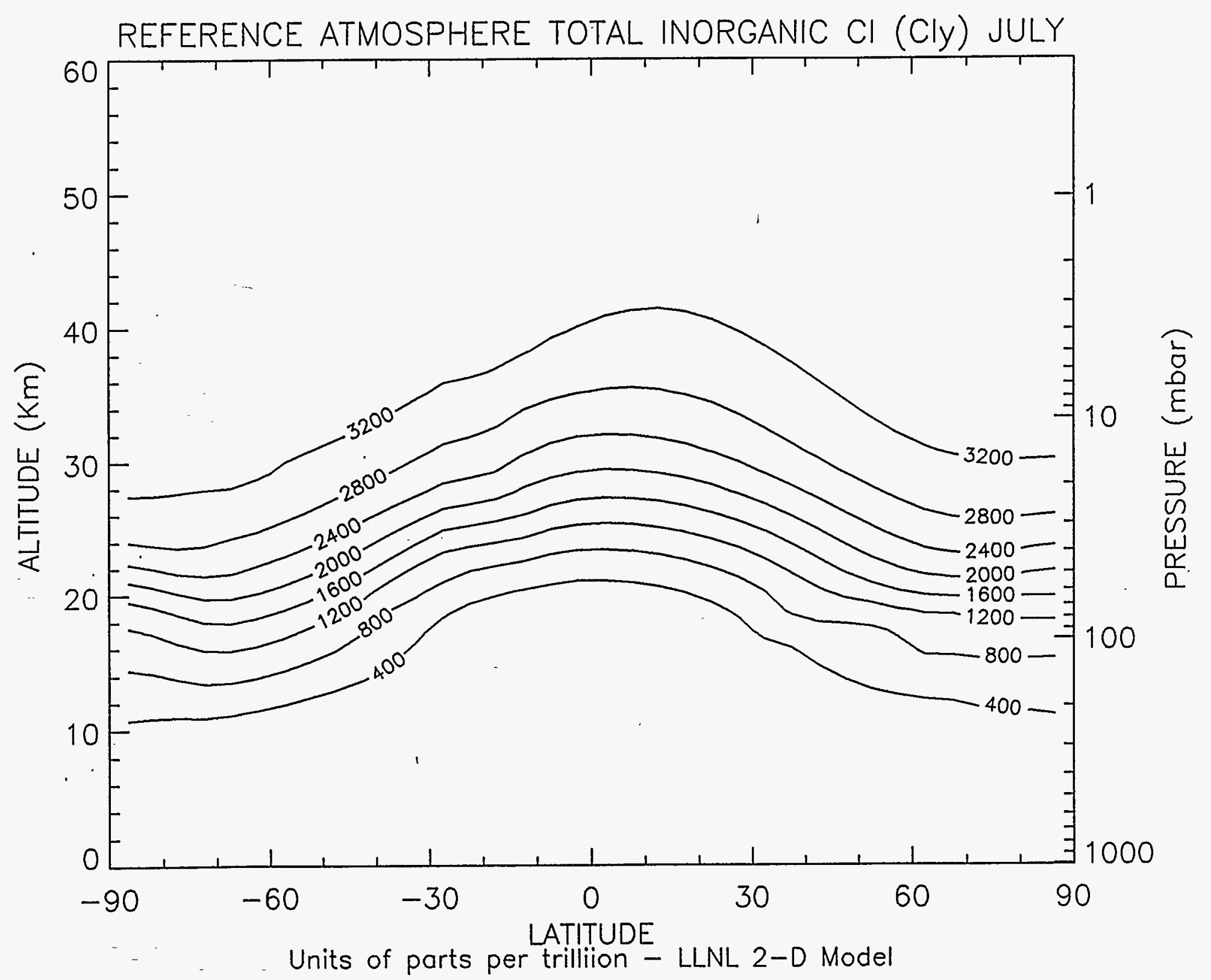

Figure 14b 


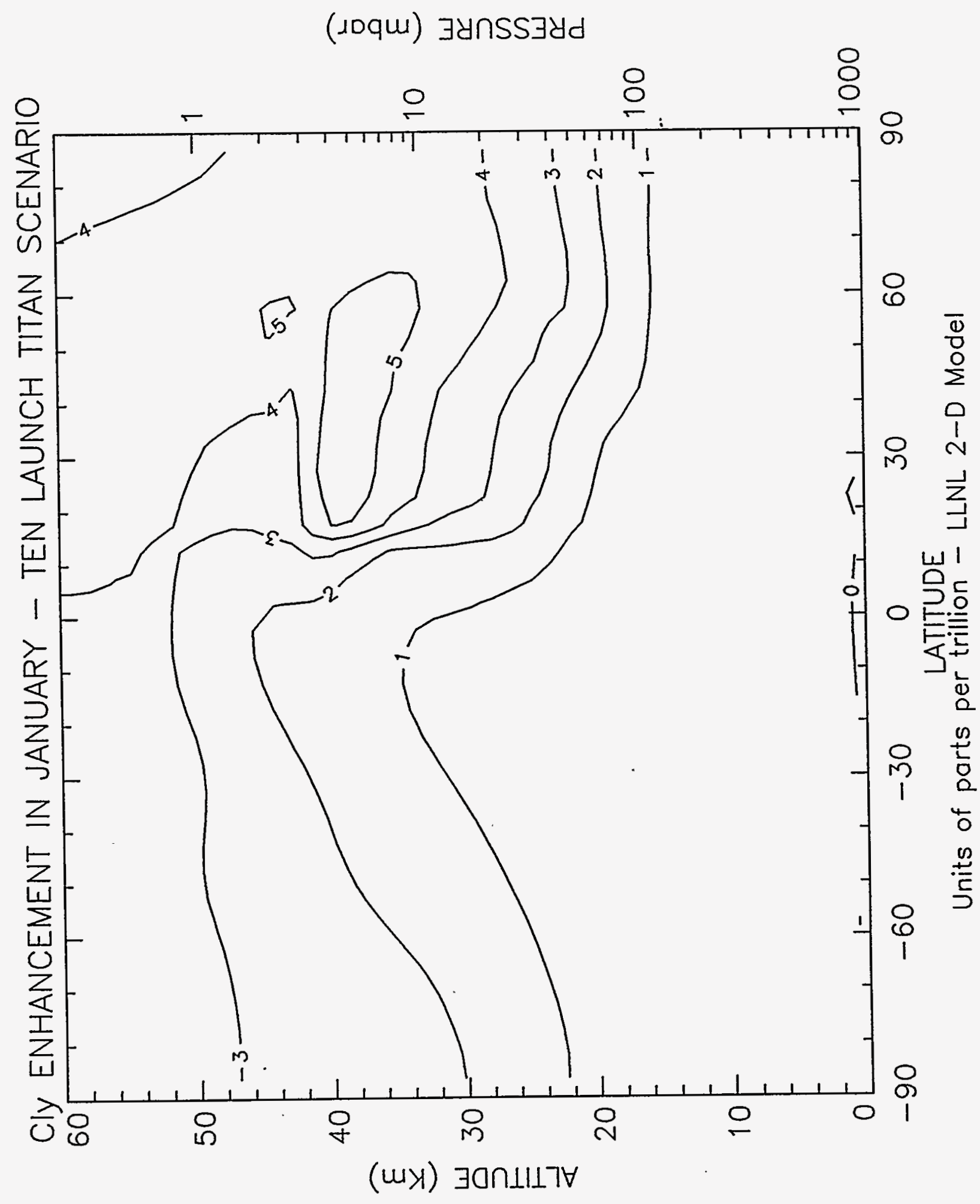

尔 


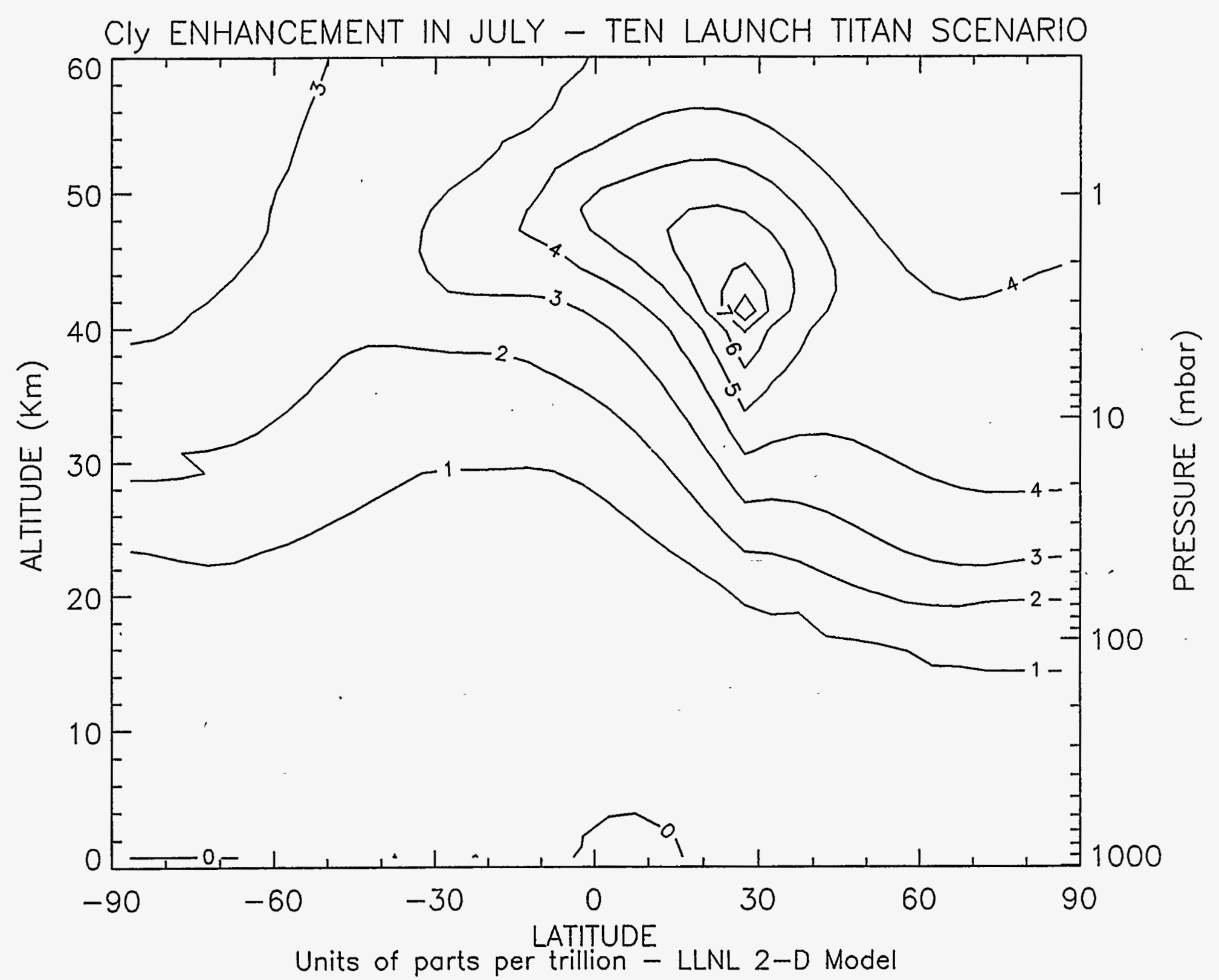

Figure 15b 


\section{(دoqu) $\exists$ ynSS $\exists$ yd}

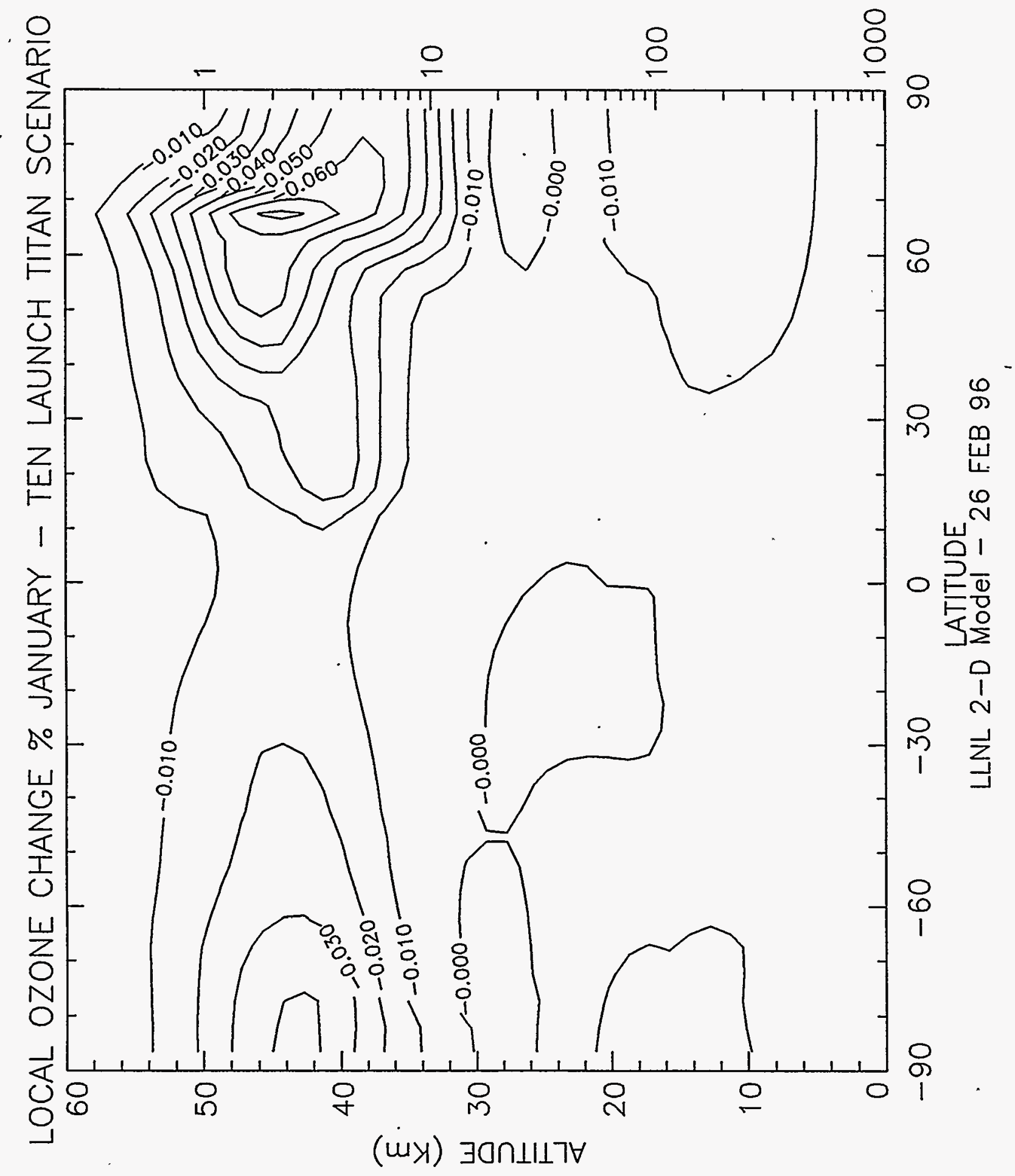

兑 


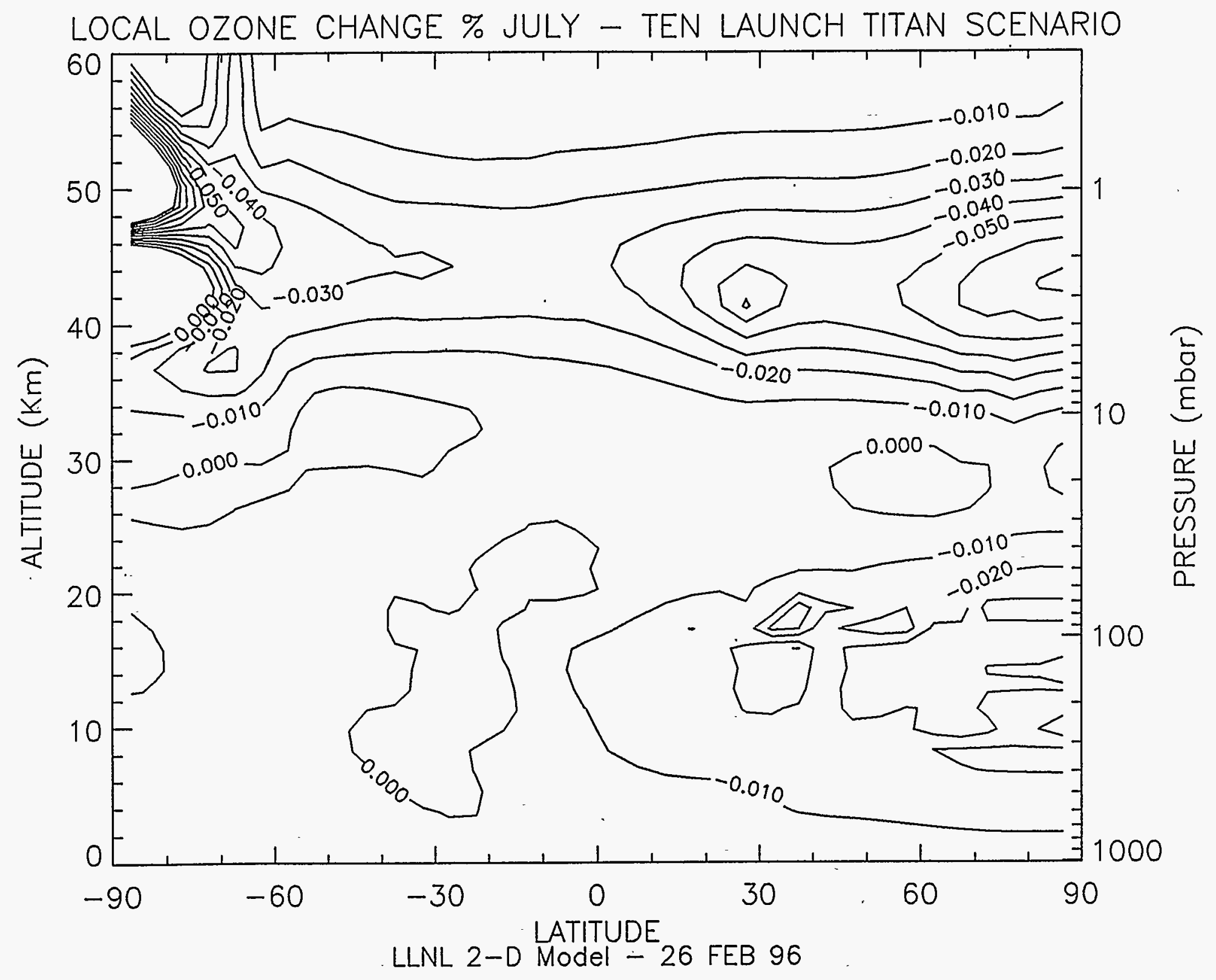

Figure $16 \mathrm{~b}$ 


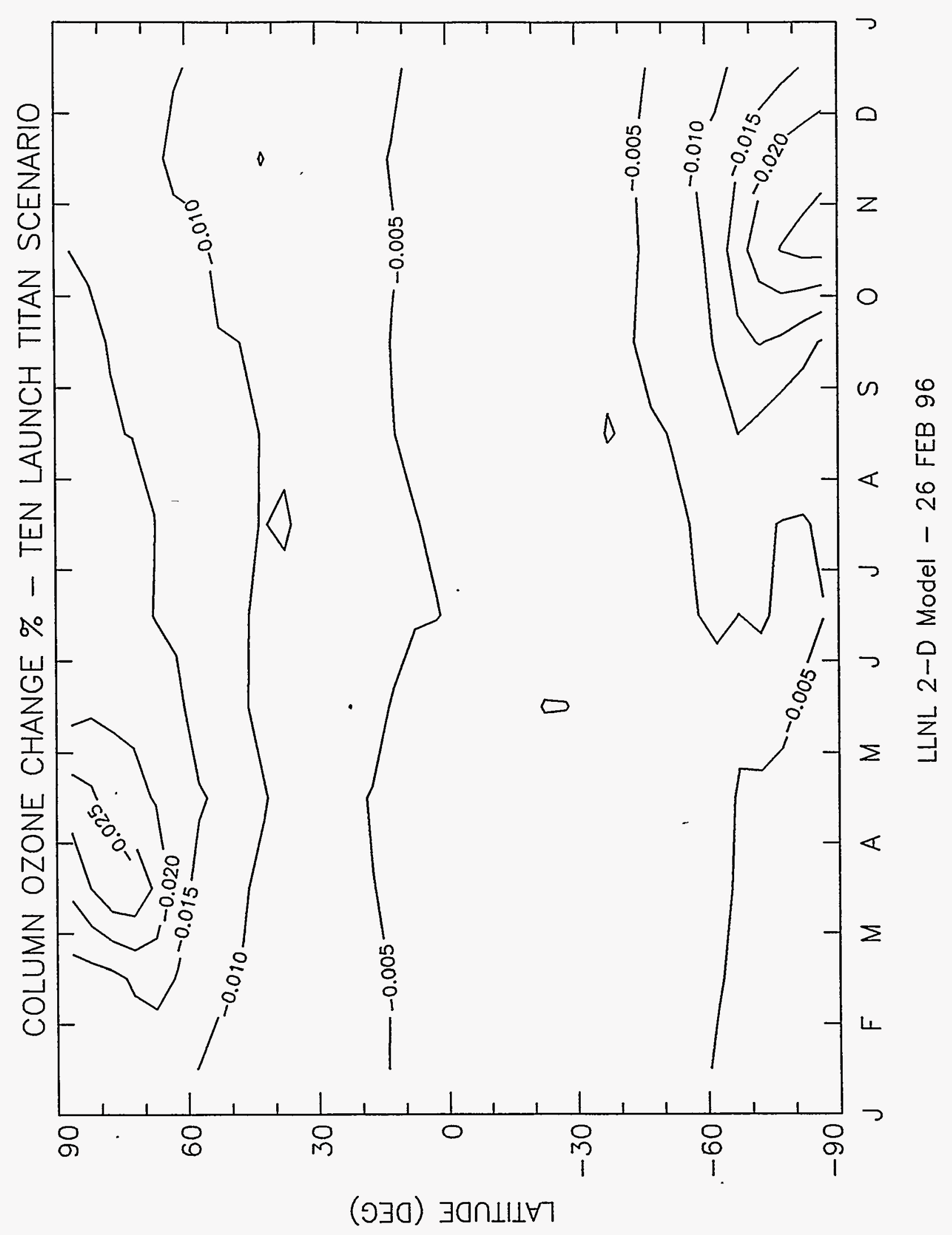

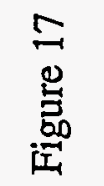




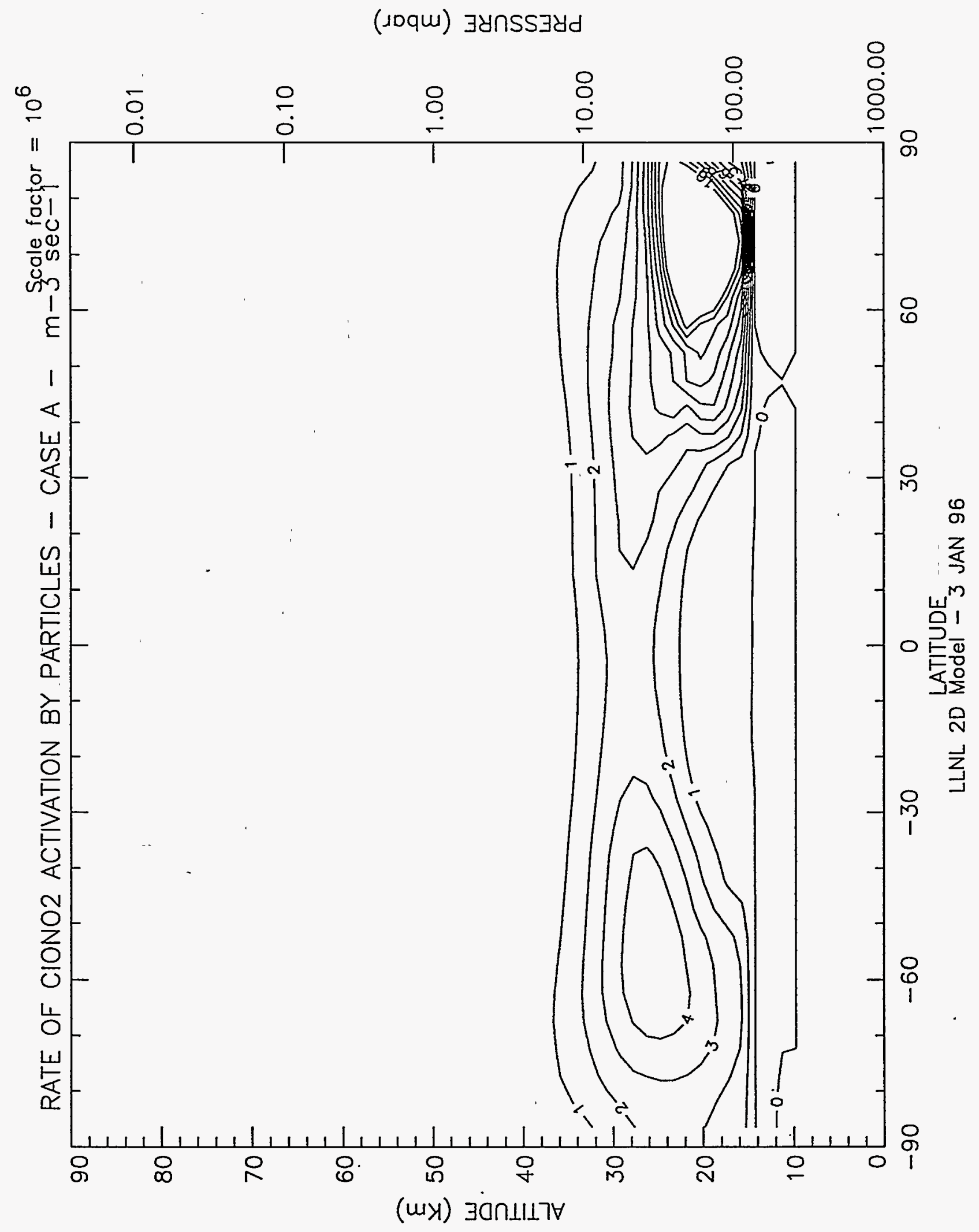

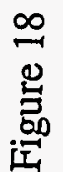




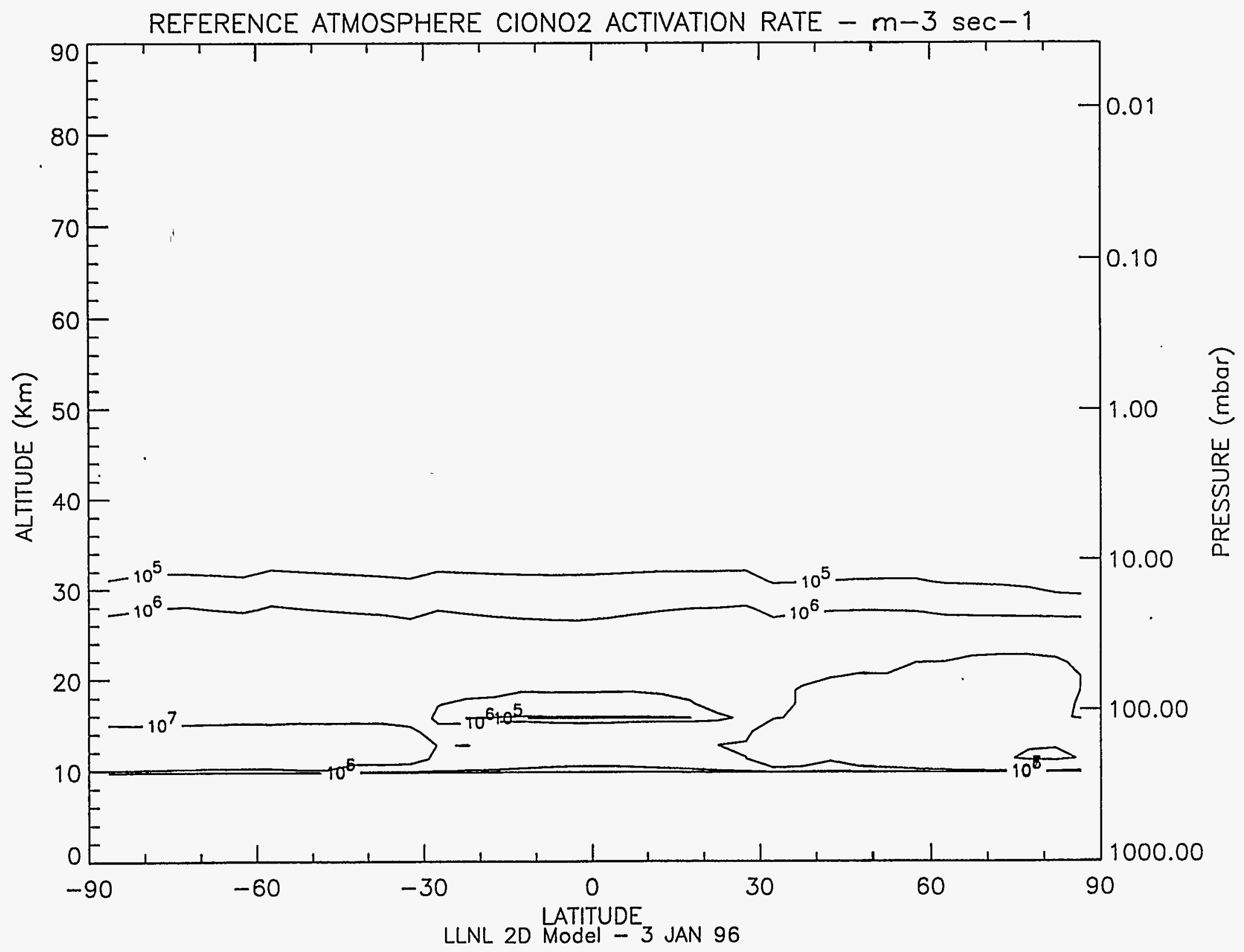

Figure 19 


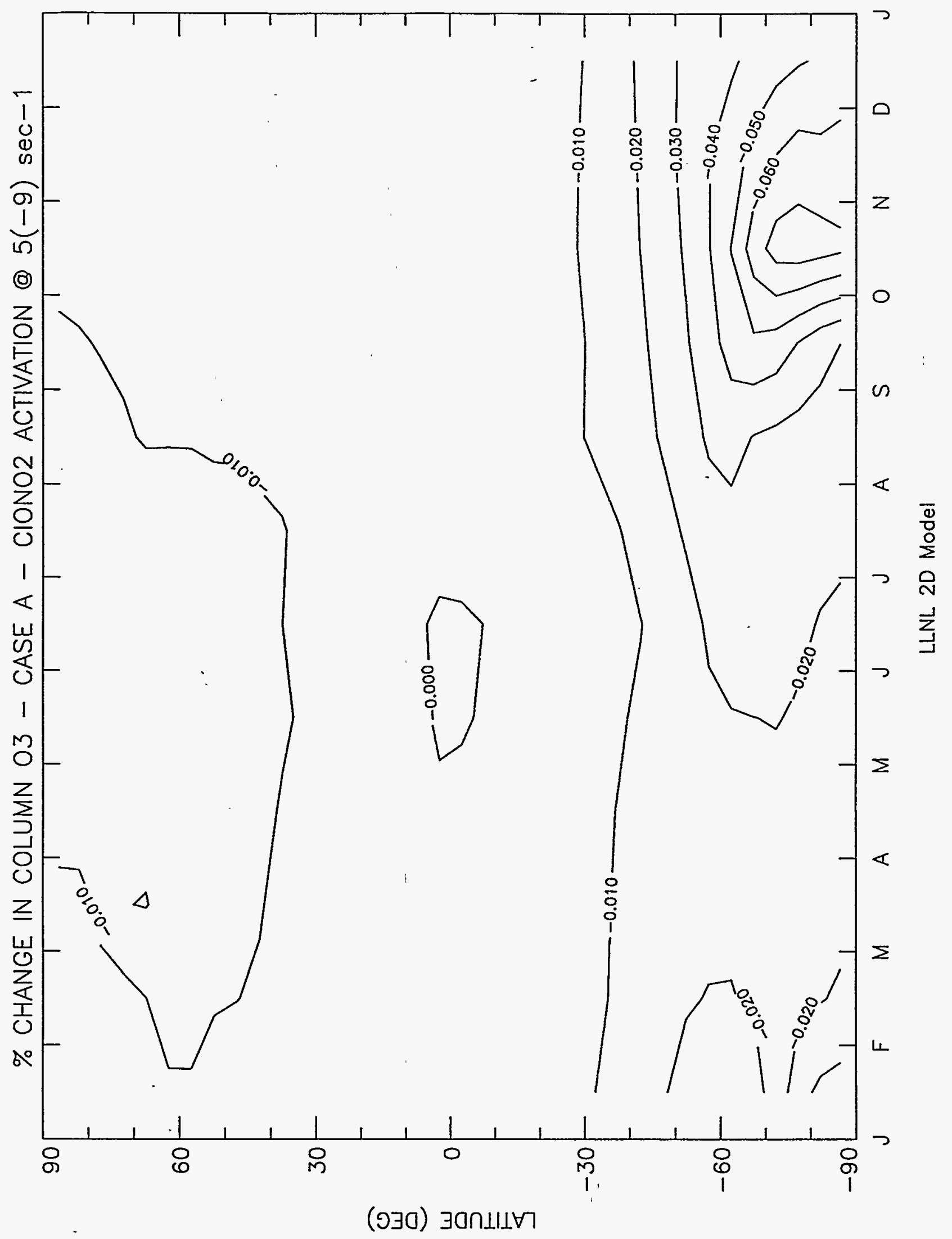

옥 